\title{
On the Controllability and Observability of Flexible Beams Under Rigid-Body Motion
}

\author{
by
}

\author{
Kyung Sang Cho \\ B. Fing. (Sung lị un Kwan (nniverisity, Seoul), 1988
}

Department of Mechanical Engincering

McGill University, Montreal

C'anada

A thesis submitled to the Faculty of Gradnate Studies and Research in partial fulfillment of the requirements for the degree of Master of Engineering

lugust 5. 1991

(c) kivung Sang ('ho 


\section{Abstract}

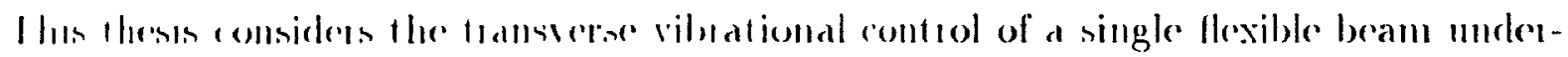
guing lange planal rotational motion. 'The bedm is modelled using a cubie spline rechnique, wheh ippoximates the lincal! chastic, continnoms beam with a finite number of nodal peints. It is shown that hinetic boundary conditions such as those assoctated with tip loads (an be included in the cubic spline model. This spatial discretization mothod provides a useful lincin relationship betwern displacement and (urvat ure, which allows the use of st rain gatges fo medsure curvature along the beam. An optimal control strategy is used to suppess lla tramserse viblations while forcmg the end tip to follow a prescribed trajectory. A Kinman hller is employed to optimally estimate state variables which are not obtained thremgh direct measurement. These state variables can be classified into two groups: 1) statc wabiales corresponding to the time rate of change of curvature, which cannot be measuled using anv existing sensor and 2) state variables associated with curvature at certain nodal points which, by having their values estimated rather than directly measured, results in a smalle number of sensons needed io contiol the entire beam, thereby reducing the required data thoughput capability and cost of the contol hardware. Although, in principle, the cutice sustem has been proven to be state controllable and observable using as little as onc senson, muncrical ill conditioning of the cont rollability and observability matrices can perent the Kalman filter fiom tecomstunctung the state estmates to a required accuracy. 'l'hus, mumerical viability of this cont rol scheme is demonst rated through extensive simulafion studies and guidelines for the numben and location of sensors to achieve good numerical conditioning are given. 'These results show that the proposed approach is very suitable for real time control of mansverse vibrat rom of the flexible beam undergoing large rotational motion at high sperd. 


\section{Résumé}

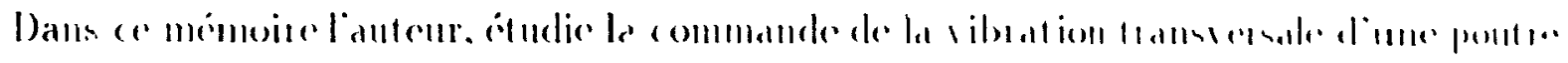

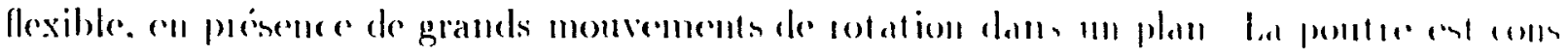

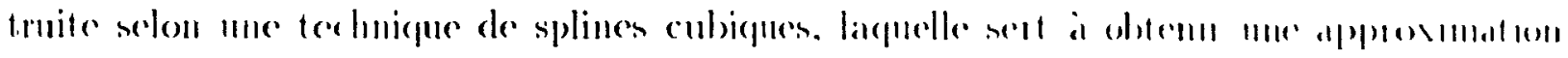

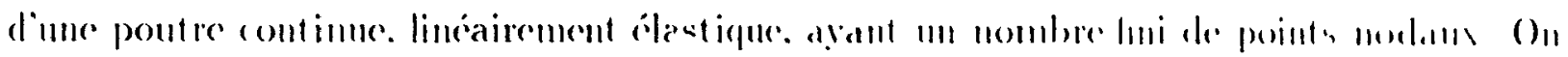

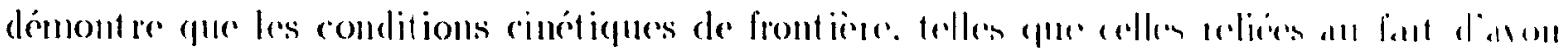

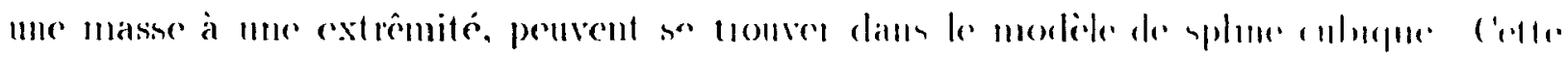

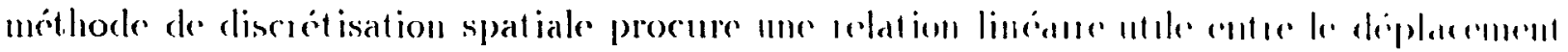

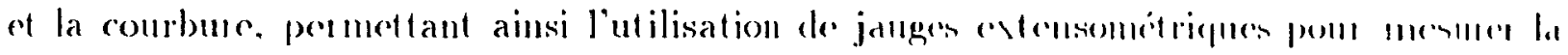

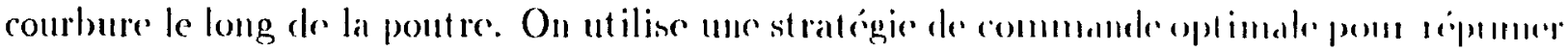

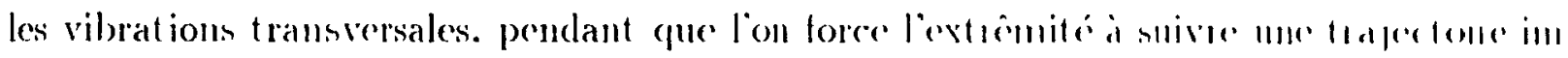
posée. On emploie un filtre de Kalman pour une est imation optimale des vallables dival.

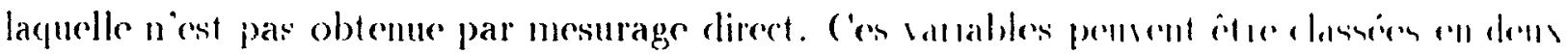

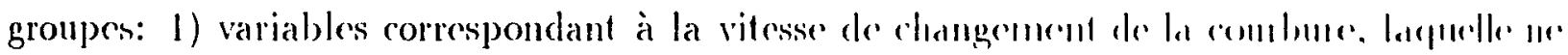

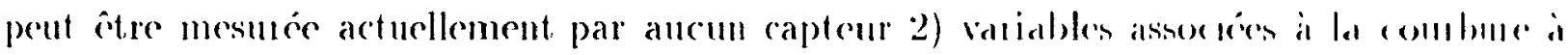

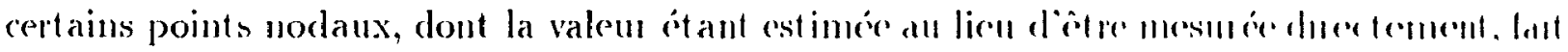
qu'un tres petit nombre de capteurs est néessaire pour commande totalement la pontar

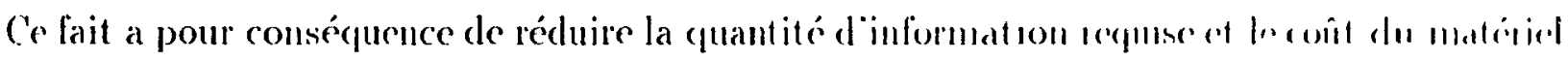

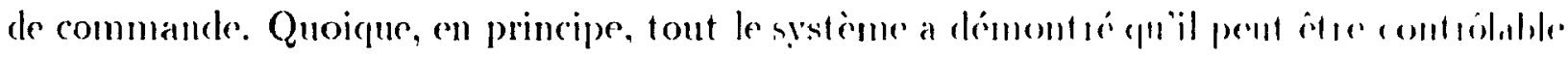

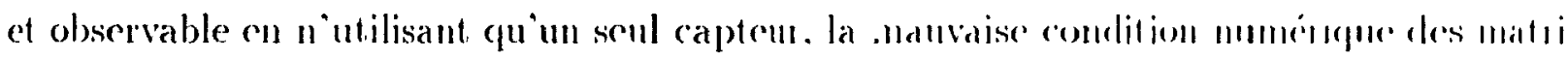

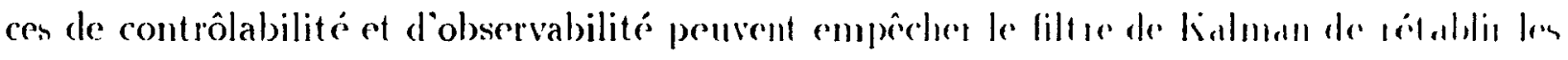

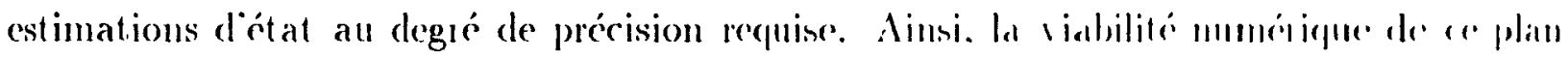

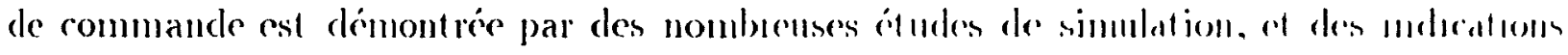

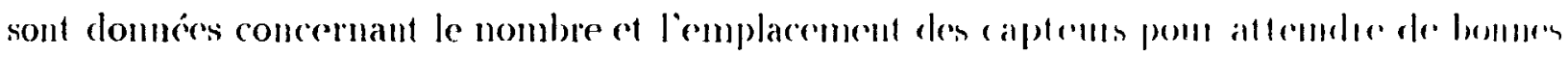

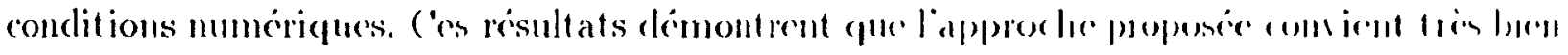

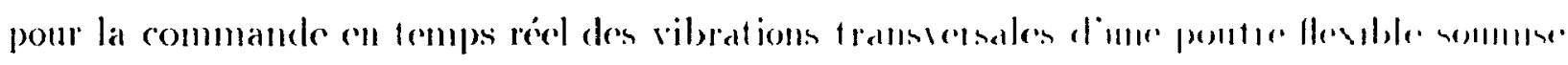
à do gaands momerments de rotation à vilesse álevée. 


\section{Acknowledgements}

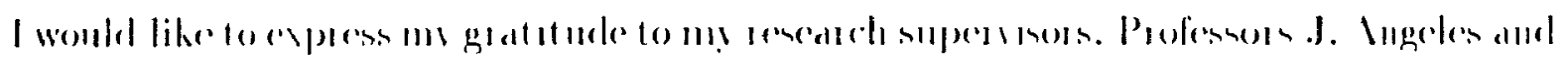

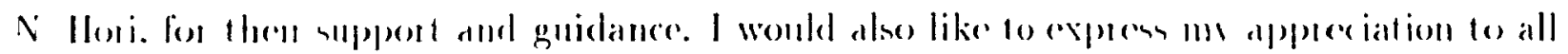

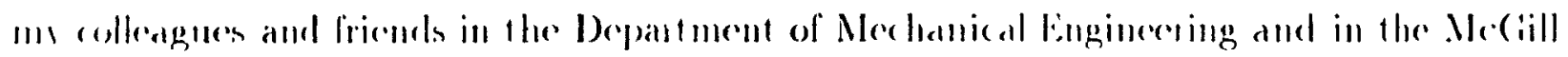

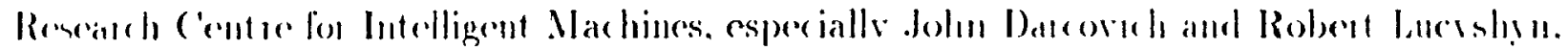

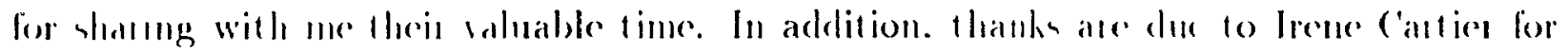

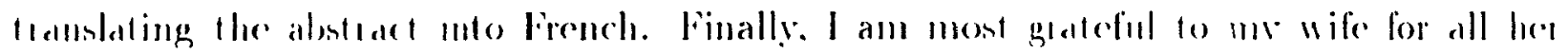
pere ions support and encouli gement.

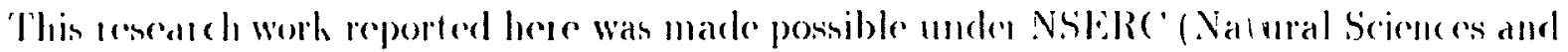
lingineromg Reseanch ('ouncil) of ('anada (irants \# A.5.3.2 and \#.1117.50. as well as IRIS (lustitute for Robotics and Intelligent Systems. a net work of ('alldilian centent of excellence) Projerel \# (' 2. 


\section{Contents}

i Introduction 1

1.1 Motilation . . . . . . . . . . . . . . . . . . . I

1.2 Provions llork ....................... . . .

1.2.1 The Numal-Mode .Malism . . . . . . . . . . .

1.2 .2 The Pinite-likenent Method . . . . . . . . .

1.2.3 The ('ubie-splime 'Technique . . . . . . . .

1.3 Objertives.............................

1.3.1 Extonded cubic-Spline'Technique... .... . . ;

1.3 .2 ('ontrol c'apabilit! ................... . . .

1.3.3 Semsing ('omsiderations. . . . . . . . . . . . . . 6

I.1 Ontline of the Remaining ('hapters .......... $\ldots$

2 Problem Formulation

2.1 Derivation of the Kinetir and Potential bineggen .... . . "

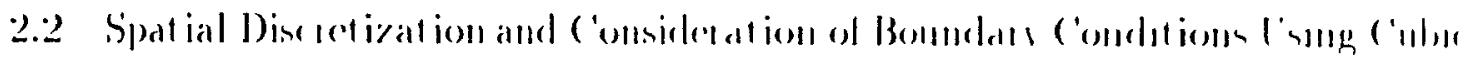
Splines...... . . . . . . . . . . . . . IL 


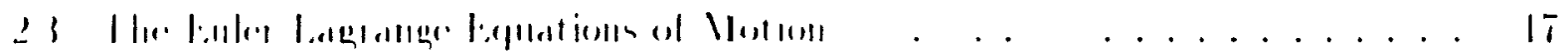

3 Optimal ('ontrol System Design $\quad 21$

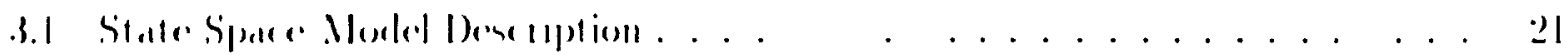

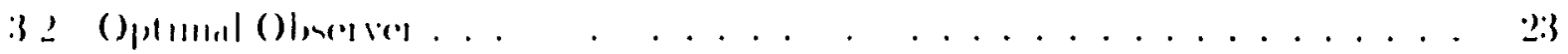

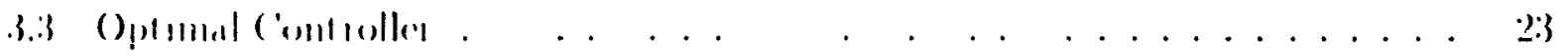

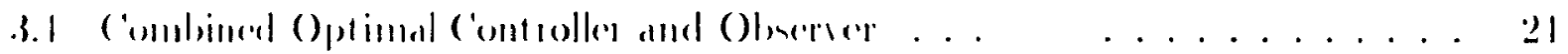

4 Simulation of Flexible Beams Under Large Rigid-Body Motion 26

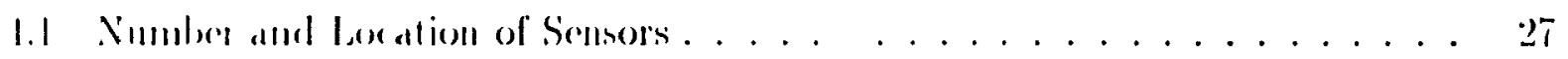

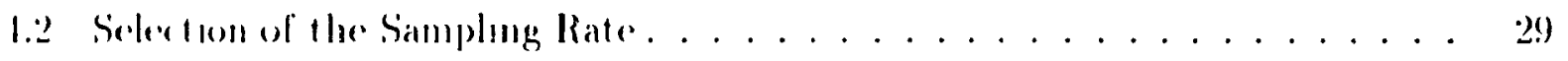

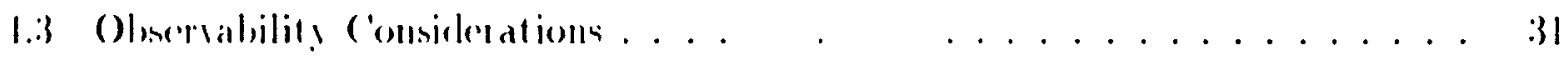

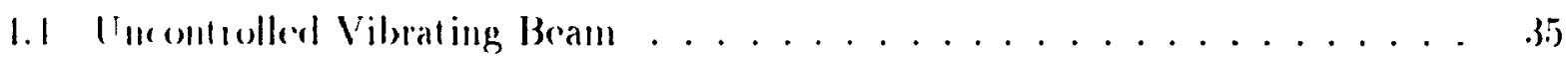

1.j (ompensaton Simulation . . . . . . . . . . . . . . . . 10

5 Conclusions and Suggestions for Further Work 47

$\begin{array}{lr}\text { References } & 49\end{array}$

$\begin{array}{ll}\text { Appendix A Derivation of Noise Covariance Matrice } & 52\end{array}$ 


\section{List of Tables}

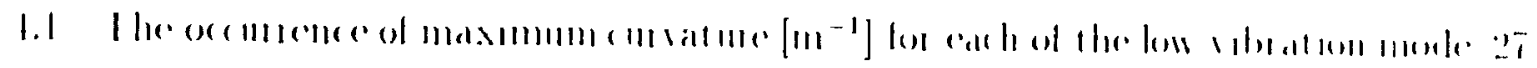

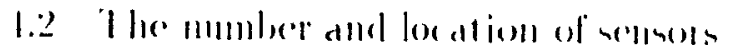
$\therefore$

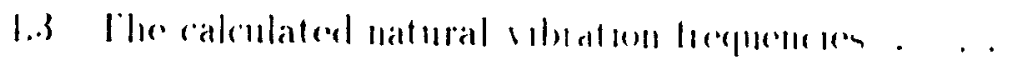

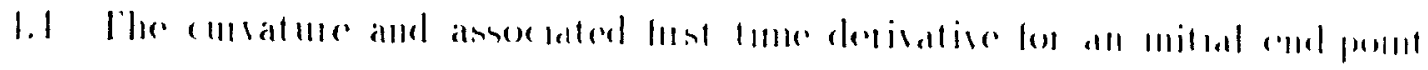
dinplacement of the lesedth

1..) Hhe material upecification of the lecalll 


\section{List of Figures}

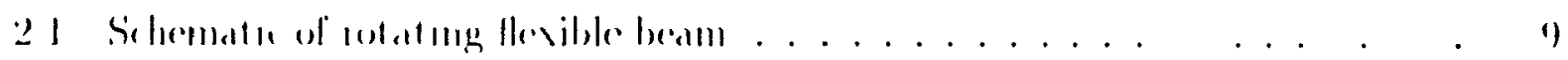

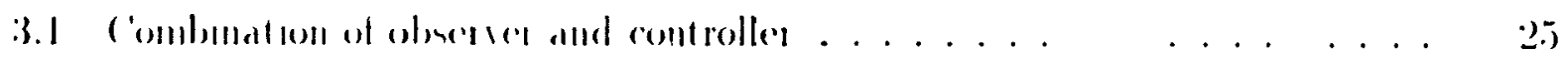

11 Fistumation entrot of the state valiables at the first nodal point without tup mass 333

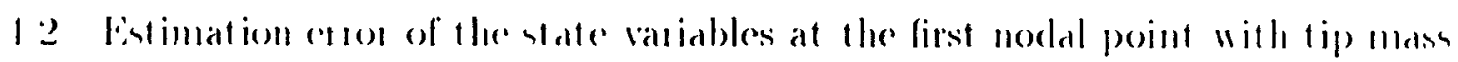

1.3 Optimal tergue input and time responses of the non-flesible heam withent tip

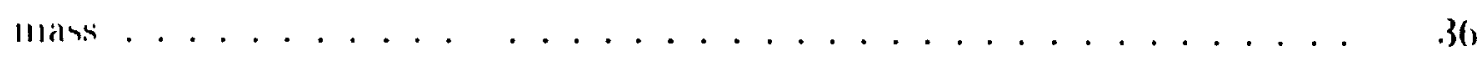

1.1 Iime aspomen of the llexible beam for an optimal toreque input of the rigiel beam without tip mass.....................

l.j) ()plimal tolque input and time responses of the nom-flexhble beam with tip)

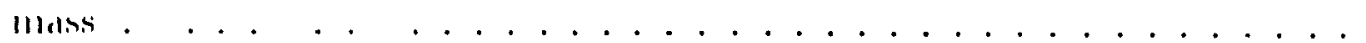

1.6 Time usponses of the llexible beam for an optimat toreque input of the rigid

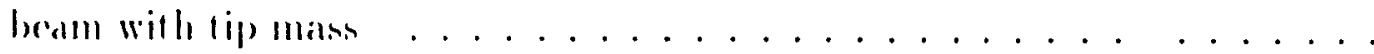

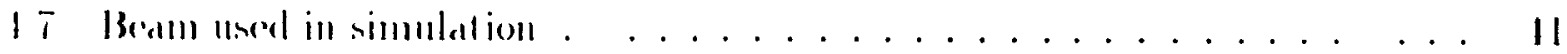

Is Smoolled step input uning encloidal motion . . . . . . . . . . . 1:3

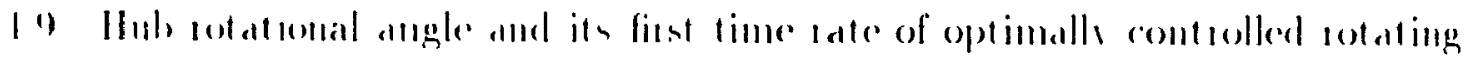

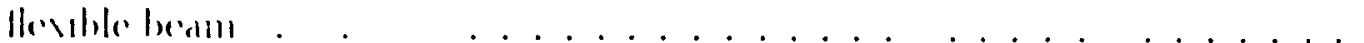

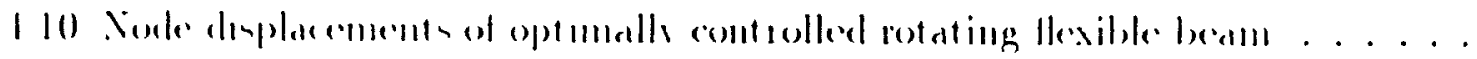




\section{Chapter 1}

\section{Introduction}

\subsection{Motivation}

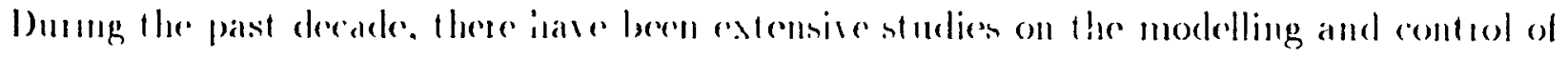

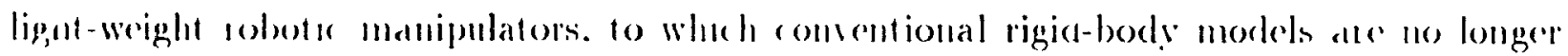

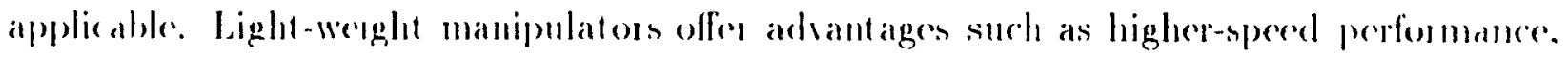
hugher podolod-to-weight tatio capacit! and lower conergy consumption (Book and Majelte

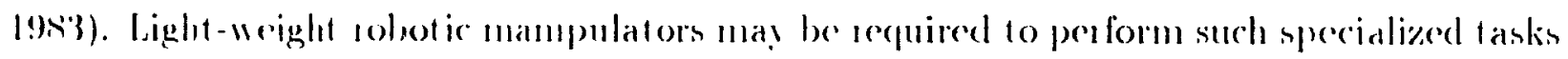

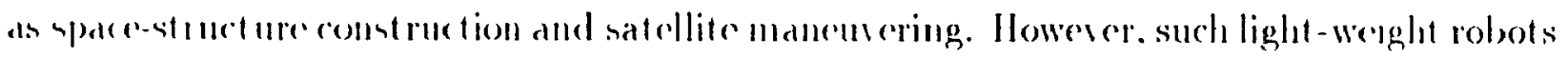

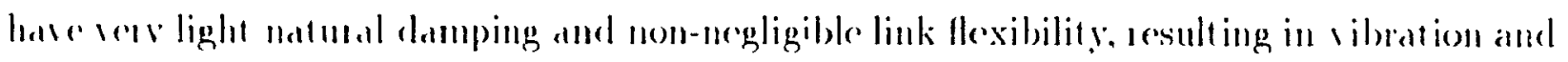

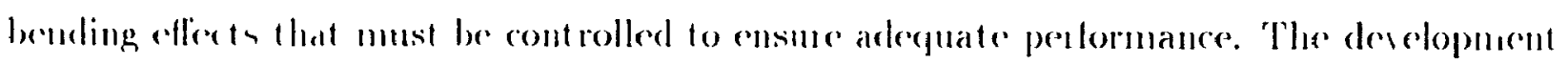
of a proper combol strateg! repuinon a suitable finite-dimensional model which takes into acrount the dy naumes of link llexibilits and, at the some time. makes on-line cont rol practical.

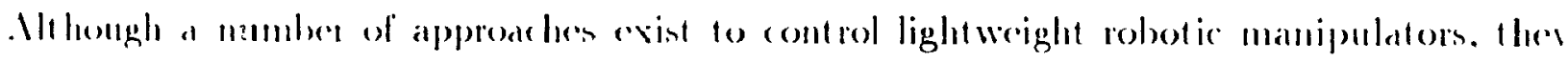

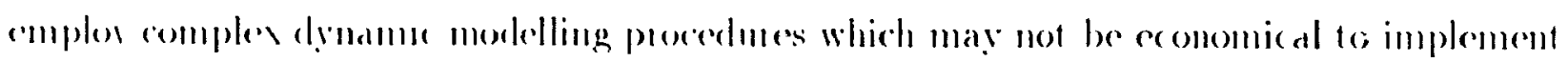

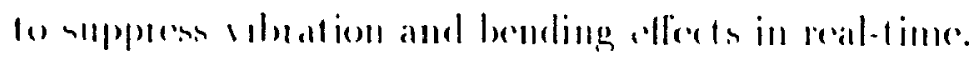

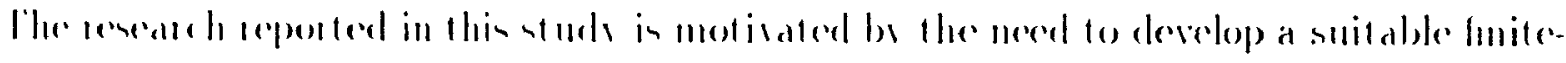

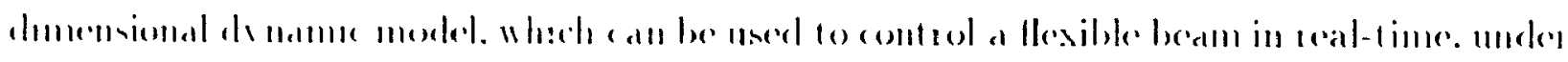

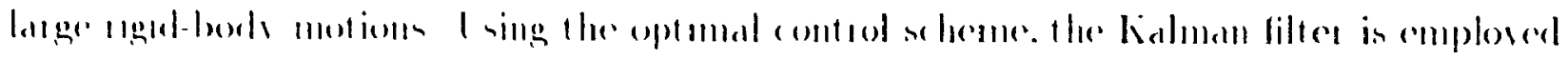




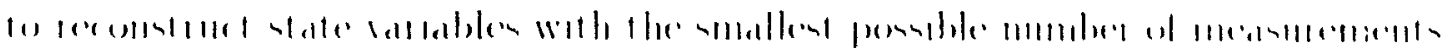

\subsection{Previous Work}

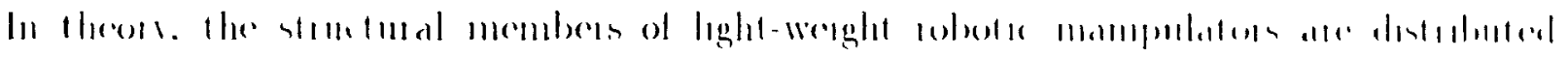

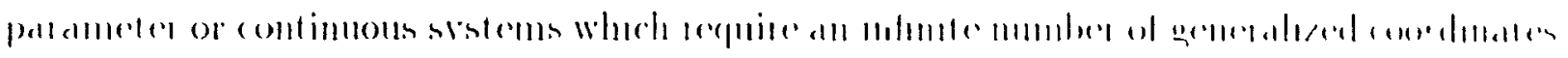

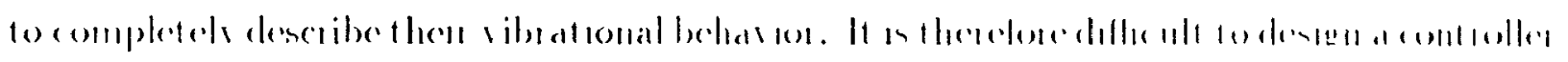

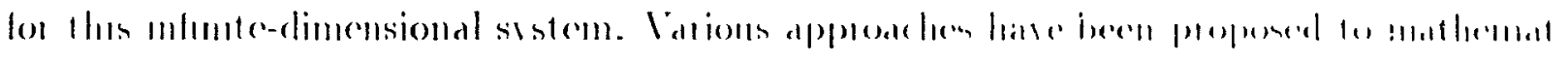

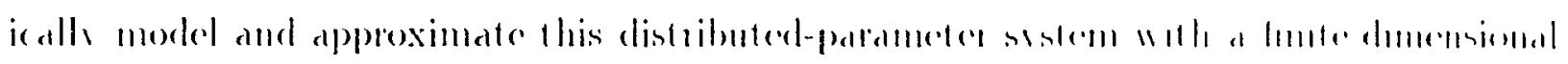

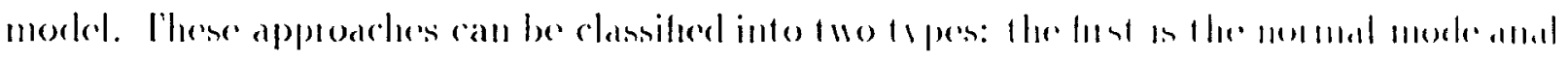

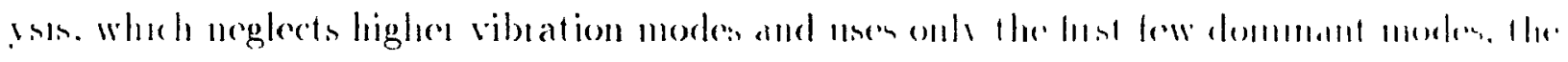

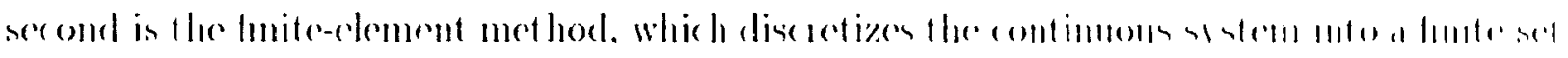

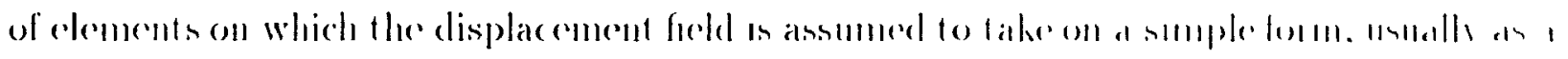

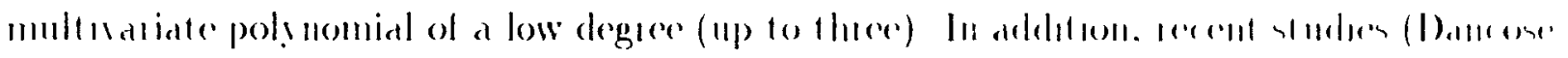

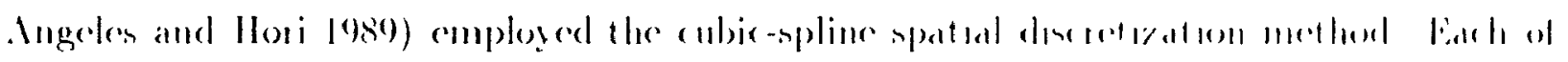
them are described below in some dotail.

\subsubsection{The Normal-Mode Analysis}

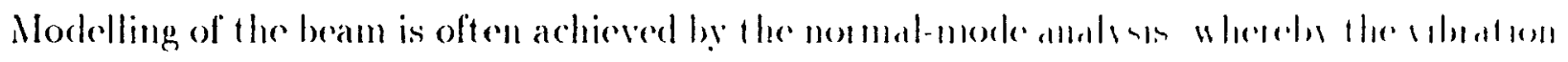

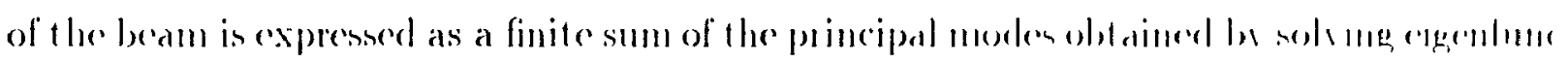

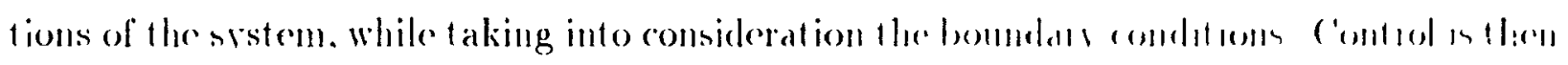

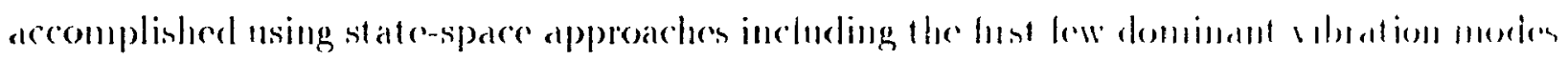

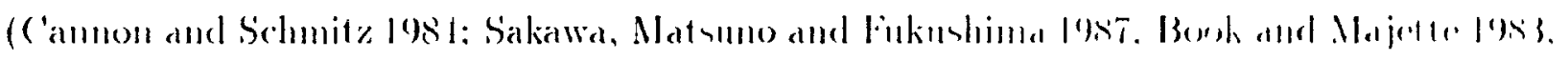

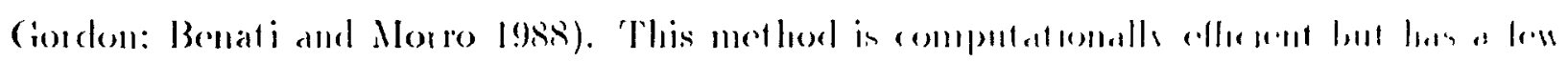

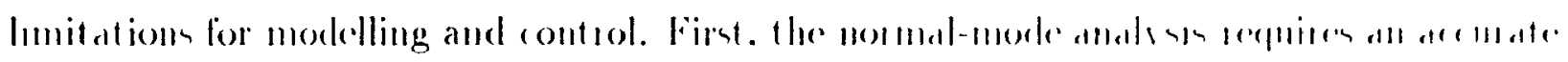

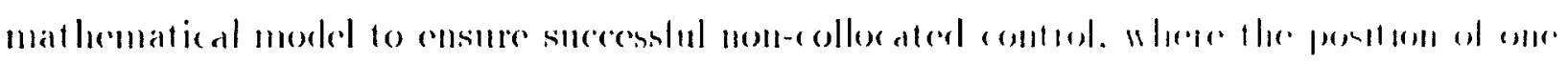

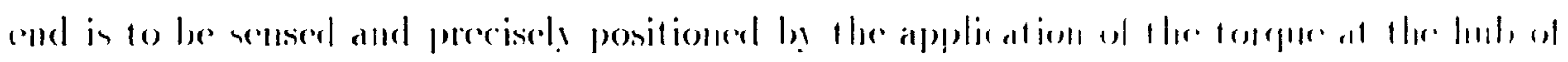

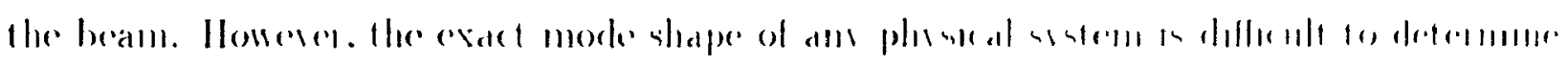




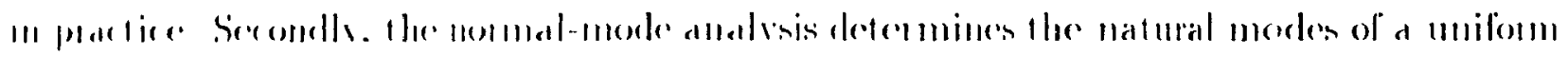

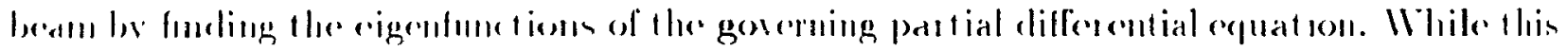

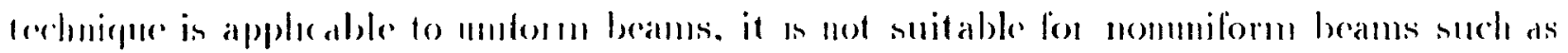

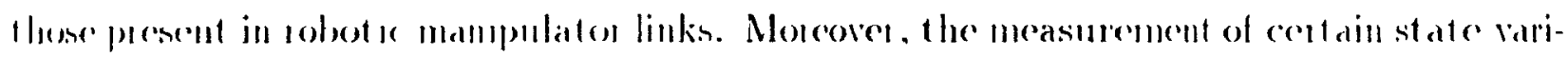

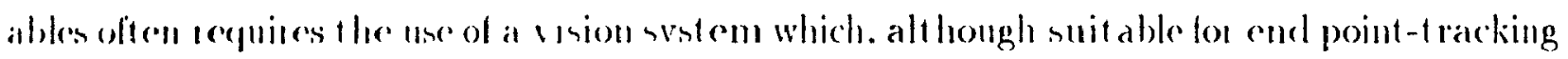
comtol. is too slow at present fon transwerse vibation control of the entiue beam. Fually.

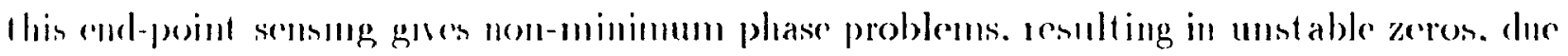
to Har non-collocaterl sensom and actuators, making it unsuitable for syistens undergoing

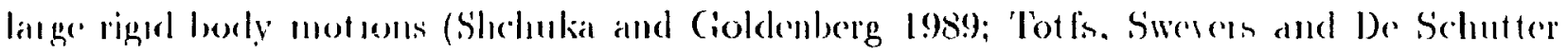
1991) In fact, in the work reponted by ('annon and Schmitz (1981), the flexible beam is

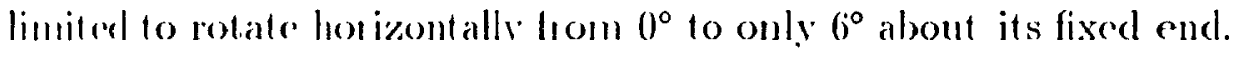

\subsubsection{The Finite-Element Method}

'Ihe ot lie commonly used approach is the finite-element method, which discretizes the continnons berm by dwiding the length of the beam into a finite set of smaller beams. llsing this method, governing equations of the flexible beam are derived as a set of second-oreler ordinam differential equations, Iathen than as a set of partial differential equations. 'This methorl allows the modelling of beams which have non-homogeneous material propertion.

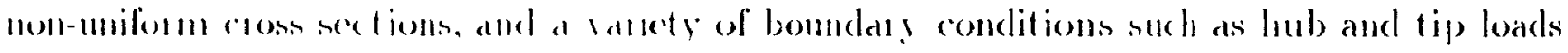

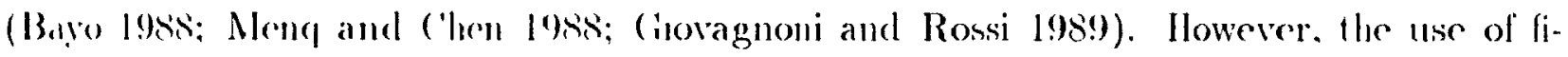
nite olement methods gencealli poduces a large system of ordinary different jal equations to model the system with sulfeient helelity, thereby requiring more expensive computational and contiol hardware. Momeoves. the use of a lage number of equations in the associated statc-space modelling incritably intoduces non-negligible numerical enors and prevents one from using a high sompling ade tor digital contsol. A high sampling rate is requited to cusme

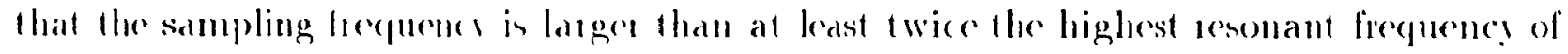

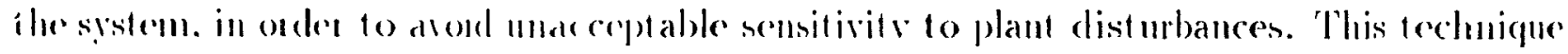
is mitable. therefore. onls for open-loop simulation and may not be adecpuate for closed l(x) control design. This mothod also often uses ond-point semsing, which is musuitable lor 


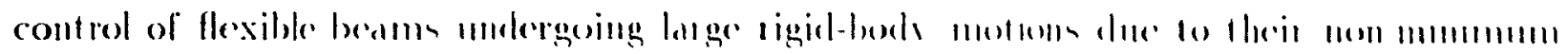

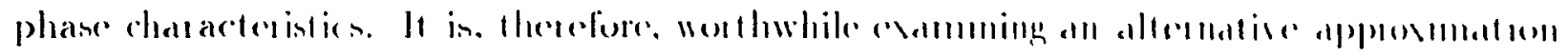

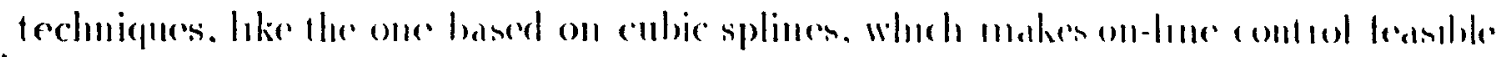

\subsubsection{The Cubic-Spline Technique}

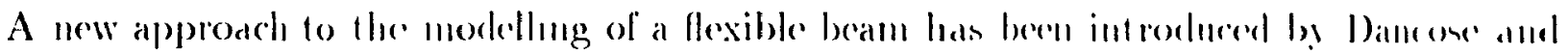

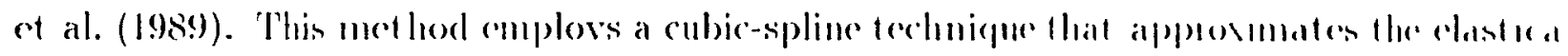
of the contimuons beam with a cubic splime passing through valuess nodal ponts atong the beam. It has been shown that this spatial discretization procodune allows one to model

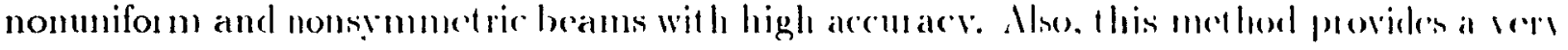
useful linear gelationship befween displacement and curtalure. Henche allowing the use ol accurate and fast strain gages to infer transwerse displacoment momomements. 'This is In contrast to other technigues using a computationally expensive usion ststem lo medsulle end-tip displacement in three-dimensional space.

However, this method does not consides a variety of hommdar conditions which ane commonly present in tobots, such as with tip loads. Moreone. the control of the flexulhe beam is obtained using an optimal regulator, where a control law in used fo dowe lle stale to

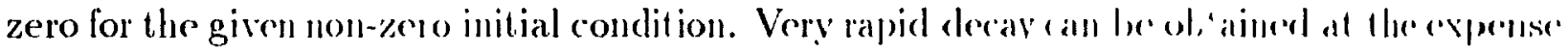
of large control energy, increasing closed-loop bandwidth and. hemer, me maning sembltivily to noise (Kailath 1980). Thus, it may not be applicable to the real-time contol of the flexible beam, which requires good transient response to the reforence munth. Funthermone.

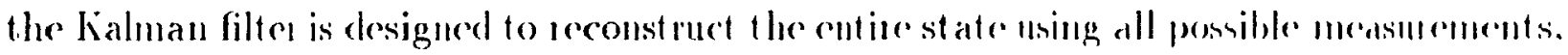
i.e., cunvatures at earh of the nodal points along the beam and hul, rolational angle. Ilonever.

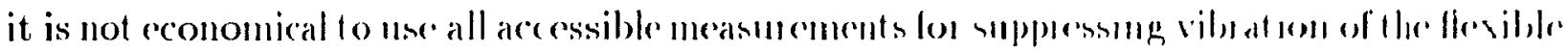
beam. since this eequires a high data thomghpul capabilits. 


\section{$1.3 \quad$ Objectives}

In this thesis. the cobje-spline terehigue in estemeded to include the rase with at tip moss. while inconperating the assoriated boundaly conditions. An optimal cont oller, at hee than

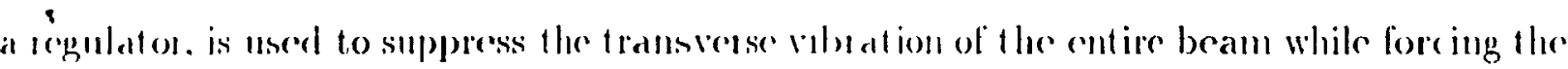

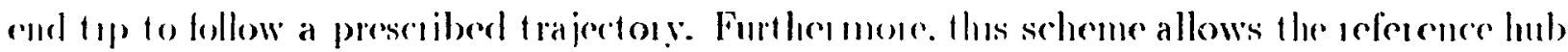
angle as well as its elocity profile to be specified for a smooth transient response. Ilsing the Kalman filter. an investigation is also conducted to assess the feasibility of a reduced mumber of measurements at a sedected number of norlal points. Moreover. the problem of semsing. Which includes the number and location of the sensors and the selection of the sampling rate, are considered. Finally, the flexible boam, carrying a tip mass and rotating horizontally liom $0^{\circ}$ to $180^{\circ}$ about its fixed end, is simulated to illustrate the effectiveness of the proposed cont rol scheme. 'This is compand with a simmlation of an uncontrolled bram to demonstrate the capability of the control system in suppressing transwerse vibuations.

\subsubsection{Extended Cubic-Spline Technique}

In order to obtain the proper dymamic model of a single link flexible bean performing tealistic tasks. the careful consideration of associated boundary conditions must be carried ont. One vers impontant example is that of a mass localed at the ond of the beam, which is considered in detail in this thesis. Typical occurrences of end masses are manipulator payloads and acitators located at the end of each link. Ising Ilamilton's principle, the governing patial differential equation of the clamped-free beam, along with two geometric bomulary conditions and two hinetic boundary conditions, ane obtained. The linet ic boundary conditions correspond to the shear fore and bending moment caused by the tip mass. The lending moment can wsualle be neglected due to the low moment of inemtia of the tip) mass. The shear forer an be computed using the tip acceleration, obtained by substituling the abse spline apptoximation into the governing partial differential equation. 'Therefore, the shean forre boundary condition and the two geometrie boundare conditions can then be included in the lormulation of the linear relationship between displacement and cun verture. 


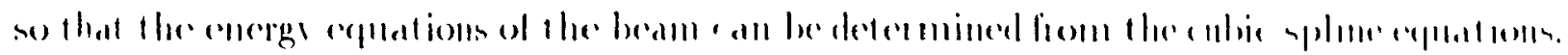

\subsubsection{Control Capability}

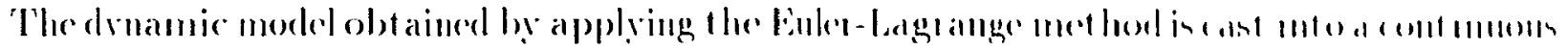

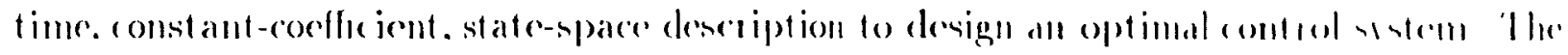

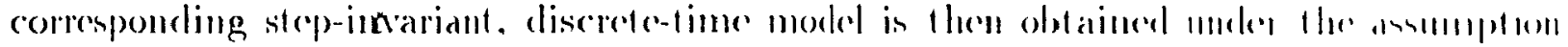

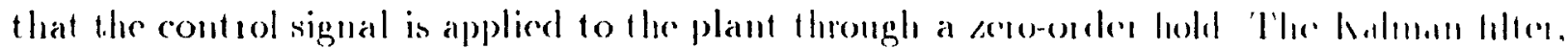

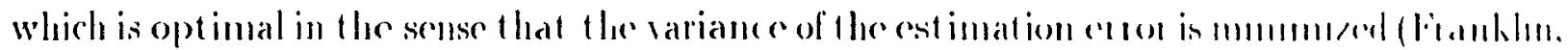

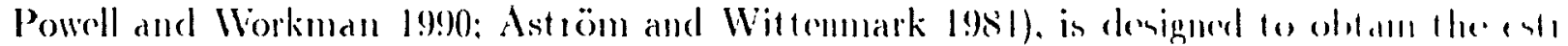
mate of the state suiables that commot be directly obtained themgh medsmements lu

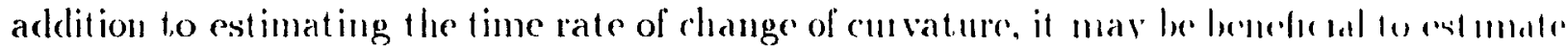

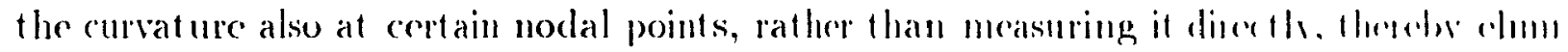

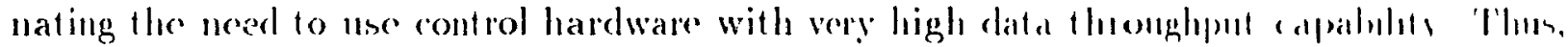
it is of practical importance to fund the smallest possible mumber of memomemonte which

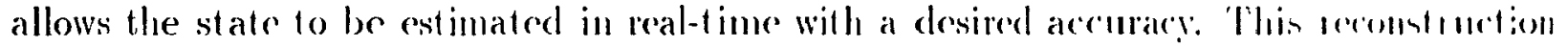

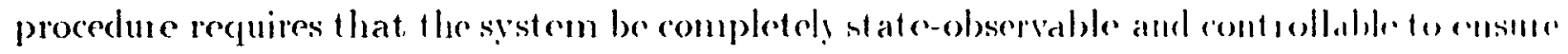
the uniqueness of a feedback gain vector. Although state-obsenvability and contcollablite: have already been theoretically proven in this situation (Balds I!) 8 ; Hnghen and Shellon

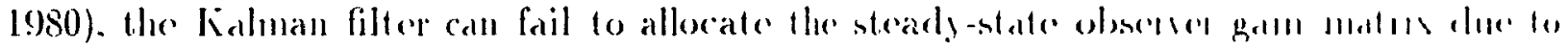

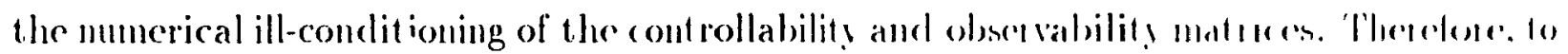
assess the numerical viability of the state estimates obtained by the halmatl hilles. estensitr simulation st udies are porformed.

\subsubsection{Sensing Considerations}

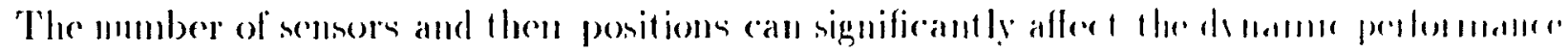

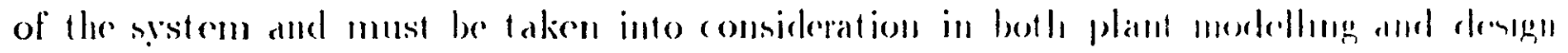

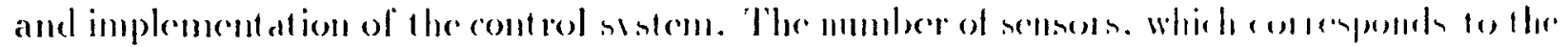

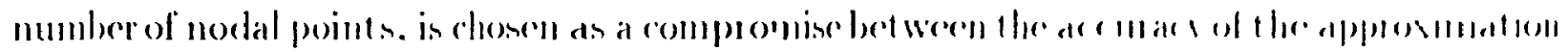




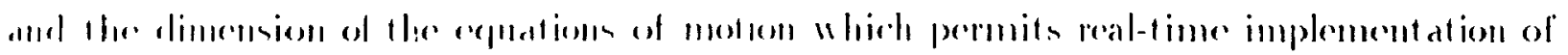

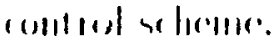

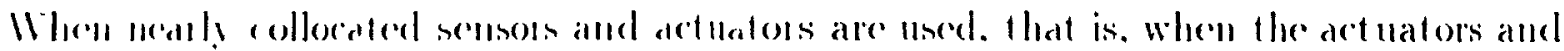

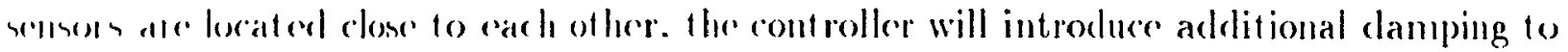

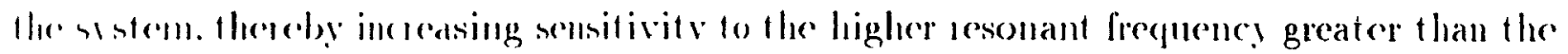

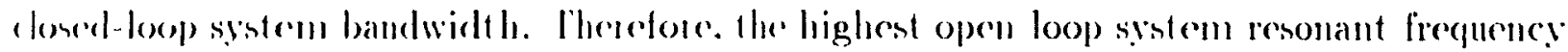
10 be controlled is nsed as the phimary chiterion for selecting the best sampling rate as sligenterd by lianklin of al. (1990).

\subsection{Outline of the Remaining Chapters}

In ('hapten 2, the problem formulation and the spatial discretization of the continuous beam using the cubic-spline method ane describerl, including the application of a variety of bound"nI conditions. 'The finite-dimensional equations of motion of the rotating flexible beam are formulated using the Euler-Lagiange equations. In (hapter 3. the step-invariant discretelime model of the continuous-time, lineat, constant-coefticient model of the system in statevariable space is derived. The design of an optimal control system using the Kalman filter is then discussed. In ('hapter 1. the cietermination of the number and location of sensors is diecusued based on the state-obsemability of the sy stem, and the selection of the sampling late is clescribed. Simulation results ale presented and discussed. Finally, in Chapter 5, the results anc summarized and suggestions for further work are peesented. 


\section{Chapter 2}

\section{Problem Formulation}

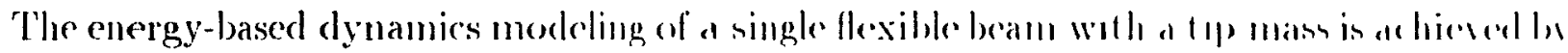

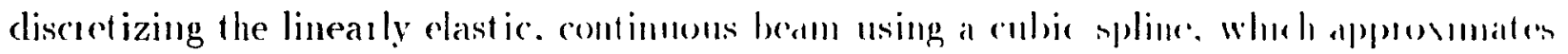
the elastica of the contimuous hedm with a hite number of nodal peints. 'Thes spalial

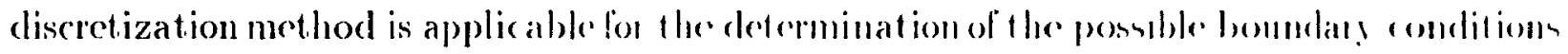

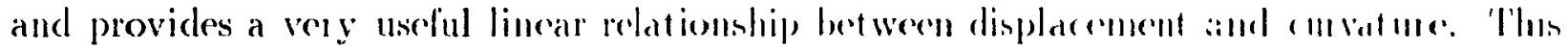

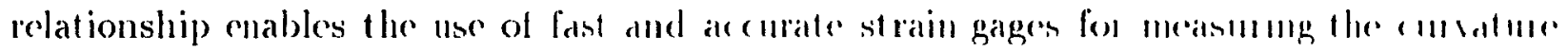
along the beam. thereby aroiding the nes of complex and computationally expensive visiont

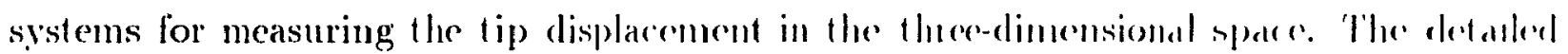
energy equations of the llexible berm. Which ale obtained b emploumg the tume-husing

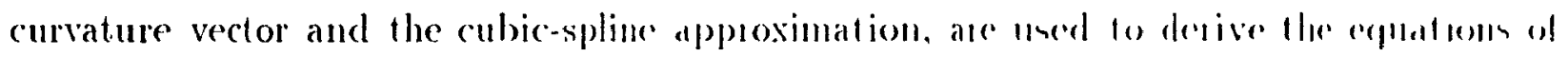
motion using the Euler-Lagıange fommulations. 


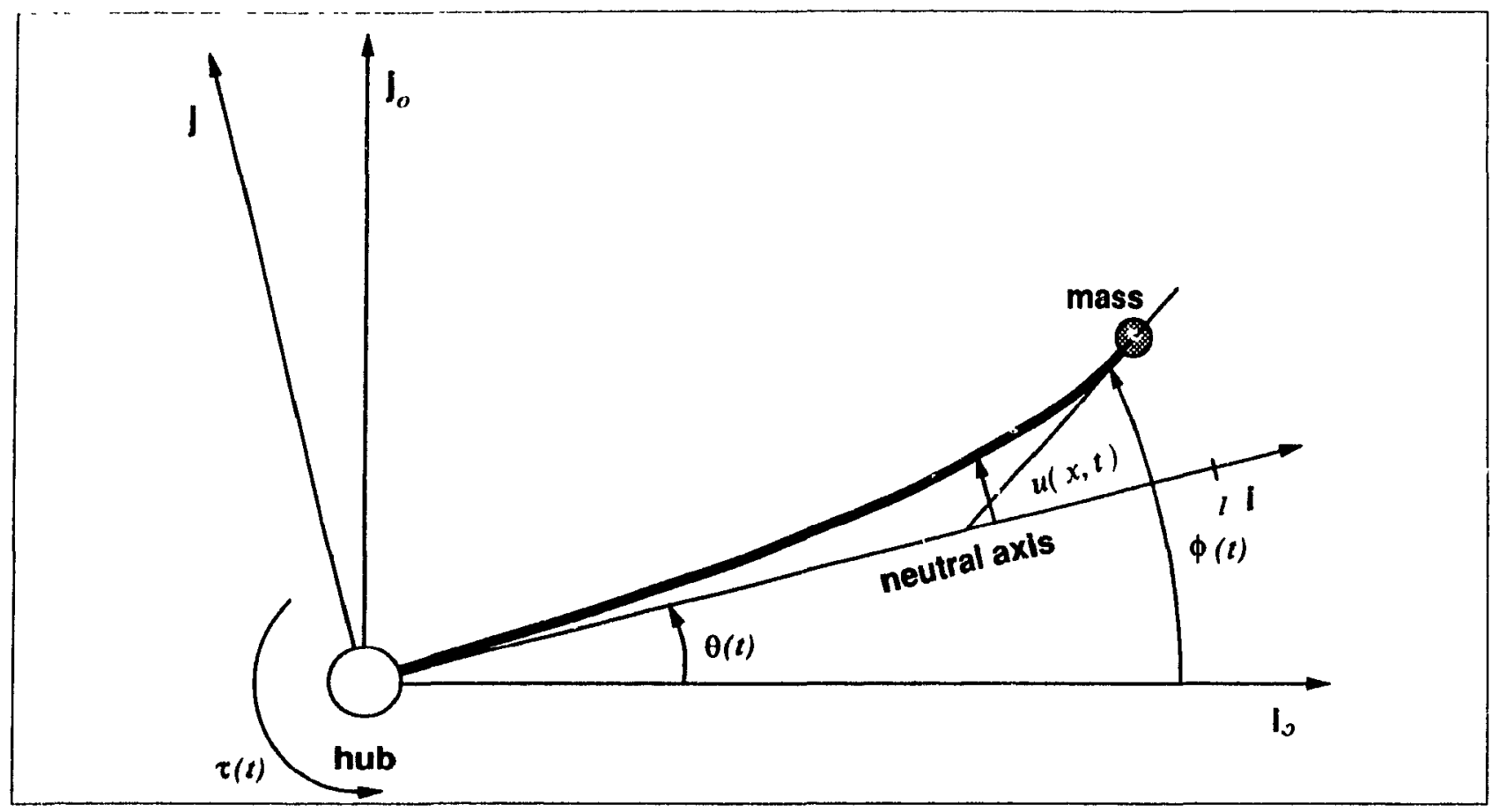

Figure 2.1: Schematic of rotating flexible beam

\subsection{Derivation of the Kinetic and Potential Energies}

The beam. rotating horizontaly about its fixed end with a concentrated tip mass, is modeled as a continuous and clamped-free beam of length $l$. as shown in Fig. 2.1. The kinetic and potential energies of the beam. denoted by $T$ and $l^{\prime}$, iespectively, are given below:

$$
\begin{aligned}
& \Psi=\frac{1}{2} \int_{0}^{l} \rho(x) \omega(x)\|\dot{\mathbf{r}}\|^{2} d x+\frac{1}{2} I_{h} \dot{\theta}^{2}+\frac{1}{2} \cdot\|\| \dot{\mathbf{r}} \|_{t=1}^{2}+\frac{1}{2} I_{m} \dot{\phi}^{2} \\
& 1^{-}=\frac{1}{2} \int_{0}^{l} E l(x . l)\left[u^{\prime \prime}(x, t)\right]^{2} d . x
\end{aligned}
$$


whes.

$$
\begin{aligned}
& 1 \text { : Ingth of the heram [m] } \\
& f(x) \quad \text { : mass densitr }\left[\mathrm{hg} / \mathrm{m}^{3}\right] \\
& \text { (.x) : cross-sectional alcal [m- } \left.\mathrm{m}^{2}\right] \\
& f l(x) \text { : fless!mal rigidiu }\left[\mathrm{kg} \mathrm{m}^{3} / \mathrm{s}^{2}\right] \\
& "(x .1) \text { : deflection of the beam from its nentad asm |min| } \\
& u^{\prime \prime}(r . t) \text { : curtature of the bedm }\left[m^{-1}\right] \\
& I_{h} \quad: \text { moment of incertia of the hulb }\left[\mathrm{kg} \mathrm{m}^{2}\right] \\
& I_{m} \quad: \text { moment of incertia of the tip mass [kg m²] } \\
& M \quad \text { : tip mass [kg] } \\
& \text { 0) : rotation angle of the hul, [rorlian] } \\
& \phi \quad \text { : rotation angle of the tip mass [tarlian] }
\end{aligned}
$$

Now we introduce the assumptions below:

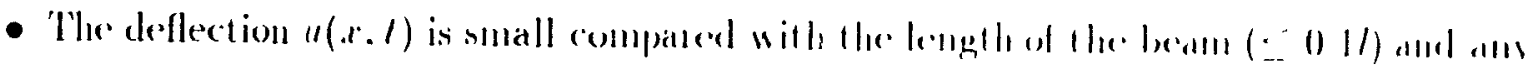
kngitudinal extension of the beam is negligible.

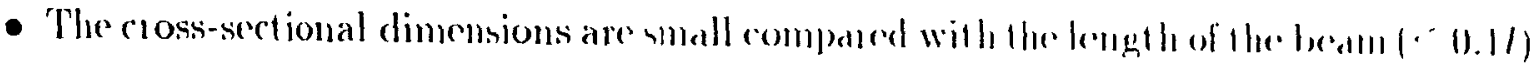

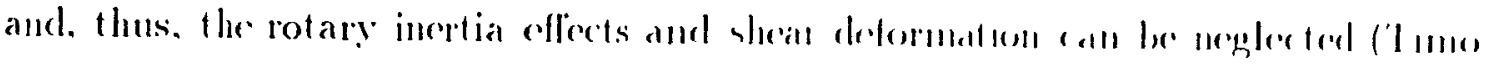
shrnko 1955).

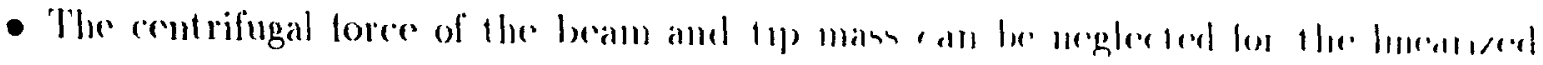
formulation of equations of motion.

- 'Thr hub is rigirl.

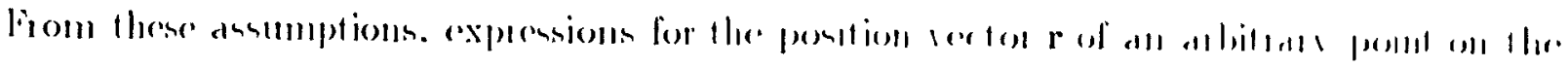




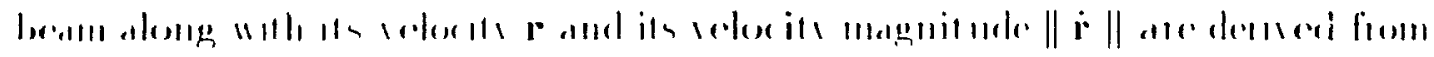

$$
\mathbf{r}=. \mathbf{i}+u \mathbf{j}
$$

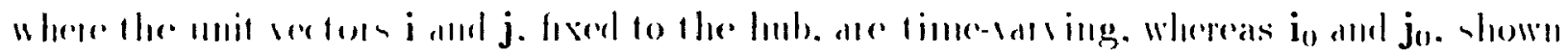

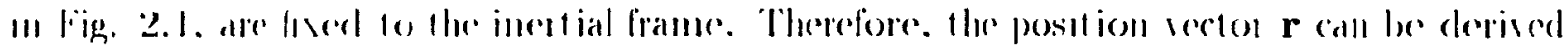

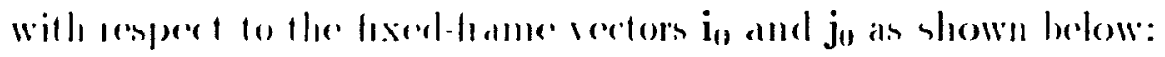

$$
\begin{aligned}
& \left.\mathbf{r}=(. \cos \theta)-\sin \theta) \mathbf{i}_{0}+(\sin \theta)+n \operatorname{sos} \theta\right) \mathbf{j}_{0} \\
& \left.\dot{r}=[(\dot{i}-n(\theta) \cos \theta)-(. \dot{\theta})+\dot{i}) \sin \theta)] \mathrm{i}_{0}+[(. t \dot{\theta}+\dot{i}) \cos \theta+(\dot{i}-u \dot{\theta}) \sin \theta)\right] \mathrm{j}_{0} \\
& \|\dot{\mathbf{r}}\|^{2} \equiv \mathbf{r} \cdot \dot{\mathbf{r}}=u^{2} \dot{j}^{2}+r^{2} \dot{j}^{2}+\dot{u}^{2}+2 \cdot \dot{d} u .
\end{aligned}
$$

The time tate of change $\phi$ of the mentral axis of the beam th the end rarrying the mass is also obtrined from the partial derivative of the position vector r. i.e..

$$
\begin{aligned}
& \left.\frac{\partial \mathbf{r}}{\partial)_{r}}\right|_{1=1}=\left(\cos \theta-u^{\prime}(1,1) \sin \theta\right) \mathbf{i}_{0}+\left(\sin \theta+u^{\prime}(l, 1) \cos \theta\right) \mathbf{j}_{0} \\
& \left.\frac{\partial}{\partial \prime}\left(\frac{\partial \vec{r}}{\partial l}\right)\right|_{l=l}=\left(-\dot{\theta} \sin \theta-\dot{u}^{\prime}(l, l) \sin \theta-u^{\prime}(l . l) \cos \theta\right) \mathbf{i}_{0} \\
& +\left(\dot{\theta} \cos \theta+\dot{u}^{\prime}(1.1) \cos \theta-u^{\prime}(1 . t) \dot{\theta} \sin \theta\right) \mathbf{j}_{0} \\
& \dot{\phi}^{2} \equiv\left\|\left.\frac{\partial}{\partial j l}\left(\frac{\partial \mathbf{r}}{\partial r r}\right)\right|_{,=l}\right\|^{2}=\left(\dot{\theta}+\dot{u}^{\prime}(l, t)\right)^{2}+u^{\prime 2}(l, l) \dot{\theta}^{2} .
\end{aligned}
$$

'To be able to use the cubic-spline spatial discretization technique, the kinetic and potential cmenges are reformulated in terms of time-varying displacement function at the noclal points along the beam and the angular velocity of the hub. namely;

$$
\begin{aligned}
& T=T_{1}+T_{2}+T_{3}+\Gamma_{1}+T_{r_{1}}+T_{t i}+T_{h} \\
& 1=\frac{1}{2} \sum_{h=1}^{n-1} \int_{h h}^{1 h+1} E I_{h}\left[u^{\prime \prime}(r .1)\right]^{2} d x
\end{aligned}
$$

wher

$$
r_{i}=\frac{1}{2}(j) \sum_{k=1}^{n-1} \int_{n k}^{h+1} \rho(r) \cdot(r) u_{k}^{2}(r . l) d r
$$




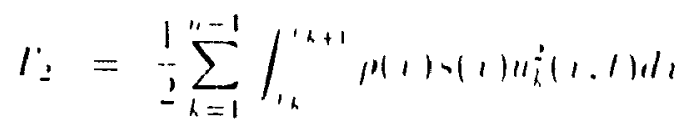

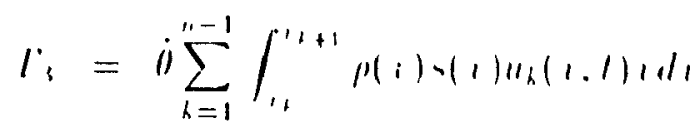

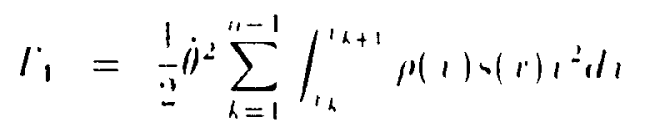

$$
\begin{aligned}
& I_{i}=\frac{1}{2} 1 /\left[11^{2}(1.1) 0^{2}+1^{2}(1)^{2}+i^{2}(1.1)+21011(1.1)\right] \\
& l_{c}=\frac{1}{2} l_{m}\left[\dot{j}^{2}+2 \dot{m} u^{\prime}(1.1)+\dot{u}^{\prime \prime}(1.1)+u^{\prime \prime}(1.1) \theta^{\prime}\right] \\
& T_{h}=\frac{1}{\underline{v}} l_{1}()^{2}
\end{aligned}
$$

\subsection{Spatial Discretization and Consideration of Bound- ary Conditions Using Cubic Splines}

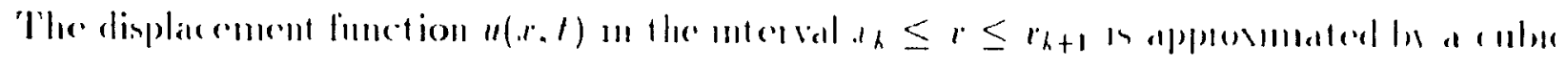
splime function as

$$
u_{h}(x \cdot 1)=\lambda_{h}\left(x-r_{h}\right)^{3}+B_{h}\left(x-r_{h}\right)^{2}+\left(x_{h}\left(.1-r_{h}\right)+b_{h}\right.
$$

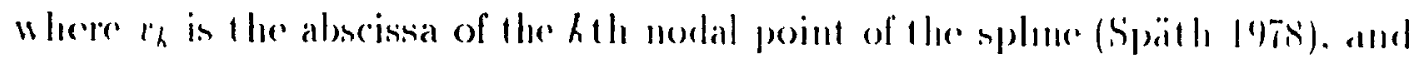

$$
\begin{aligned}
& I_{h}=\frac{1}{6 \Delta x_{h}}\left(u_{h+1}^{\prime \prime}-u_{h}^{\prime \prime}\right) \\
& B_{h}=\frac{1}{2} u_{h}^{\prime \prime} \\
& c_{h}=\frac{\Delta u_{h}}{\Delta_{h}}-\frac{1}{6} \Delta_{h} r_{h}\left(u_{h+1}^{\prime \prime}+2 u_{h}^{\prime \prime}\right) \\
& D_{h}=u_{h}
\end{aligned}
$$

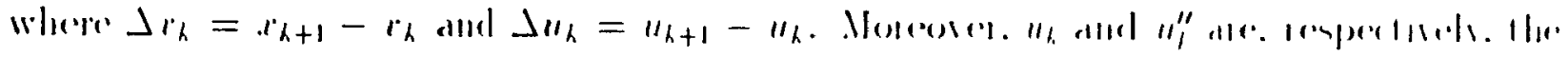
displacement and the courvatume at the kith merlal point. 


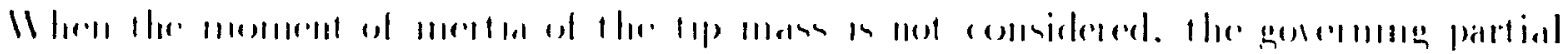

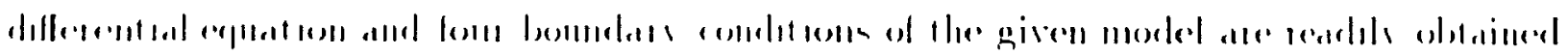

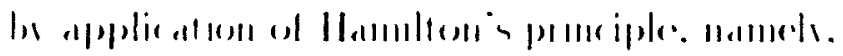

$$
l l(1) \frac{\partial)^{\prime} \prime \prime}{d r^{\prime}}+i n(1) \frac{\partial)^{2} \|}{d)^{2}}=0
$$

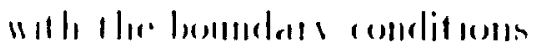

$$
\text { "t } 1=0 .\left\{\begin{array}{l}
u(x . t)=0 \\
\frac{.1 \prime}{1 \prime}=0
\end{array}\right.
$$

and

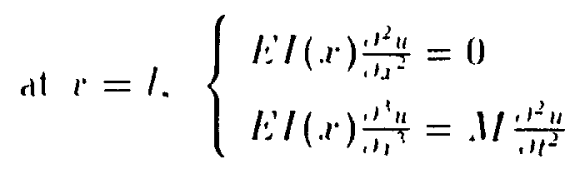

where $m(x)$ in the mass of the beam per enit length at an arbitran point and $1 /$ is the tip) mass. The geomethi bonndan condition du/dgr=0 at the noot of the beam then loads to

$$
\left.\frac{\partial u}{\partial u_{1}}\right|_{1=0} \equiv u_{1}^{\prime}(1)=0=\frac{1}{J \cdot r_{1}}\left(u_{2}-u_{1}\right)-\frac{1}{6} \Delta \cdot r_{1}\left(u_{2}^{\prime \prime}+2 u_{1}^{\prime \prime}\right)
$$

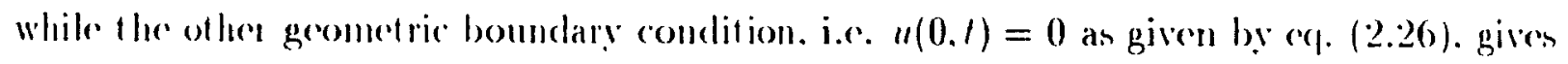

$$
2 n_{1} u_{1}^{\prime \prime}+n_{1} u_{2}^{\prime \prime}=6 i_{1} u_{2}
$$

Where $a_{h} \equiv \Delta \cdot r_{h}$ and $y_{k} \equiv 1 / \Delta_{h}$.

Pinthermore, the presence of a kinetic boundary condition at the tip, which is expresserl III terms of the shear lonce, can be considered by finding the end-point acceleration of the leam using the gorerning partial diffenchtial equation (Davis and Hirschom 1988). Thus lickls

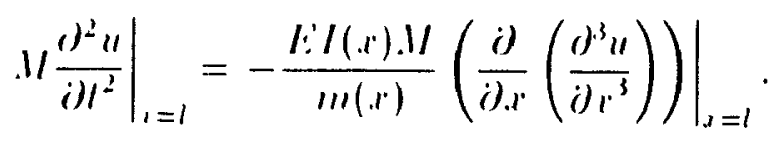

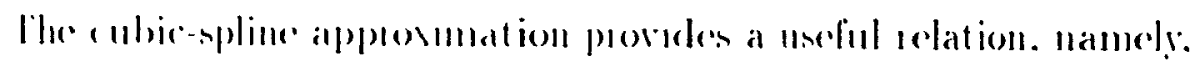

$$
\left.u_{n}^{\prime \prime \prime}=1_{n-1}=\right\}_{n-1}\left(u_{n}^{\prime \prime}-u_{n-1}^{\prime \prime}\right)
$$


Home. (1). (2..30) beromen

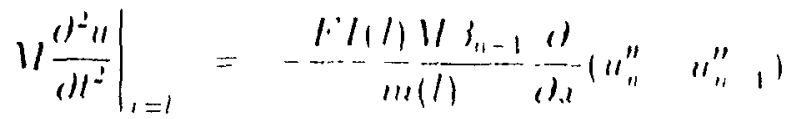

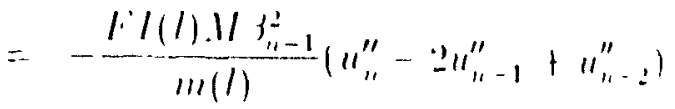

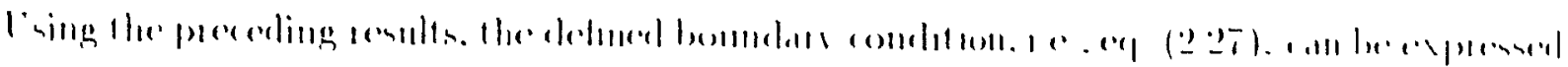
in

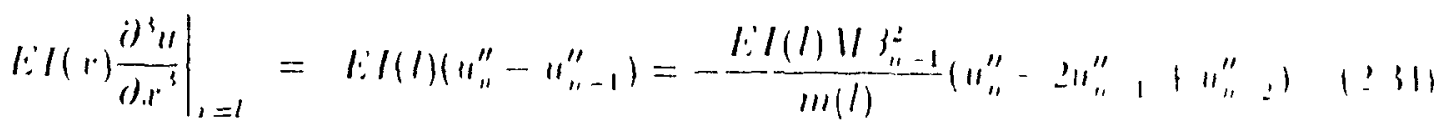

IIIr)

$$
u_{n}^{\prime \prime}=1 I_{n} u_{n-1}^{\prime \prime}-.1 I_{n, u_{n-2}^{\prime \prime}}
$$

"ith $1 /$, and $.1 /$, rlofmerl as

$$
\begin{aligned}
& U_{n}=\frac{1+2\left(.1 / 33_{n-1}^{2} / m(l)\right)}{1+\left(.1 / 3_{n-1}^{2} / m(I)\right)} \\
& V_{n}=\frac{\left.1.1 / 33_{n-1}^{2} / m(l)\right)}{1+\left(1 / 3_{n-1}^{2} / m(I)\right)} .
\end{aligned}
$$

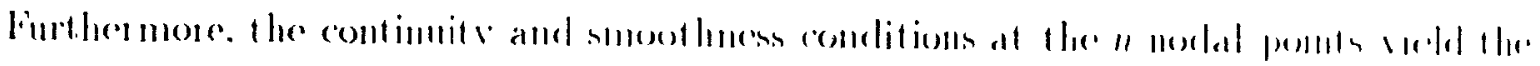

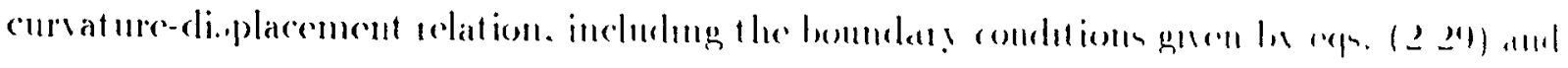
$(2.35)$, as

$$
A_{n} u^{\prime \prime}={ }_{i} C_{n} u
$$

whore

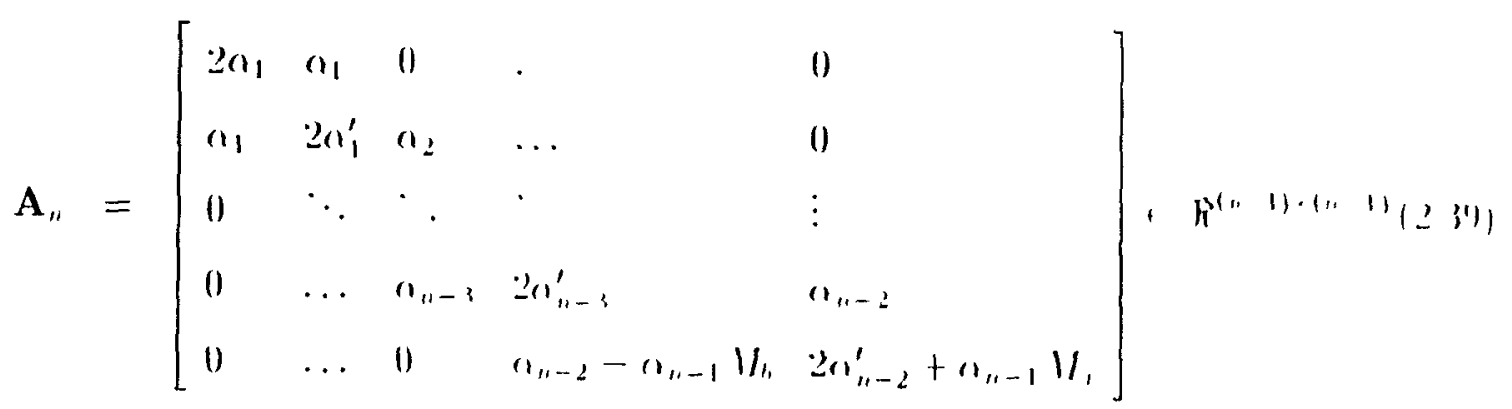




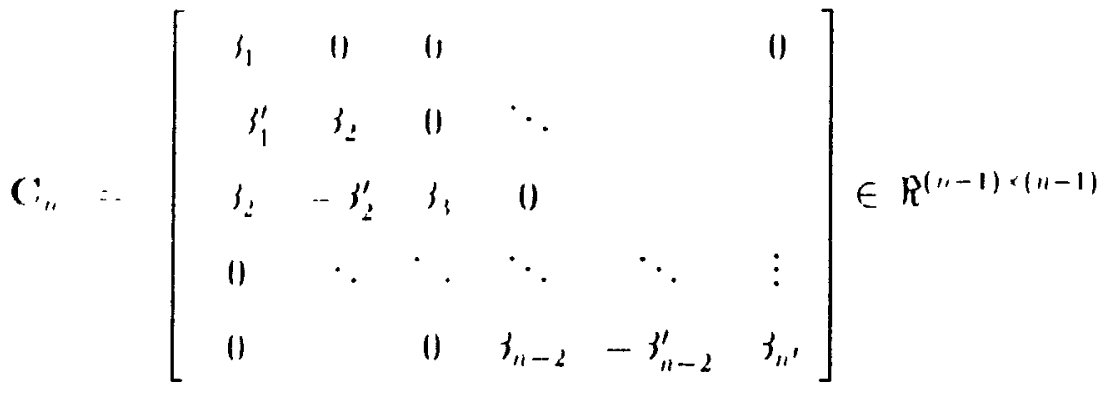

$$
\begin{aligned}
& n_{1} \equiv \Delta r_{1} . \quad f_{1} \equiv 1 / \Delta r_{1} . \quad \text { lor } 1=1, \ldots n-1 \\
& a_{1}^{\prime} \equiv a_{1}+a_{1+1} . f_{1}^{\prime} \equiv 3_{1}+3_{1+1} \text {. for } 1=1, \ldots . n-3
\end{aligned}
$$

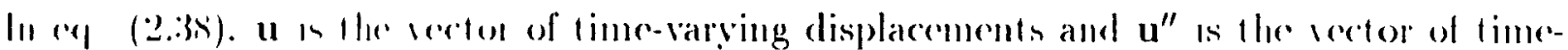

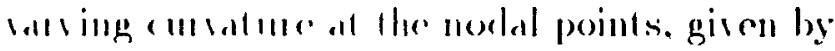

$$
\begin{aligned}
\mathbf{u} & =\left[u_{2} \ldots \ldots u_{n}\right]^{r} \in \mathrm{R}^{(n-1)} \\
\mathbf{u}^{\prime \prime} & =\left[u_{1}^{\prime \prime} \ldots \ldots u_{n-1}^{\prime \prime}\right]^{T} \in \mathrm{R}^{(n-1)}
\end{aligned}
$$

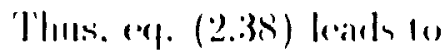

$$
\mathbf{u}=\mathbf{N} \mathbf{u}^{\prime \prime}
$$

Whene

$$
\mathbf{N}=\frac{1}{6} \mathbf{C}_{n}^{-1} \mathbf{A}_{n}
$$

$C_{\prime \prime}$ being non singulan.

The displatement function $\|_{h}(x, t)$ can be expressed also as a function of $u$ as slown lowlow.

$$
\prime \prime_{h}(x . l)=\left[\begin{array}{llll}
\left(x-x_{h}\right)^{3} & \left(x-x_{h}\right)^{2} & \left(x-x_{h}\right) & 1
\end{array}\right]\left[\begin{array}{l}
A_{h}(l) \\
B_{h}(l) \\
C_{h}(l) \\
D_{h}(l)
\end{array}\right]
$$

D)

$$
\mathrm{s}_{h}^{\prime}(x) \equiv\left[\begin{array}{llll}
\left(1-. x_{h}\right)^{3} & (x-. r k)^{2} & \left(r-x_{h}\right) & 1
\end{array}\right] .
$$




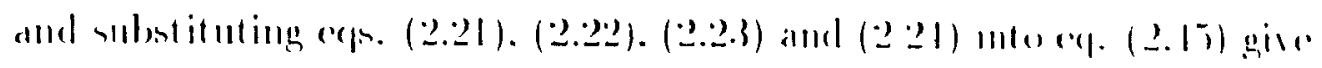

$$
\begin{aligned}
& u_{h}(. r . l)=s_{h}^{l}(. r)\left[\begin{array}{c}
\left(u_{h+1}^{\prime \prime}-u_{h}^{\prime \prime}\right) / n \Delta_{1} \\
u_{h}^{\prime \prime} / 2 \\
\left(u_{h+1}-u_{h}\right) / \Delta r_{h}-\left(u_{h+1}^{\prime \prime}+2_{h}^{\prime \prime}\right) \Delta_{h} / h_{1} \\
u_{h}
\end{array}\right] \\
& =s_{h}^{T}(. x)\left[\begin{array}{c}
\left(u_{h+1}^{\prime \prime}-u_{h}^{\prime \prime}\right) /\left(\Delta x_{h}\right. \\
u_{h}^{\prime \prime} / 2 \\
-\left(u_{h+1}^{\prime \prime}+2 u_{h}^{\prime \prime}\right) \Delta_{h} / 6 \\
0
\end{array}\right]+s_{h}^{\prime}(1)\left[\begin{array}{c}
u \\
0 \\
\left(u_{h+1}-u_{h}\right) / \Delta u_{h} \\
u_{h}
\end{array}\right]
\end{aligned}
$$

Which results in the relationship

$$
u_{h}(x . l)=\mathbf{s}_{h}^{l} \mathbf{U}_{h}^{\prime \prime} \mathbf{u}^{\prime \prime}+\mathbf{s}_{h}^{l} \mathrm{U}_{h} \mathbf{u} .
$$

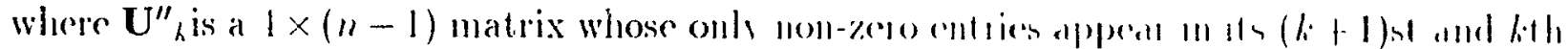
columms, namely,

$$
\mathbf{U}_{k}^{\prime \prime}=\left[\begin{array}{cccccccc}
0 & \ldots & 0 & -i_{h} / 6 & s_{h} / 6 & 0 & \ldots & 0 \\
0 & \ldots & 0 & 1 / 2 & 0 & 0 & . & 0 \\
0 & \ldots & 0 & -\sigma_{h} / 3 & -a_{h} / 6 & 0 & & 0 \\
0 & \ldots & 0 & 0 & 0 & 0 & \ldots & 0
\end{array}\right]
$$

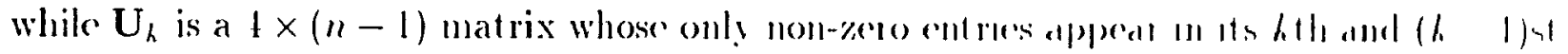
colummis, i.c..

$$
\mathbf{U}_{h}=\left[\begin{array}{cccccccc}
0 & \ldots & 0 & 0 & 0 & 0 & \ldots & 0 \\
0 & . & 0 & 0 & 0 & 0 & & 0 \\
0 & \ldots & 0 & -i_{h} & 3_{h} & 0 & . & 0 \\
0 & \ldots & 0 & 1 & 0 & 0 & . & 0
\end{array}\right]
$$

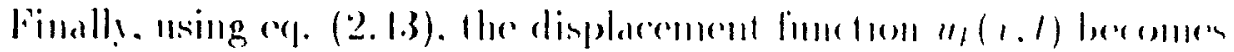

$$
u_{h}(r, l)=\mathbf{s}_{h}^{l}\left(\mathrm{U}_{h}^{\prime \prime}+\mathrm{U}_{h} \mathrm{~N}\right) \mathbf{u}^{\prime \prime}
$$




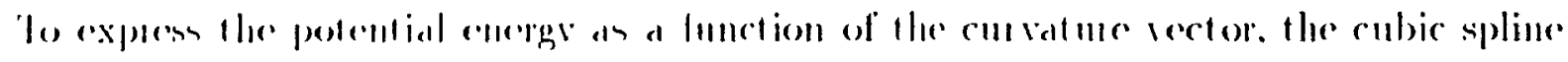
function defuned in ep. (2.20) is used. Taking the seromd serivative of the displacement

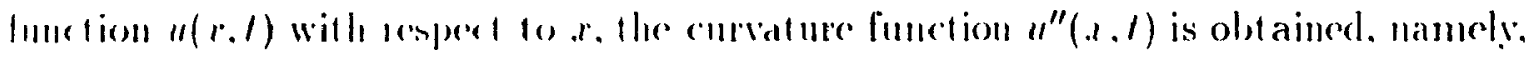

$$
\begin{aligned}
& u_{h}^{\prime \prime}=6 l_{h}\left(x-x_{h}\right)+2 B_{h} \\
& =\left[\begin{array}{ll}
\left(x-x_{h}\right) & 1
\end{array}\right]\left[\begin{array}{c}
\left(u_{h+1}^{\prime \prime}-u_{h}^{\prime \prime}\right) / \Delta x_{h} \\
u_{h}^{\prime \prime}
\end{array}\right] .
\end{aligned}
$$

Now, we define

$$
\mathbf{t}_{h}^{\prime}(x) \equiv\left[\left(x-x_{h}\right) 1\right]
$$

which loads to

$$
u_{h}^{\prime \prime}=\mathbf{t}_{k}^{T}(x) \mathbf{F}_{h}^{\prime \prime} \mathbf{u}^{\prime \prime}
$$

where

$$
\mathbf{F}_{h}^{\prime \prime}=\left[\begin{array}{cccccccc}
0 & \ldots & 0 & -\beta_{h} & \beta_{h} & 0 & \ldots & 0 \\
0 & \ldots & 0 & 1 & 0 & 0 & \ldots & 0
\end{array}\right]
$$

Note that $\mathbf{F}_{h}{ }_{h}$ is a $2 \times(n-1)$ matrix whose only non-zero entries dppear in its $(k+1)$ st and hilh columins.

'The kinetic and potential energy equations of the flexible beam can then be reformulated using eqs. (2.52) and (2.56), which allow the use of the cubic-spline technique, in terms of the curvature vector.

\subsection{The Euler-Lagrange Equations of Motion}

IIhen the terms due to the cont rifugal force are neglected. the kinetic and potential energ." (xprensions ale givell by

$$
\begin{aligned}
& T=\frac{1}{2}\left[l_{1} \dot{\theta}^{2}+\dot{\mathbf{u}}^{\prime \prime \prime}\left(\mathbf{M}_{1}^{\prime \prime}+\mathbf{M}_{2}^{\prime \prime}+\mathbf{M}_{3}^{\prime \prime}\right) \dot{\mathbf{u}}^{\prime \prime}+2 \dot{\theta}\left(\gamma_{1}^{r}+\gamma_{2}^{T}+\gamma_{3}^{T}\right) \dot{\mathbf{u}}^{\prime \prime}\right] \\
& I=\frac{1}{2} \mathbf{u}^{\prime \prime l} \mathbf{K}^{\prime \prime} \mathbf{u}^{\prime \prime}
\end{aligned}
$$


"lin"

$$
I_{t}=I_{h}+I_{1}+I_{m}+I^{2}
$$

and the $h_{h}$ is the moment of imertia of the mollesed rigid beam. Mlopenen,

$$
\begin{aligned}
& \mathbf{M}_{1}^{\prime \prime}=\sum_{h=1}^{n-1}\left(\mathbf{N}^{l} \mathbf{U}_{h}^{l}+\mathbf{U}_{h}^{\prime \prime r}\right) \mathbf{P}_{h}\left(\mathbf{U}_{h}^{\prime \prime}+\mathbf{U}_{h} \mathbf{N}\right) \\
& \mathbf{M}_{2}^{\prime \prime}=\left(\mathbf{N}^{l} \mathbf{U}_{n-1}^{\prime}+\mathbf{U}_{n-1}^{\prime \prime}\right) \mathbf{P}_{n-1}\left(\mathbf{U}_{n-1}^{\prime \prime}+\mathbf{U}_{n-1} \mathbf{N}\right) \\
& \mathbf{M}_{1}^{\prime \prime}=\left(\mathbf{N}^{T} \mathbf{U}_{n-1}^{T}+\mathbf{U}_{n-1}^{\prime \prime}\right) \mathbf{P}_{n-1}^{\prime}\left(\mathbf{U}_{n-1}^{\prime \prime}+\mathbf{U}_{n-1} \mathbf{N}\right)
\end{aligned}
$$

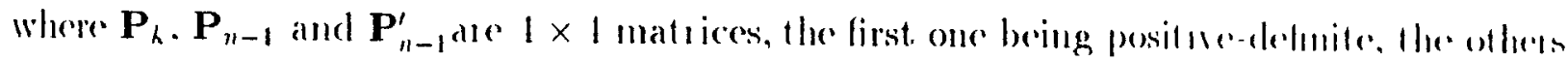
positive-somidefinite, namely,

$$
\begin{aligned}
& \mathbf{P}_{h}=\int_{1 h}^{d h+1} \rho_{h \cdot h} \mathrm{~s}_{h}(x) \mathbf{s}_{h}^{T}(x) d l \cdot \\
& \mathbf{P}_{n-1}=. M \mathbf{s}_{n-1}(l) \mathbf{s}_{n-1}^{T}(l) \\
& \mathbf{P}_{n-1}^{\prime}=I_{m} \mathbf{s}_{n-1}^{\prime}(l) \mathbf{s}_{n-1}^{T}(l)
\end{aligned}
$$

where $\mathbf{s}_{n-1}^{\prime}(l)$ denotes the derivative $\mathrm{s}_{n-1}^{\prime}(x)$ emaluated at $x=1$. 'The $\gamma_{1}^{l} \cdot \gamma_{2}^{\prime}$ and $\gamma_{1}^{\prime}$ ane alen, derived from eqs. (2.15). (2.17), (2.18) and e(1. (2.52), which yicld

$$
\begin{aligned}
& \gamma_{1}^{T}=\sum_{h=1}^{n-1} \mathbf{m}_{h}^{\prime \prime}+\left(\sum_{h=1}^{n-1} \mathbf{m}_{h}^{T}\right) \mathbf{N} \\
& \gamma_{2}^{T}=\mathbf{m}_{n-1}^{\prime \prime}+\mathbf{m}_{n-1}^{T} \mathbf{N} \\
& \gamma_{3}^{T}=\dot{\mathbf{m}}_{n-1}^{\prime \prime}+\dot{\mathbf{m}}_{n-1}^{T} \mathbf{N}
\end{aligned}
$$

where

$$
\begin{array}{rlrl}
\mathbf{m}_{h}^{\prime \prime T} & \equiv \mathbf{p}_{h}^{T} \mathbf{U}_{h}^{\prime \prime} & \mathbf{m}_{h}^{l} \equiv \mathbf{p}_{h}^{l} \mathbf{U}_{h} \\
\mathbf{m}_{n-1}^{\prime \prime} \equiv \mathbf{p}_{n-1}^{T} \mathbf{U}_{n-1}^{\prime \prime} & \mathbf{m}_{n-1}^{l} \equiv \mathbf{p}_{n-1}^{l} \mathbf{U}_{n-1} \\
\dot{\mathbf{m}}_{n-1}^{\prime \prime l} \equiv \mathbf{p}_{n-1}^{\prime r} \mathbf{U}_{n-1}^{\prime \prime} & \mathbf{m}_{n-1}^{l} \equiv \mathbf{p}_{n-1}^{\prime l} \mathbf{U}_{n-1}
\end{array}
$$

will

$$
\mathbf{p}_{h}^{l}=\int_{h h}^{\prime h+1} \rho_{h} \cdot r_{h} \cdot r \mathbf{s}_{h}^{l}(r) d \cdot r
$$




$$
\begin{aligned}
& \mathbf{p}_{n-1}^{\prime}=I / / \mathbf{s}_{n-1}^{\prime}(l) \\
& \mathbf{p}_{n-1}^{\prime \prime}=I_{m} / \mathbf{s}_{n-1}^{\prime \prime}(l) .
\end{aligned}
$$

The positive definitestifluess matrix $\mathbf{K}$ is clefuned as

$$
\mathbf{K}=\sum_{h=1}^{n-1} \mathbf{F}_{h}^{\prime \prime} \mathbf{Q}_{h} \mathbf{F}_{h}^{\prime \prime}
$$

with

$$
\mathbf{Q}_{h}=\int_{x_{h}}^{l_{h+1}} l I_{h} \mathbf{t}_{h}(x) \mathbf{t}_{h}^{l}(r) d x \in R^{(2 \times 2)}
$$

Where $Q_{h}$ is positive definite.

The kimetic and potential energy expressions can be simplified using the buler-Lagrange repuation as

$$
T=\frac{1}{2} \dot{\mathbf{q}}^{T} \mathbf{M} \dot{\mathbf{q}} \cdot \quad I^{\cdot}=\frac{1}{2} \mathbf{q}^{T} \mathbf{K} \mathbf{q}
$$

where

$$
\mathbf{M}=\left[\begin{array}{cc}
\mathbf{M}^{\prime \prime} & \boldsymbol{\gamma} \\
\boldsymbol{\gamma}^{T} & J_{t}
\end{array}\right], \mathbf{K}=\left[\begin{array}{cc}
\mathbf{K}^{\prime \prime} & \mathbf{0}_{n \times 1} \\
\mathbf{0}_{1 \times n} & 0
\end{array}\right]
$$

are the mass and stiffuess matrices, with

$$
\begin{aligned}
\mathbf{M}^{\prime \prime} & \equiv \mathbf{M}_{1}^{\prime \prime}+\mathbf{M}_{2}^{\prime \prime}+\mathbf{M}_{3}^{\prime \prime} \\
\gamma & \equiv \gamma_{1}+\gamma_{2}+\gamma_{3} .
\end{aligned}
$$

while the rector of generalized coordinates is defined as

$$
\mathrm{q}=\left[\mathbf{u}^{\prime \prime T} \theta\right]^{T}
$$

Finalls. the equatron of motion of the beam is olviained as

$$
\mathbf{M} \ddot{\mathbf{q}}+\mathbf{K q}=\varphi(l)
$$

"lien"

$$
\boldsymbol{\varphi}(t)=\left[\mathbf{0}_{(1+1)}^{T} T(l)\right]^{T}
$$




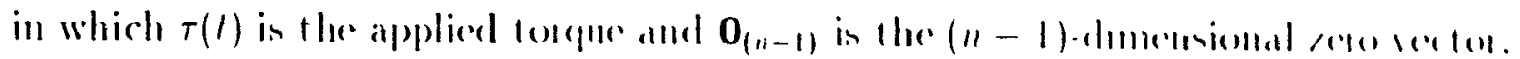

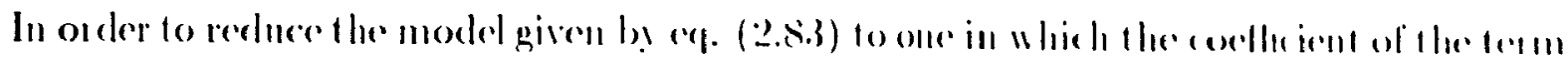

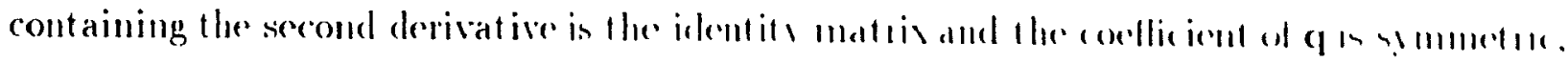

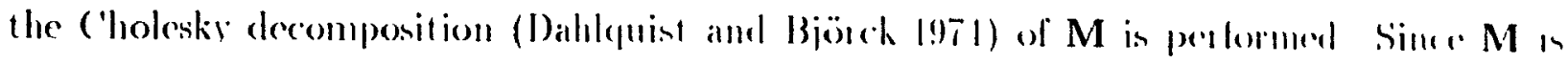

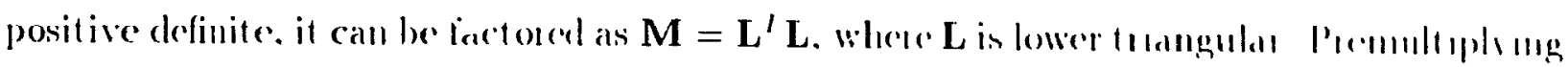
both sides of e(1. (2.53) by $\mathbf{L}^{-T}$. Hhe thanspose of $\mathbf{L}^{-1}$. gires.

$$
\mathbf{L} \ddot{\mathbf{q}}+\mathbf{L}^{-l} \mathbf{K q}=\mathbf{L}^{-l} \boldsymbol{\varphi}
$$

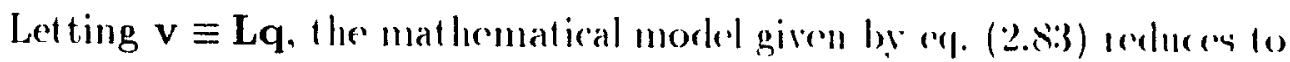

$$
\ddot{\mathbf{v}}+\mathbf{W} \mathbf{v}=\boldsymbol{\psi}
$$

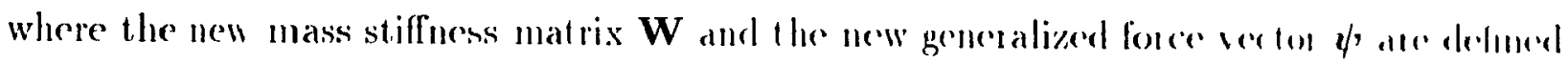
as

$$
\mathbf{W} \equiv \mathbf{L}^{-I} \mathbf{K L}^{-1} \cdot \psi \equiv \mathbf{L}^{-1} \varphi
$$

in which $\mathbf{W}$ is also positive definite. 


\section{Chapter 3}

\section{Optimal Control System Design}

The design of a contuoller for the flexible beam must take into consideration the presence of uncerlain and time-vatying parametess due to imperfect modelling of system dyuamics, as well as the presence of noise due to the imperfection of st a ain gages used for measurements. Theretore, an optimal control approach is chosen to minimize these effects and to aid in the determitiation of the desired pole location. The optimal contol strategy is two-fold: one is the design of the ralman filte which minimizes the variance of state estimation errors, while the other is the determination of the optimal contiol law to minimize the specified performance criterion from the estimated states.

\subsection{State-Space Model Description}

The Lagrangian model of the flexible beam can be described as a continuous-time. linear. constant-coedliciont system in state-rariable space, namely.

$$
\begin{aligned}
& \dot{\mathbf{x}}=\mathbf{A x}(l)+\mathbf{b} u(l), \mathbf{x}(0)=\mathbf{x}_{0} \\
& \mathbf{y}=\mathbf{C x}(l)
\end{aligned}
$$


where

$$
\begin{aligned}
& \mathbf{A}=\left[\begin{array}{cc}
\mathbf{O} & 1 \\
-\mathbf{W} & 0
\end{array}\right] \in \Re^{(2 n \times 2 n)} \\
& \mathbf{b}=\left[\begin{array}{c}
\mathbf{0} \\
\mathbf{L}^{-1} \mathbf{w}
\end{array}\right] \in \Re^{2 n}, \mathbf{w}=\left[\begin{array}{c}
\mathbf{0}_{(n-1)} \\
1
\end{array}\right], \mathbf{C} \in \Re^{(p \times 2 n)}
\end{aligned}
$$

in which $\mathrm{O}$ and $\mathbf{1}$ denote the $n \times n$ zero and identity matrices, respectively. Morover, 0 m the $n$-dimensional zero vector, $\mathbf{0}_{(n-1)}$ is the $(n-1)$-dimonsional zero vertor, and $p$ dentes the number of sensors. The state vector and scalar input anc also defined as

$$
\mathbf{x}=\left[\begin{array}{c}
\mathbf{v} \\
\dot{\mathbf{v}}
\end{array}\right], u(t)=\tau(t)
$$

It is impractical to assume that all of the state variables are avilable through morisurement

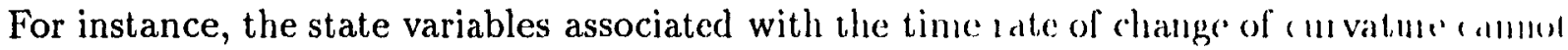
be measured directly with any existing sensor. Furthemore, the use of a large mumber of sensors would require more complicated control hardware having a high dala thinomlypul. capability. The approach adopted here is to measure a subset of the statce variables and to estimate on-line the remaining ones. Therefore, the measured output through $p$ sensors is expressed as a linear combination of the available state variables, i.e.

$$
y=C^{\prime}\left[\begin{array}{c}
q \\
\dot{q}
\end{array}\right]
$$

where $\mathbf{C}^{\prime} \equiv \mathbf{C L} \in \Re^{(p \times 2 n)}$.

A digital control signal is assumed to be applied via a zero-order hold, the associntinl discrete-time system being the step-invariant model given by

$$
\begin{aligned}
\mathbf{x}(k+1) & =\mathbf{\Phi} \mathbf{x}(k)+\Gamma u(k)+\omega(k) \\
\mathbf{y}(k) & =\mathbf{H} \mathbf{x}(k)+\boldsymbol{v}(k)
\end{aligned}
$$

where

$$
\begin{aligned}
\boldsymbol{\Phi} & =e^{\mathbf{A} \Delta} \\
\mathbf{\Gamma} & =\left(\int_{0}^{\Delta} e^{\mathbf{A} \eta} d \eta\right) \mathbf{b} \\
\mathbf{H} & =\mathbf{C}
\end{aligned}
$$




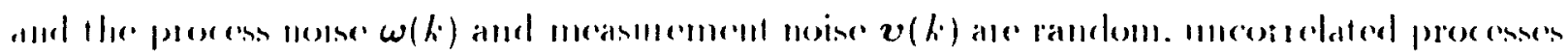

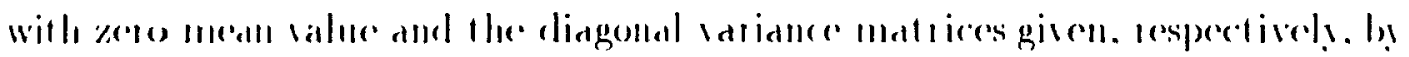

$$
l:\left\{\boldsymbol{\omega}(k \cdot) \boldsymbol{\omega}(k \cdot)^{\prime}\right\}=\mathbf{R}_{i \cdot .} \quad l\left\{\boldsymbol{v}(k) \boldsymbol{v}(k)^{\prime}\right\}=\mathbf{R}_{r} .
$$

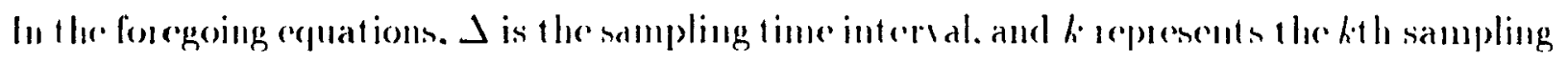
limes step).

\subsection{Optimal Observer}

Let the state observer be given by

$$
\hat{\mathbf{x}}(k+1)=\boldsymbol{\Phi} \hat{\mathbf{x}}(k)+\Gamma u(k)+\mathbf{L}_{\alpha}[\mathbf{y}(k)-\mathbf{H} \hat{\mathbf{x}}(k)]
$$

where $L$, is the steady-state, discrete-time. Kalman filter gain matrix. It is well known (Middleton and (ioodwin 1990) that if the pair $(\mathbf{H}, \boldsymbol{\Phi})$ is observable, the eigenvalues of $(\Phi-\mathbf{L}, \mathbf{H})$ (an be arbit rarily assigned by appropriate design of the steady-state gain matrix, L... It is also known (Luenberger 1971) that the observer does not impair the closed loop stability. 'Therelore, the design of an opt imal observer reduces to optimizat ion of the steadystate obscrer gain matrix $\mathbf{L}_{\infty}$ so as to minimize the estimation error $\dot{\mathbf{x}}=\mathbf{x}-\hat{\mathbf{x}}$ governed lug

$$
\dot{\mathbf{x}}(k+1)=\left[\mathbf{\Phi}-\mathbf{L}_{\curvearrowright} \mathbf{H}\right] \dot{\mathbf{x}}(k)+\omega(k)-\mathbf{L}_{\curvearrowright} v(k) .
$$

'To find the steady-state, discrete-time, Kalman filter gain $\mathbf{L}_{\infty}$ (current observer gain), the patametric optimization problem associated with the covariance of the estimation errot ( $R$ ström and Witlemmark 1984; Hanklin. Powell and Workman 1990) is solved in the presence of noiss.

\subsection{Optimal Controller}

The reference state $x$, in derived fiom the reference input theough the relation

$$
\mathbf{x}_{1}(k)=\mathbf{T}_{1} r(k)
$$




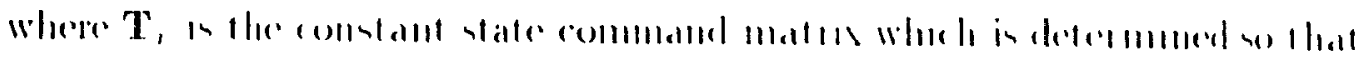

$$
\lim _{h \rightarrow !} x_{1}(h)=x_{n}(k)
$$

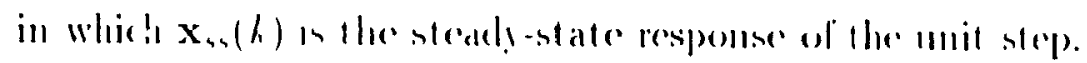

The coutuel inpult is then generated lor

$$
u(k)=-k^{\prime}\left(\dot{x}(k)-\mathbf{x}_{1}(k)\right)
$$

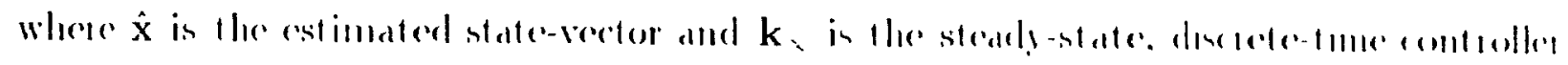
gain. Which minimizes the cost function given h

$$
I=\frac{1}{2} \sum_{k=0}^{N}\left[\mathbf{x}^{\prime}(k) \mathbf{Q} \mathbf{x}(k)+q u^{2}(k)\right]
$$

under the comstraint

$$
-\mathbf{x}(k+1)+\boldsymbol{\Phi} \mathbf{x}(k)+\boldsymbol{\Gamma} u(k)=0 . \quad k=0.1 . \quad \ldots l
$$

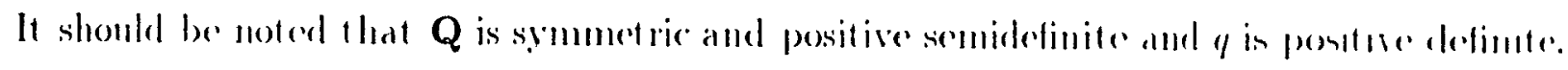

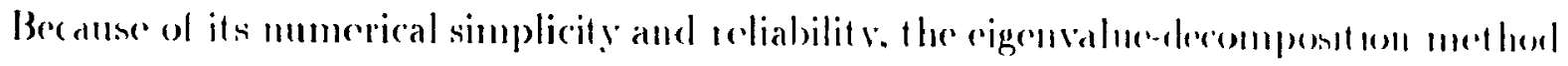
associated with the Ilamiltonian matrix is used to find the optimal stedely statre conteol gain $k_{2}$. instead of solving the discrete algeblate Riccati c(puat ion, which a an have multiple. solutions. 'The llamilion equations ate:

$$
\left[\begin{array}{c}
\mathbf{x} \\
\boldsymbol{\lambda}
\end{array}\right]_{h+1}=\left[\begin{array}{cc}
\boldsymbol{\Phi}+\boldsymbol{\Gamma} \mathbf{Q}^{-1} \boldsymbol{\Gamma}^{r} \boldsymbol{\Phi}^{-1} \eta & -\boldsymbol{\Gamma} r^{-1} \boldsymbol{\Gamma}^{l} \boldsymbol{\Phi}^{-l} \\
-\boldsymbol{\Phi}^{-T} \mathbf{Q} & \boldsymbol{\Phi}^{-l}
\end{array}\right]\left[\begin{array}{l}
\mathbf{x} \\
\boldsymbol{\lambda}
\end{array}\right]_{h}
$$

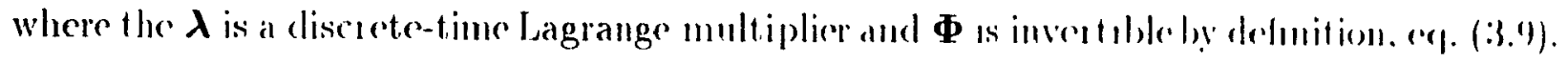

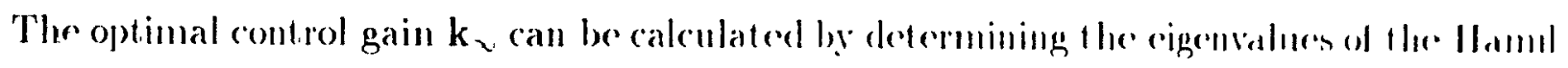
tonian matrix.

\subsection{Combined Optimal Controller and Observer}

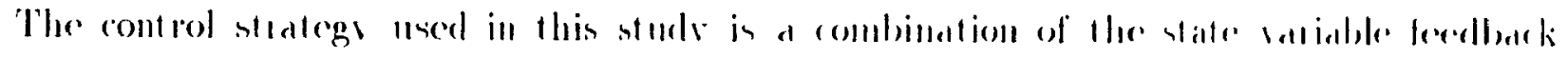

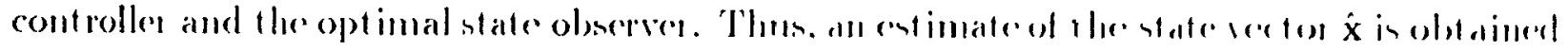


mang the halman hlter. Hamed.

$$
\dot{\mathbf{x}}(k)=[\mathbf{\Phi}-\Gamma \mathbf{k} !-\mathbf{L}, \mathbf{H}] \dot{\mathbf{x}}(k-1)+\mathbf{L}, \mathbf{y}(k-1)
$$

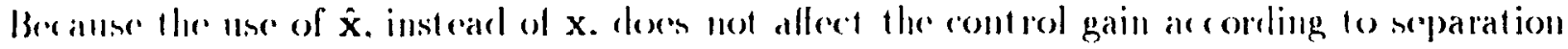

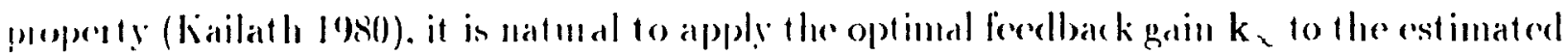
unterever $\hat{\mathbf{x}}$. that is

$$
u(h)=-\mathbf{k} !\left[\hat{\mathbf{x}}(h)-\mathbf{x}_{1}(k)\right]
$$

Therelore. the model of the overall stestem becomes

$$
\mathbf{x}(k+1)=\mathbf{\Phi} \mathbf{x}(k)-\Gamma \mathbf{k}^{T}[\hat{\mathbf{x}}(k)-\mathbf{x},(h)]
$$

wholh is shown in Figure 3.1 in block-diagram lom mo.

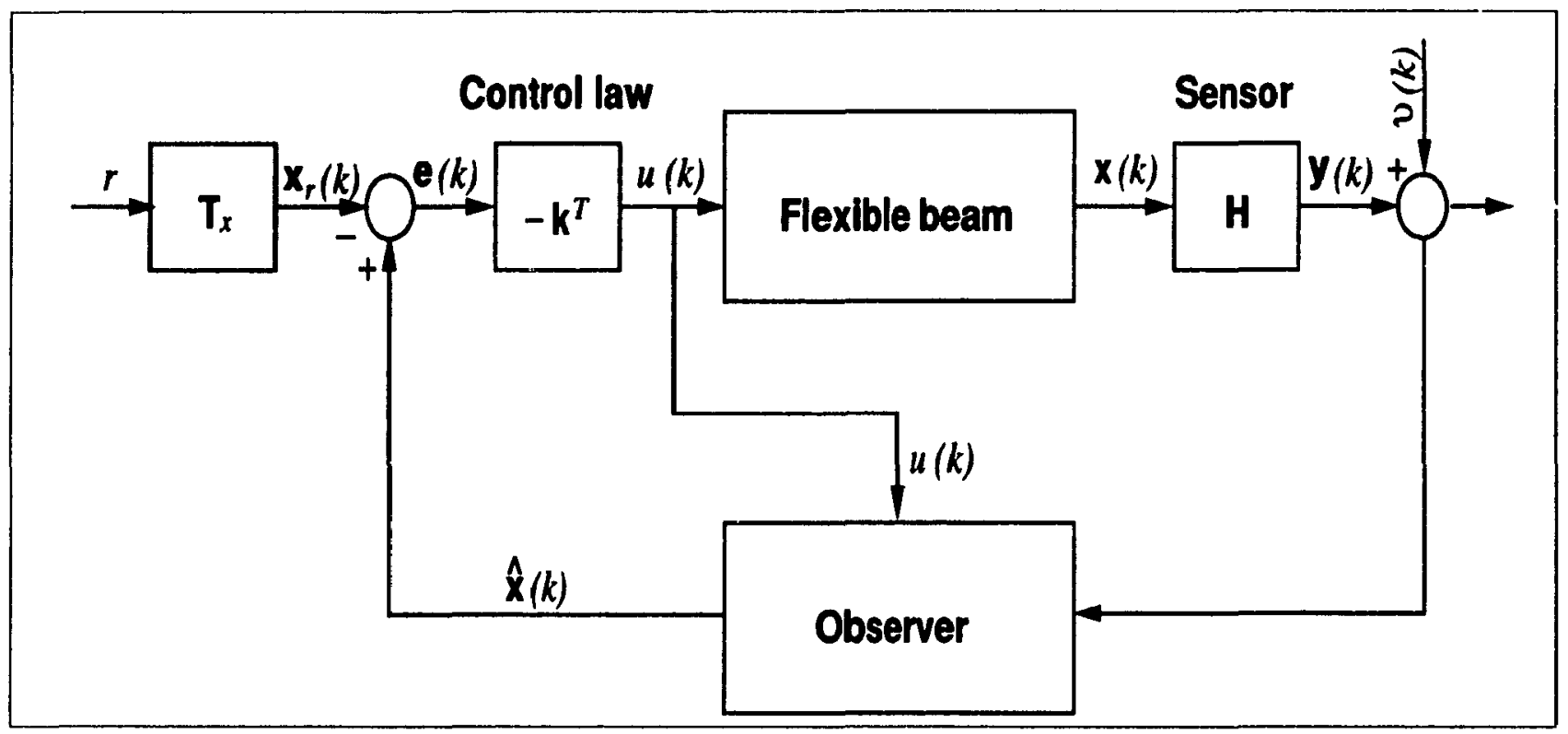

Figure 3.1: ('ombination of observer and controller 


\section{Chapter 4}

\section{Simulation of Flexible Beams Under Large Rigid-Body Motion}

Sonsing considerations are essential to a uncressful teal-time implementation of the puppened control scheme. These considerations include the selection of the simpling rate and the determination of the number and location of sensons (which ate and tually the mumber and location of the nodal points of the approximating (cubic splime).

The cubic-spline technique and opt imal cont rol scheme described in ('hapters 2 and 3 will be applied to the modelling and simulation of the flexible beam. The controller in designed to suppress the transverse vibrations while forcing the end tip to follow the prescrilued tad jee tory. State-observability and controllability problems associated with the redured mumber of measurements are investigated through simulation studies in two cases, i.e., with and willunt tip mass for purposes of comparison. In addition. an investigation is comdurted for demon strate the dynamic effects of link flexibility by applying an optimal terpue input. computerl

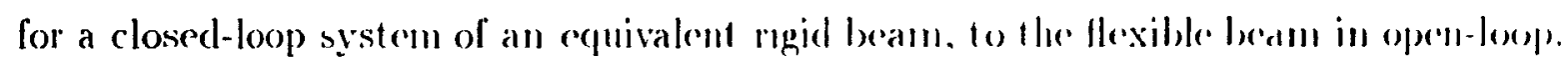




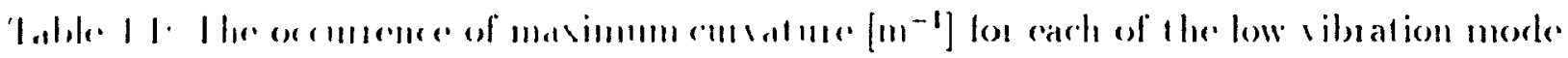

\begin{tabular}{|c|c|c|c|c|c|}
\hline III) & loxat|un in 111 | & Here le mosle & the 2."nes morle & the: $3^{121}$ morle & ther I $^{\text {th }}$ miode \\
\hline 1 & (). 0 & 2.0 & 2.0 & 2.0 & 2.0 \\
\hline 2 & 0.2 .2 & 1.399660 & $-0.02 \leqslant(6.1)$ & -0.963375 & -1.32262 \\
\hline 3 & 0.30 & 1.1817 .5 & $-(1) .6 .3110$ & -1.31485 & $-0.79 \cdot 178$ \\
\hline 4 & 0.50 & 0.6790 .5 & $-1.1: 27: 3: 3$ & $0.0: 39: 37$ & 1.41424 \\
\hline 5 & 10.52 & $0.6: 3: 3: 21$ & -1.43920 & $0.2610: 3$ & $1.378: 36$ \\
\hline 6 & 0.72 & $0.210: 30$ & $-(0.966 .27$ & 1.51056 & -1.10616 \\
\hline 7 & 0.80 & 0.1277 .1 & $-0.6(0) 211$ & 1.20901 & -1.50758 \\
\hline
\end{tabular}

\subsection{Number and Location of Sensors}

Normalh. the accuracy of the approxmation of the spatial discretization of the continuous beam imploves with an increase in the number of nodal points: however, a large number of modal points can produces a latges system of equations. thereby making the on-line cont rol Imfeasible Thus. the propes selection of the number of sensors is a compromise between the accurac! of the approximation and the feasibility of on-line implementation. Furthermore. the positioning of the sensons can strongly affect the dynamic performance of the system and must be considened in both the plant-morlellng and design of the cont rol system. Guidelines for the mimmum number of sensors required for salisfactory performance have stated that the mumber must be at least as latge as the mumber of monitored vibration modes (Barsh and ('hoe 19s!)). Which is in lact the number of generalized coordinates in the system represented (1. (․:B:3).

Iloweven, a different approach for choosing the mumber and location of sensors is taken. Fitst. it is to be moted that the th viblational morle has , points at which the bending monent raches a maximum. In addition, simulation results. some of which are presented later in this thesis, hate shown that locating a sensor at the position of maximum bending moment provides the most acemate estimation. This is because this location yields the highest signal 


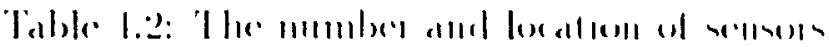

\begin{tabular}{|c|c|c|}
\hline 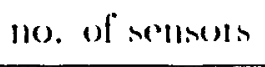 & locillion in m & m.1 \\
\hline 1 & 00 & 2.0 \\
\hline 2 & 0.2 .2 & $-13: 26: 2$ \\
\hline 3 & 1). 301 & -1 31 \\
\hline 1 & 1) 诖 & $-1.1: 34 \geq 11$ \\
\hline 5 & 0.7 .2 & 151176 \\
\hline 6 & 0.50 & 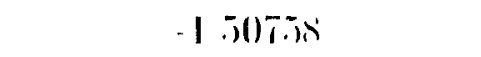 \\
\hline
\end{tabular}

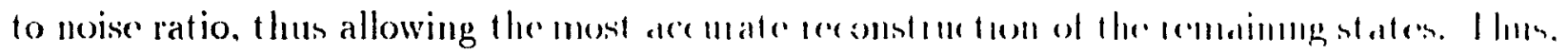

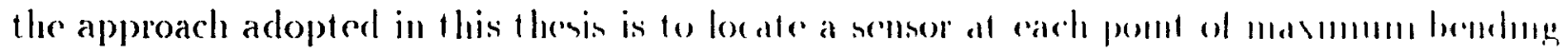

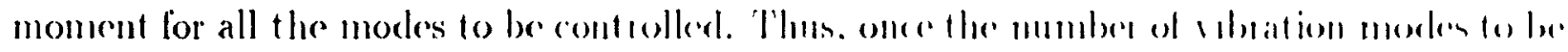

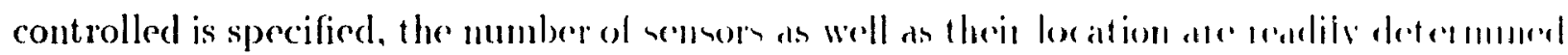

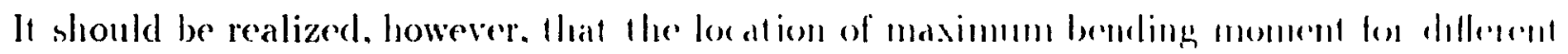

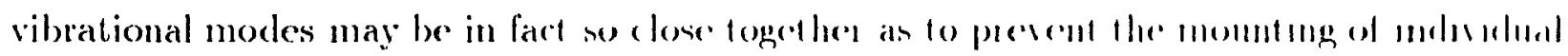

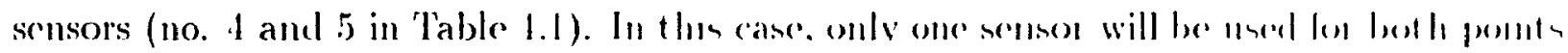

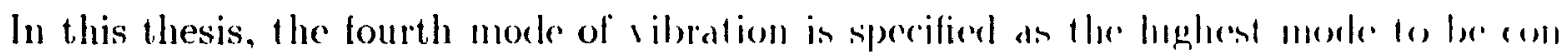

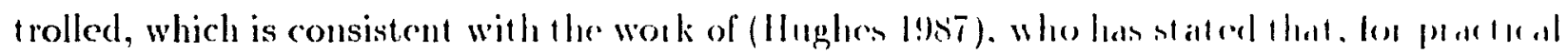

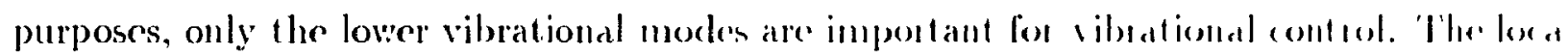

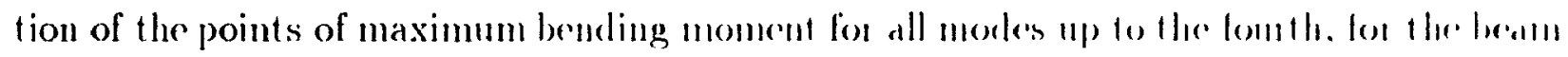

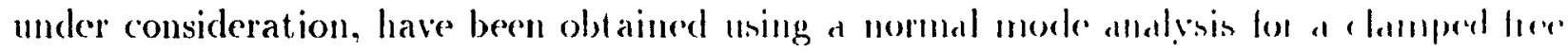

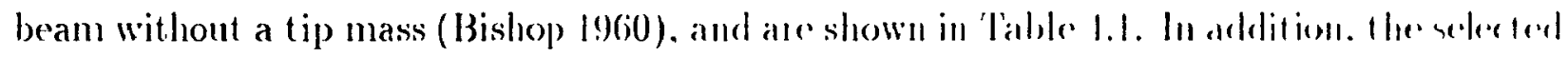
number and location of the sensoms are shown in Thble l.2. It is impentant to realize that

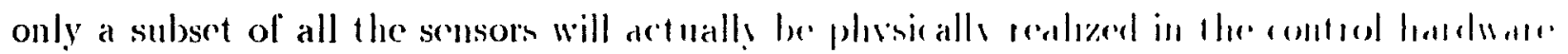

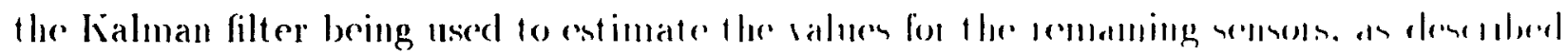
in grater detail in Section 1.:3. 


\subsection{Selection of the Sampling Rate}

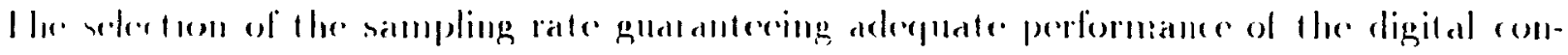

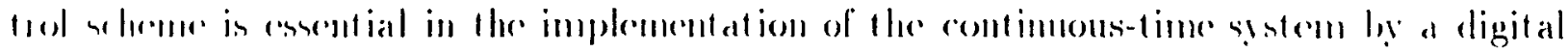
computer. A stowes sampling ate leats to a less of control infomation associated with

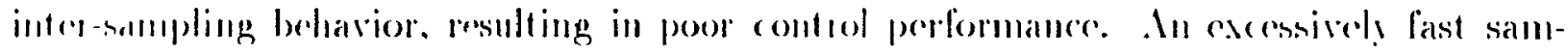

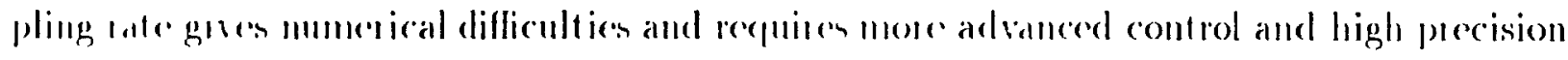
compuldtomal houdware. Ilener. the tradeofls must be canchully examined. Bloreover, high

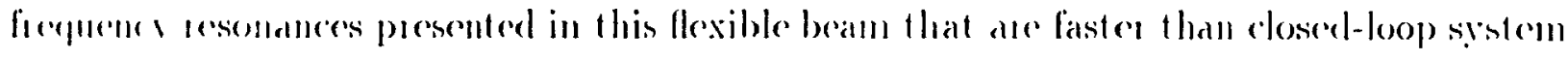
bandwelth must be considered for the selection of appropriate sampling rate.

The llatural or resonance frequencies of the open-loop sytem model are found by using the equations of motion given in (hapter 2. The equation of motion obtainerl from the Finkelaglange formulation was given as

$$
\mathbf{M} \ddot{\mathbf{q}}+\mathbf{K q}=\varphi(l)
$$

where

$$
\begin{gathered}
\mathbf{M}=\left[\begin{array}{cc}
\mathbf{M}^{\prime \prime} & \gamma \\
\gamma^{T} & l_{t}
\end{array}\right] . \mathbf{K}=\left[\begin{array}{cc}
\mathbf{K}^{\prime \prime} & \mathbf{0}_{n \times 1} \\
\mathbf{0}_{1 \times n} & 0
\end{array}\right] \\
\varphi(\ell)=\left[\begin{array}{ll}
\mathbf{0}^{T} & \tau(l)
\end{array}\right]^{T} .
\end{gathered}
$$

while $\tau(1)$ is the applied torque and 0 is the $(n-1)$-dimensional zero vector. Morrover, the matrices $\mathbf{M}^{\prime \prime}$ and $\mathrm{K}^{\prime \prime}$. the vector $\gamma$, and the scalar $I_{t}$ specific to this example are given as

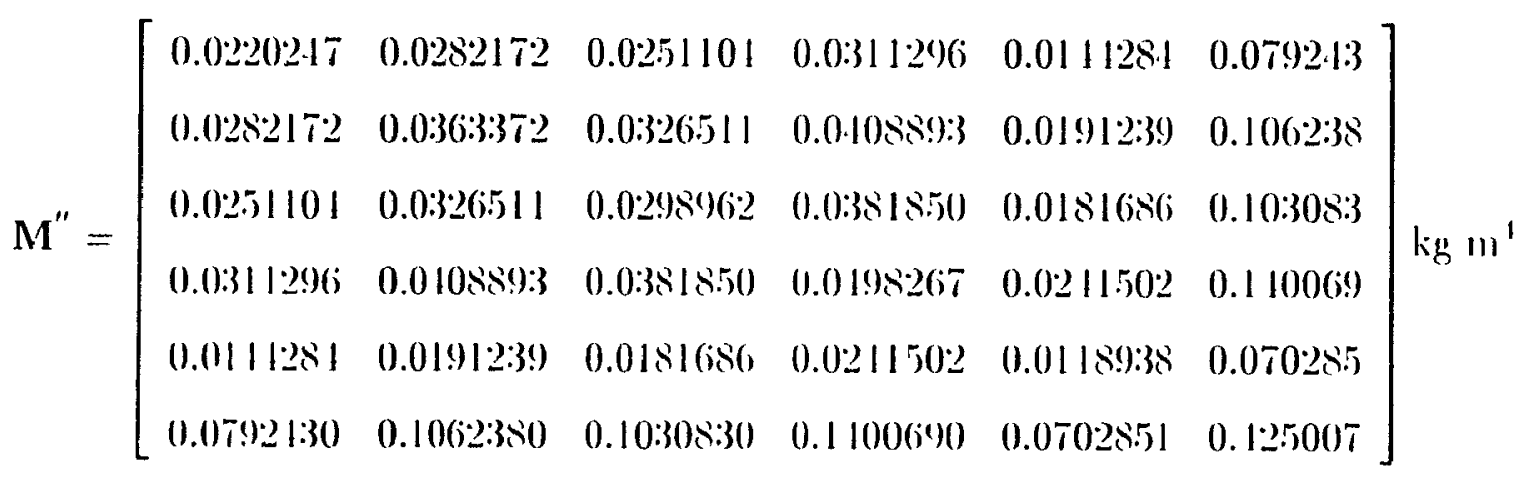




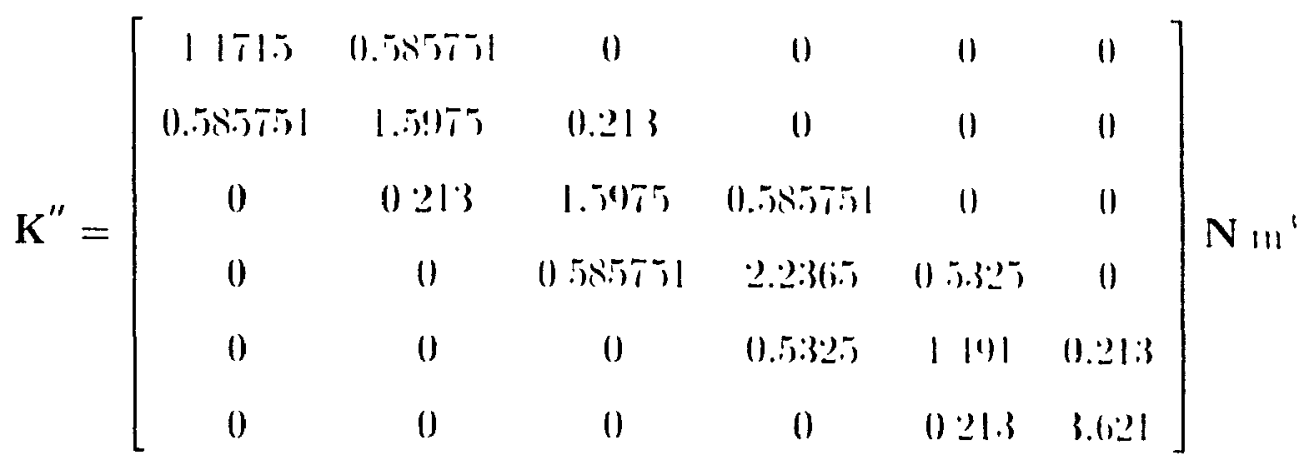

$$
\begin{aligned}
& \gamma=\left[\begin{array}{l}
0.2091 .20) \\
0.26(609) ! \\
0.23(60552 \\
0.2906021 \\
0.1333861 \\
0.729920
\end{array}\right] \mathrm{kg} \mathrm{m} \mathrm{m}^{3} \\
& I_{t}=1.991 .35 \mathrm{~kg} \mathrm{~m}^{2} .
\end{aligned}
$$

The calculated resonance frequencies of the open-loop) system with and whthoul a tup

\begin{tabular}{|c|c|c|c|c|c|c|}
\hline Mode Number & the lst & ther $2^{n+1}$ & the $: 3^{\prime \prime \prime}$ & l.he $1^{\prime \prime \prime}$ & $1 / 10.5^{t h}$ & $\ln 16^{11}$ \\
\hline Frequency with mass $(\mathrm{Hz})$ & $0.7: 309$ & $11.78: 31$ & 10.9813 & $8(0.59)(61$ & $1: 38.1216$ & $2(05 ! 919)$ \\
\hline Frequency without mass $\left(\mathrm{H}_{z}\right)$ & 9.1581 & 20.94 .3 .5 & 18.2876 & $8 T .12 \cdot 2 \cdot 2$ & 150.1857 & נ: \\
\hline
\end{tabular}
mass de given in Table 1.3 .

Table 1.3: The calculated matumal viluation liegunencies

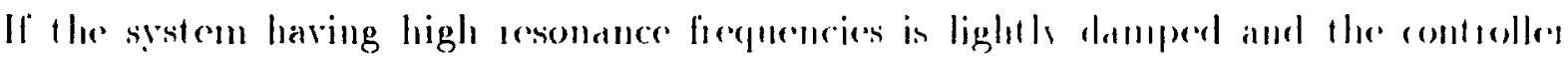
introduces adelitional damping to those morken wheh are faster than the bandwidth of the

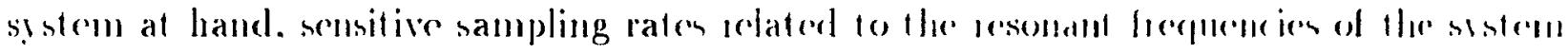

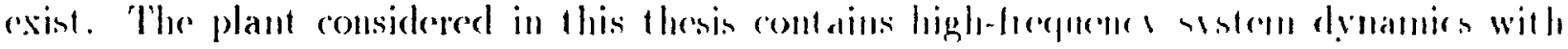




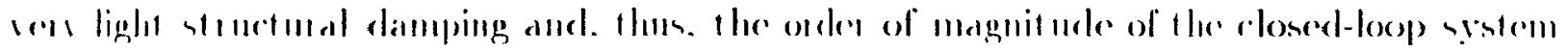

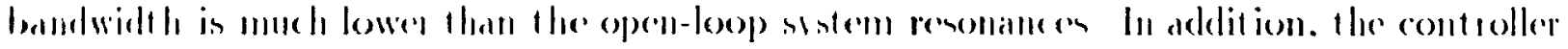

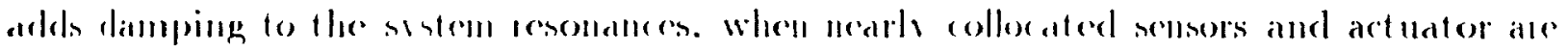

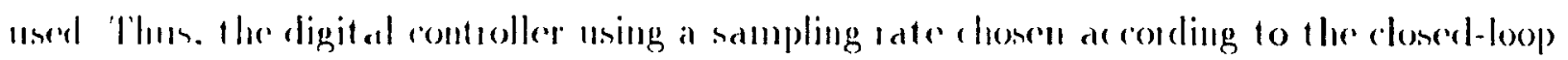

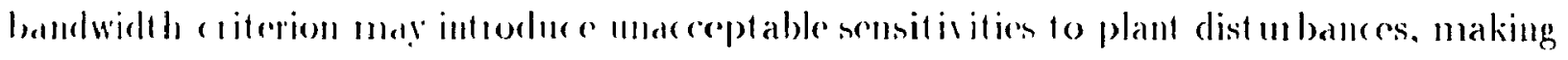

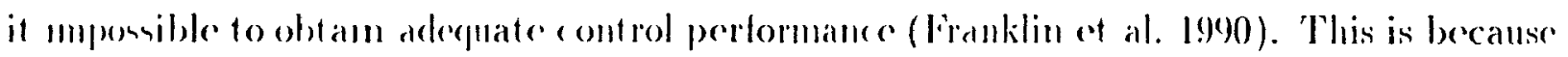
if the sampling rate sedected arcolding to the clened-loop bandwidth of the system is less than twice an important open loop system sesonance. the contiolled system mav be more

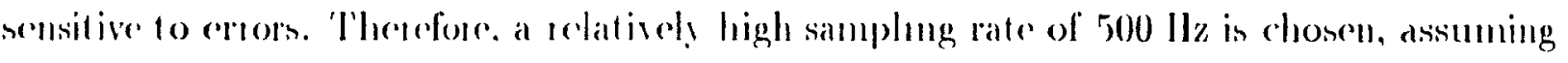
that the highest open-loop system resonance to be cont rolled is the lourth nat ural vibration modr.

\subsection{Observability Considerations}

It is often not pedetical to assume that the entire state vecton is available throngh measureIments. In this thesis. an investigation is conducted to assess the possibility of a reduced number of medsurements tahen at a solected mumber of nodal points. The Kalman filter is used to optimally estimate the curvature at the other pounts as well as its time rate of change. Whether we will he able to use patial measurenents depends upon the state-observability and contudlability of the system In princeple. one mal prove state-obsen vability and contwollabilıt by showing that the associated obser ability and cont ollability mat rices are cach of full iank. The obsenability and controllabilit has aheady been studied by Balas (1978) and Huges and Shelton (1980). It has also bern shown that a system having only one senson makes the sistem both state-contiollable and observable. However. the mumerical ill-conditioning of the associated controlbablity and obsenability matrices an prevent the kinhmon filter from reconstucting the state estimates to a reasondble acculace especiall! when there is a tip mass, making the ststem unobservable for practical purposes.

It in denimable to ansess the mumerical viability of the state estimation using a reduced mumber of meanmements. In adelition. it is also bencheid to imvestigate the effectiveness of 


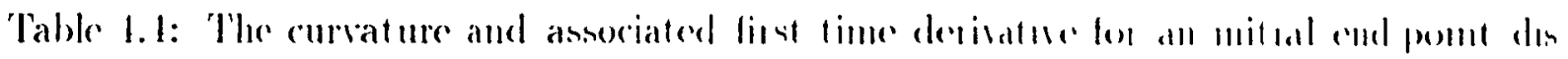
placement of the beam

\begin{tabular}{c|c|c|c}
\hline nodal point & $r[\mathrm{~m}]$ & $u^{\prime \prime}\left[\mathrm{m}^{-1}\right]$ & $i^{\prime \prime}\left[\mathrm{m}^{-1} \mathrm{~s}^{-1}\right]$ \\
\hline 1 & 0.0 & 2.0 & 0 \\
2 & 0.2 .2 & $1.396(96)$ & 0 \\
3 & 0.30 & 1.18175 & 0 \\
1 & 0.52 & 0.659005 & 0 \\
5 & 0.72 & 0.21030 & 0 \\
6 & 0.80 & 0.12571 & 0 \\
\hline
\end{tabular}

locating the sensors at the points of maximum bending moment.

This shall be done by analyzing the response of the beam to an inilial end-point dis

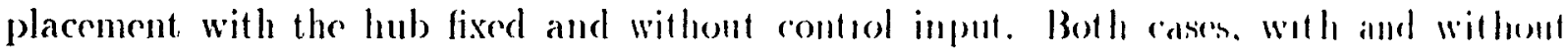
tip mass, shall be analyzed. The initial comditions are listed in 'Table 1.1. The lowslts of

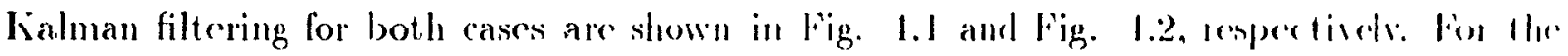
no mass on the tip case with two measurements, i.e., the curvature at the root of the lenem

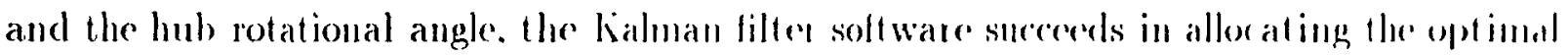

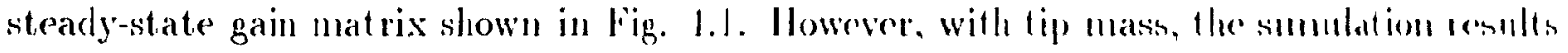

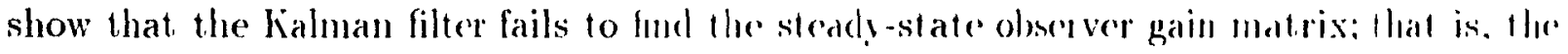
system. although mathematically obsemable. is not olservable in a practical nense due to roundoff ertors. Nevertheless. state estimation of the flexible beam with tip mass a all be

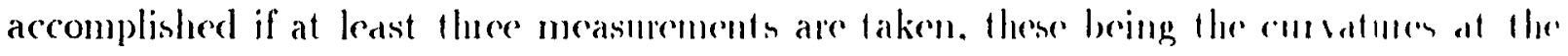
the first and second nodal points. as well as the hub rotational angle. Fig. I.2 showe the

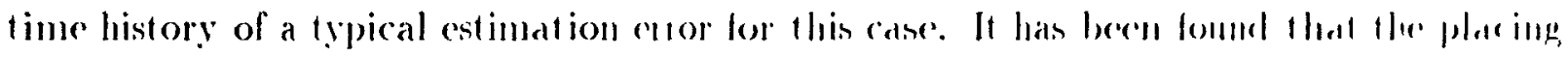

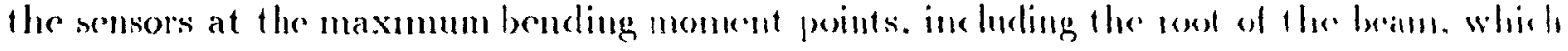

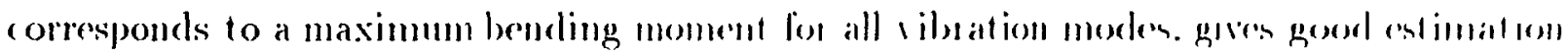
results. 

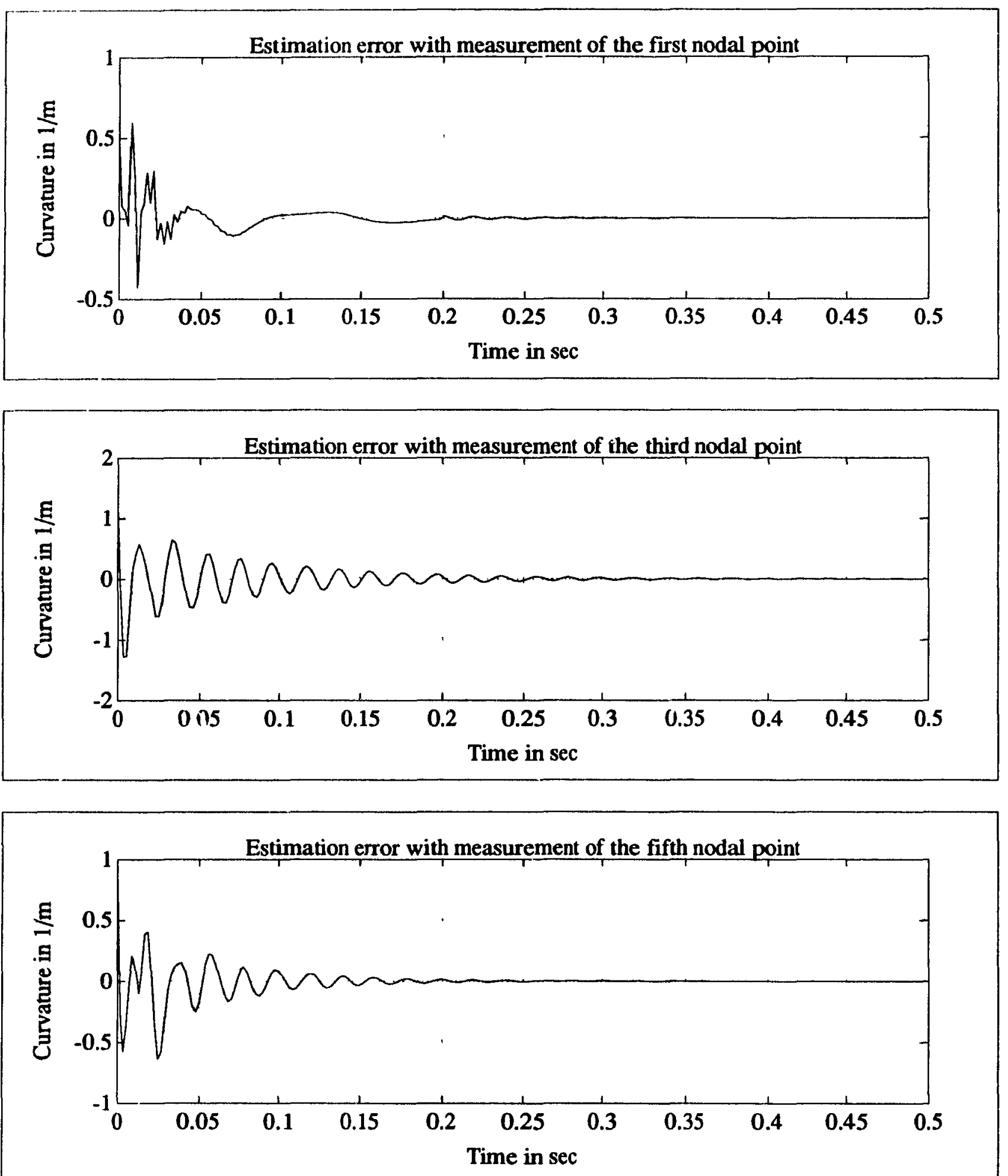

Fingure 1.1: listimation ertor of the state variables at the first nodal point withont tip matss 

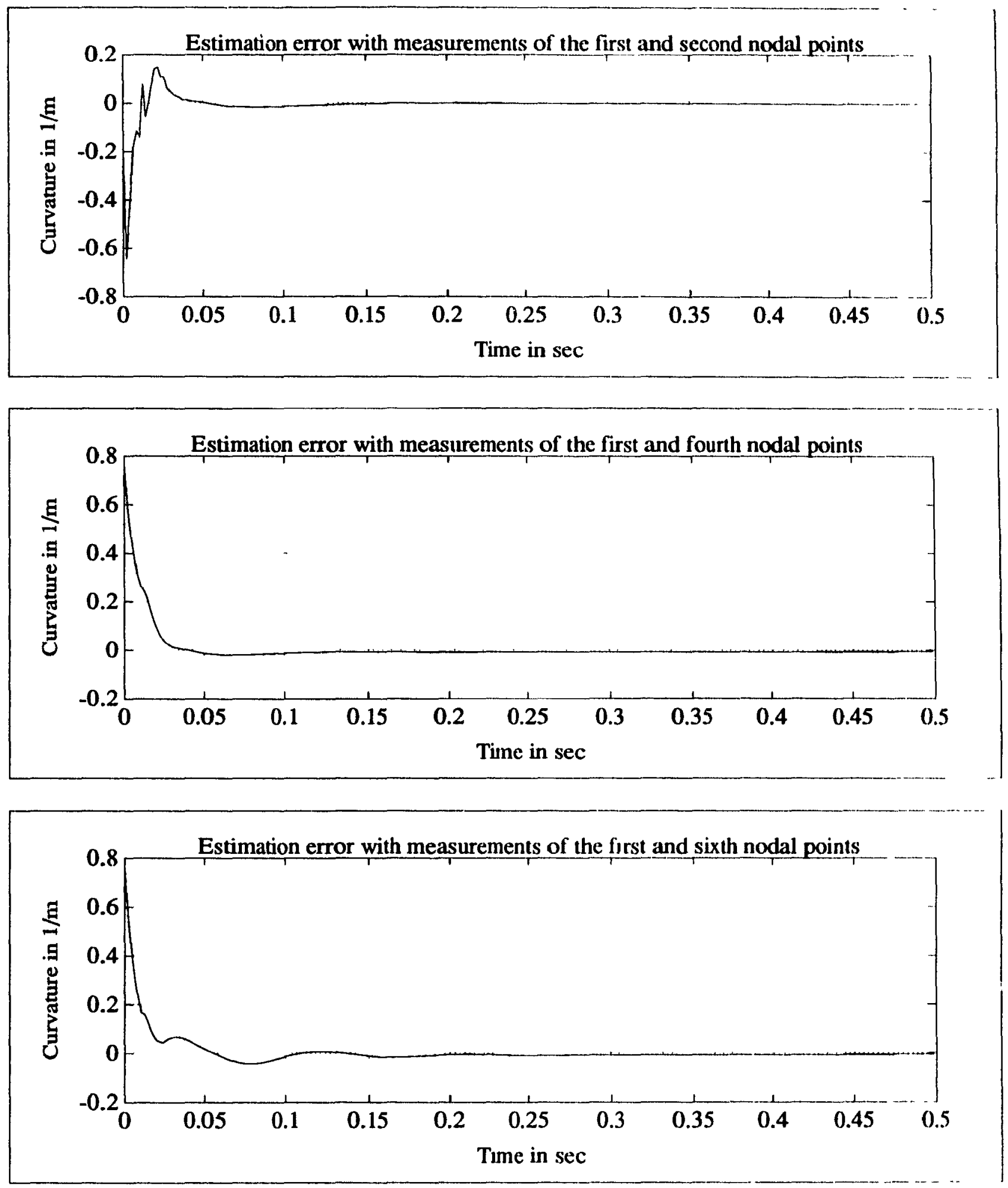

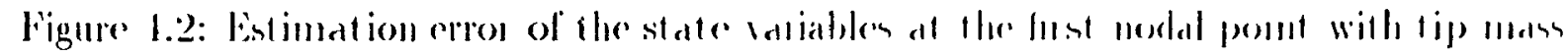




\subsection{Uncontrolled Vibrating Beam}

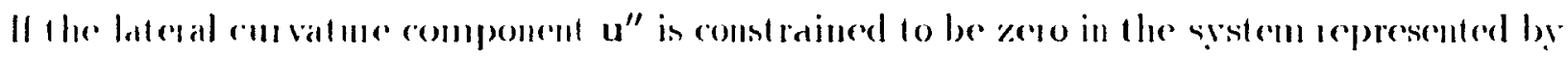

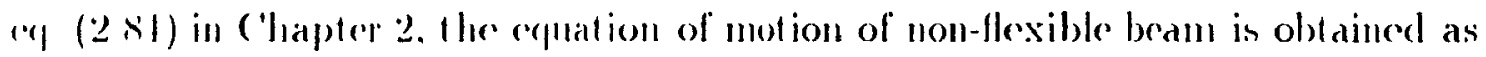

$$
l, \ddot{\theta}=\tau(l)
$$

'This can be described as a contumons-time, linear, constant-coeflicient șystem in stateVilliablo sparce. Hambly,

$$
\begin{aligned}
& \dot{\mathbf{z}}(l)=\mathbf{A}, \mathbf{z}(l)+\mathbf{b}, u(t), \mathbf{z}(0)=\mathbf{z}_{0} \\
& \mathbf{y}(t)=\mathbf{c}^{T} \mathbf{z}(l)
\end{aligned}
$$

where

$$
\begin{aligned}
& \mathbf{A}_{1}=\left[\begin{array}{ll}
0 & 1 \\
0 & 0
\end{array}\right] \in \Re^{(2 \times 2)} \\
& \mathbf{b}_{1}=\left[\begin{array}{c}
0 \\
1 / I_{t}
\end{array}\right] \in \Re^{2}, \mathbf{c}^{T} \in \Re^{2} .
\end{aligned}
$$

'The state vector and scalar inpul are also defined as

$$
\mathrm{z}=\left[\begin{array}{l}
0 \\
j
\end{array}\right], \quad u(t)=\tau(1)
$$

In order to find the computed torque input of this non-flexible beam, the associated stepinvariant. discrete-time model is used. The computed torque of the non-flexible bean for a step input of hub cotational angle is readily obtained by employing the Kalman filter and is applied to the open-foop system of the flexible beam. This is performed for both cases with and wilhout a tip mass. 'The computed tomques and their time responses of the non-flexible ststem ane shown in ligs. 1.3 and 1.5. The time esponses of the flexible bedm obtained by" applying the same computed tomgue inputs of the non-flexible beams are also shown in Figs. I.I and 1.ti. These show that large oscillations in the gesponses of the hub rotational angle and mode displanenuents are attributed to the meglented link flexibility. 


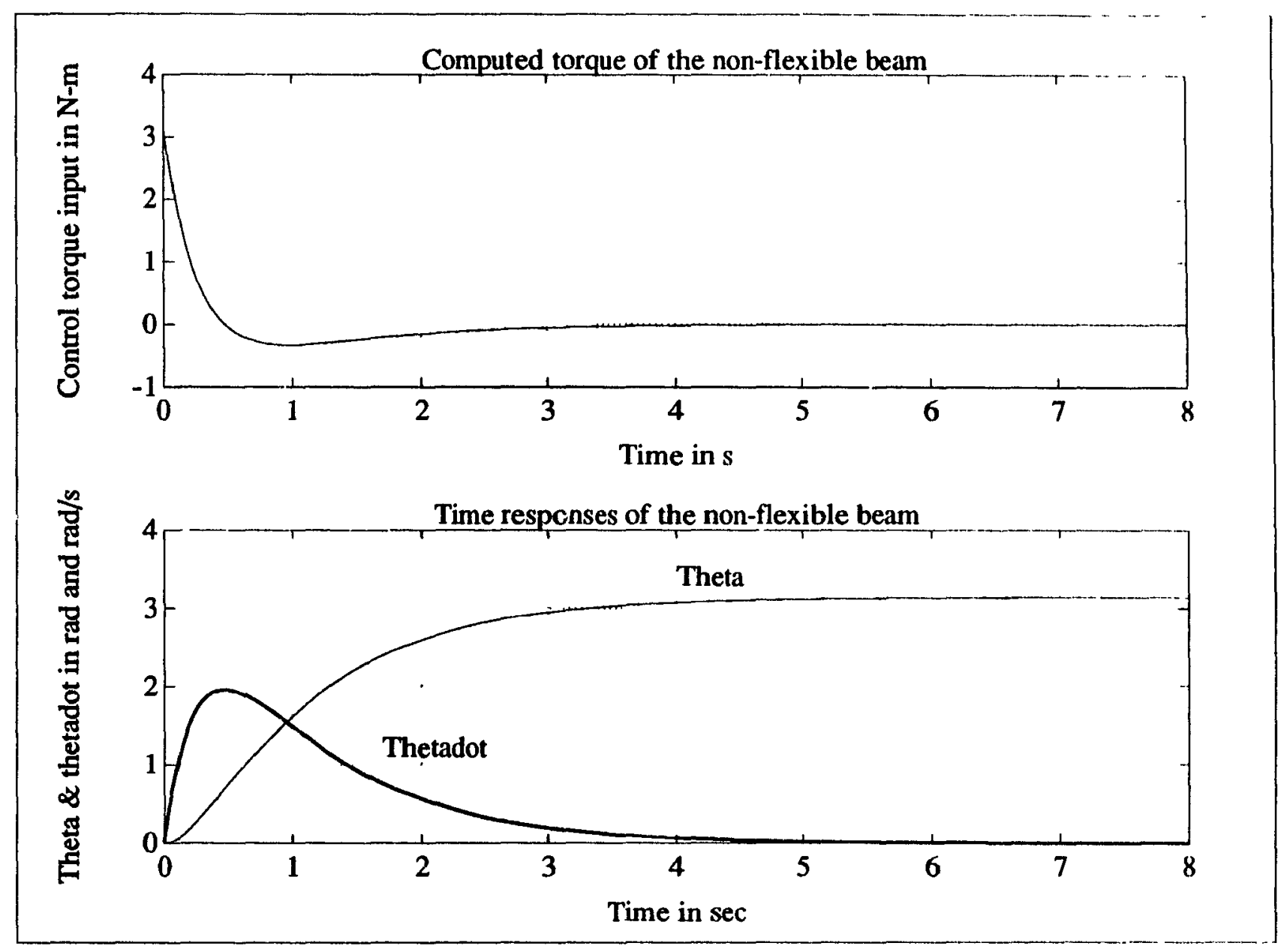

Figure 4.3: Optimal torque input and time responses of the non-flevalbe beam withoul tip mass 


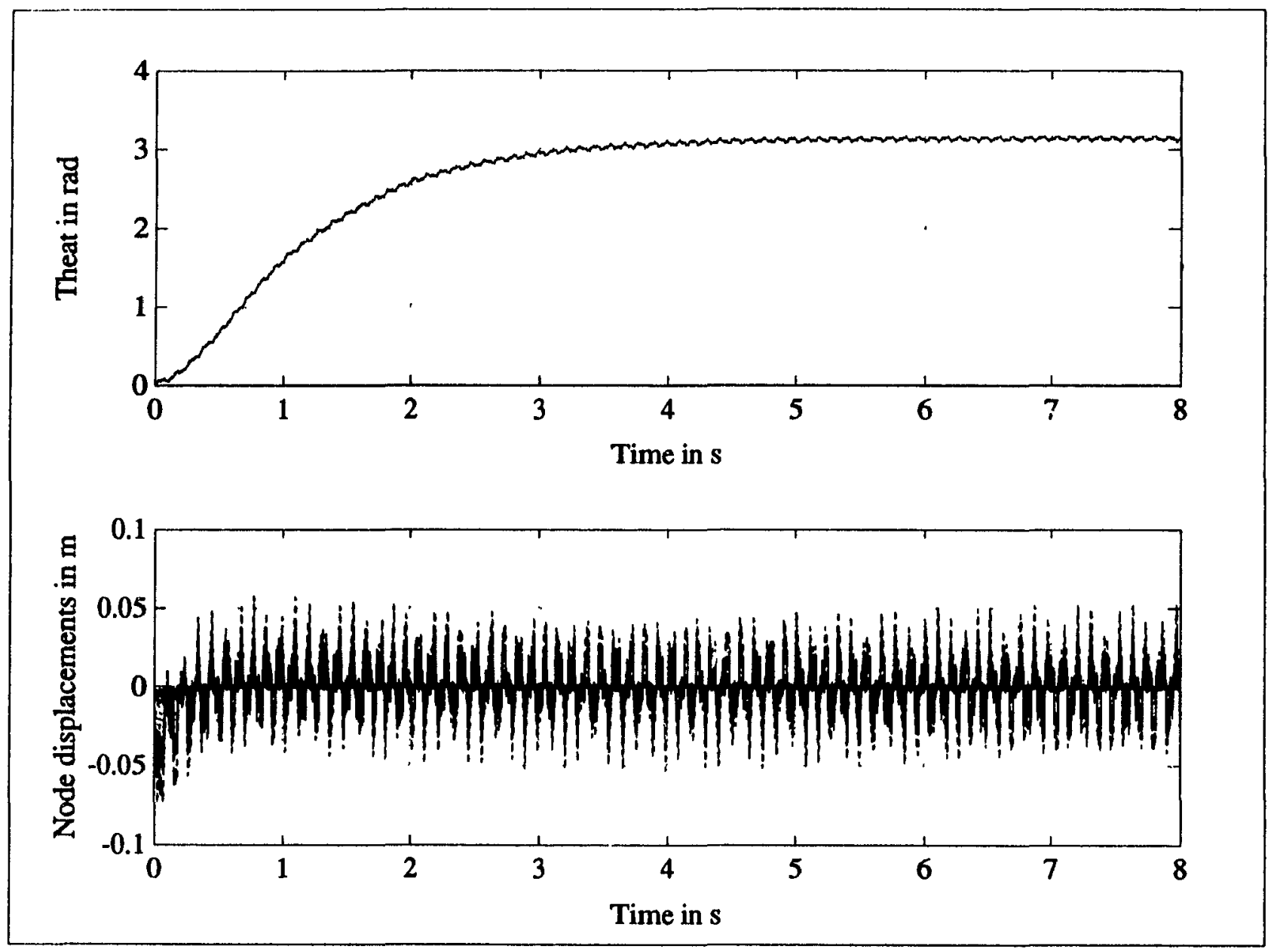

Figure 1.1: T'ime responses of the flexible beam for an optimal torque input of the rigid boam without tip mass 

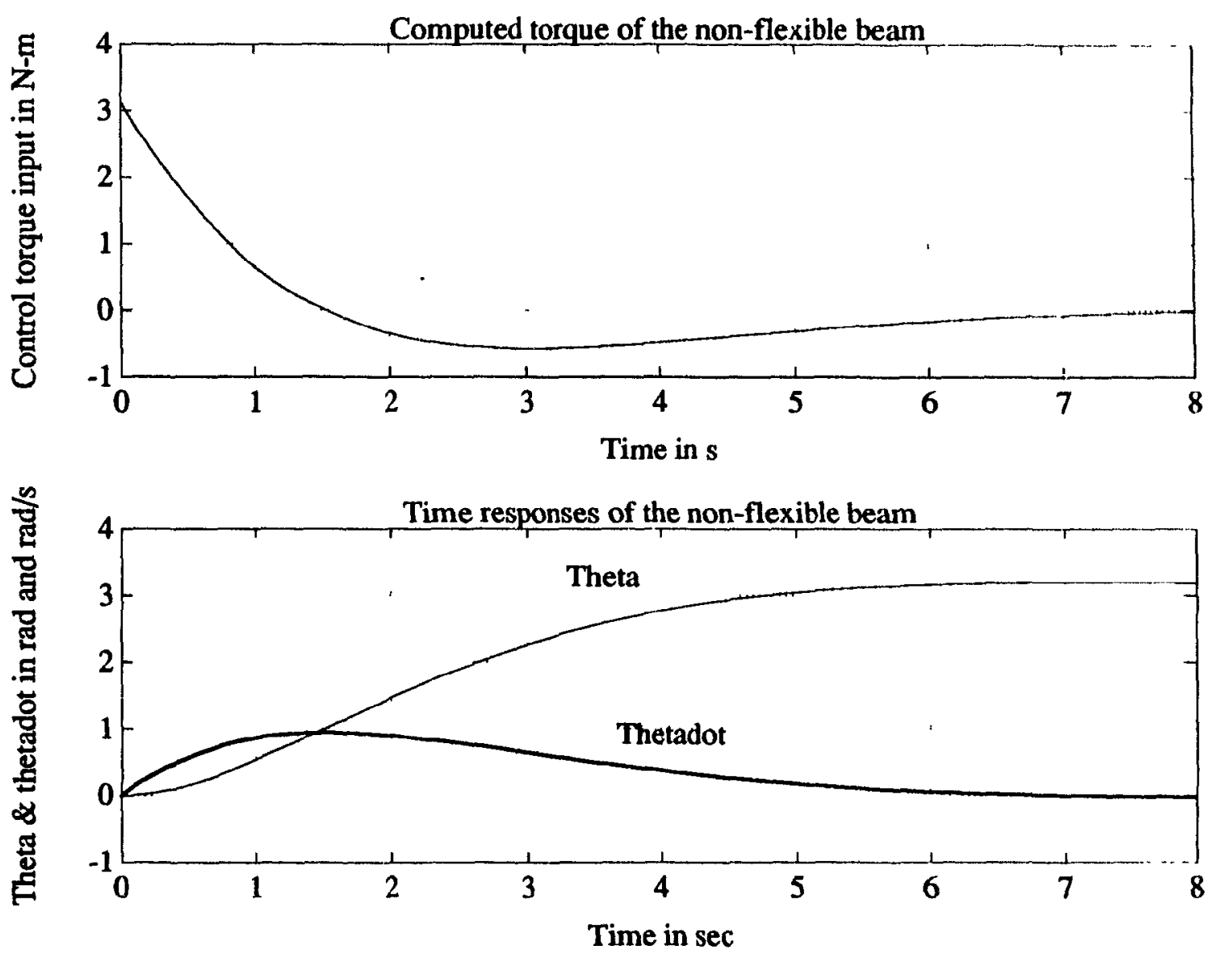

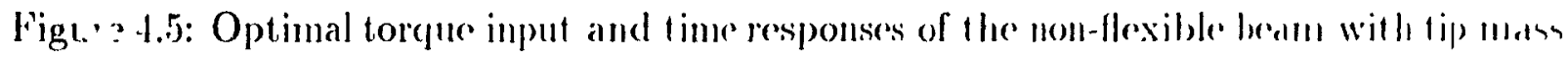




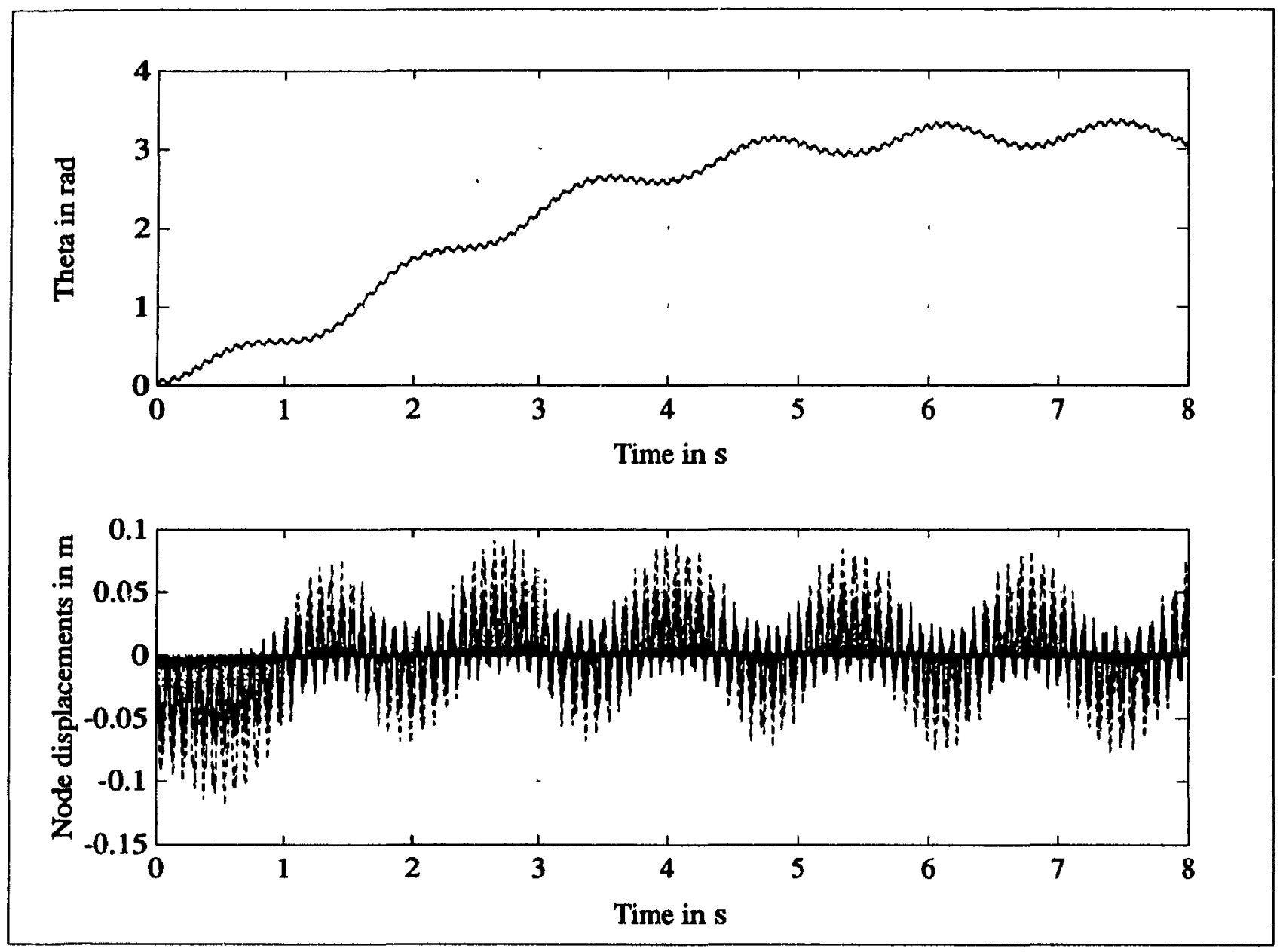

Figner 1.6: 'lime responses of the flexible beam for an optimal torque input of the rigid borm with tip mass 
Table 4.5: The material specification of the beam

\begin{tabular}{|c||c|}
\hline Number of nodal points $(n)$ & 7 \\
Material & Aluminum \\
Mass density $\left[\mathrm{kg} / \mathrm{m}^{3}\right]$ & 2712 \\
Young's modulus [GPa] & 71.0 \\
Moment of inertia of the hub $\left[\mathrm{kg}-\mathrm{m}^{2}\right]$ & 0.000831 \\
Moment of inertia of the tip mass $\left[\mathrm{kg}-\mathrm{m}^{2}\right]$ & 0.90571986 \\
Section moment of inertia of the beam $\left[\mathrm{m}^{4}\right]$ & $2.25 \times 10^{-10}$ \\
Moment of inertia of unflexed rigid beam $\left[\mathrm{kg}^{2}-\mathrm{m}^{2}\right]$ & 0.2712 \\
\hline
\end{tabular}

\subsection{Compensator Simulation}

A simulation study was performed for the rotating flexible beam shown in lig. 4.7 and described in Table 4.5, which exhibits high-frequency vibrations. A relatively high sam pling rate of $500 \mathrm{~Hz}$ was chosen, based on the highest natural frequency of the boum to be controlled, for both control and measurement loops.

The initial conditions used were

$$
\begin{aligned}
& \mathbf{q}(0)=0 \\
& \dot{\mathbf{q}}(0)=0
\end{aligned}
$$

where $\mathbf{0}$ is the $n$-dimensional vector. Moreover, performing the calculations results in the 


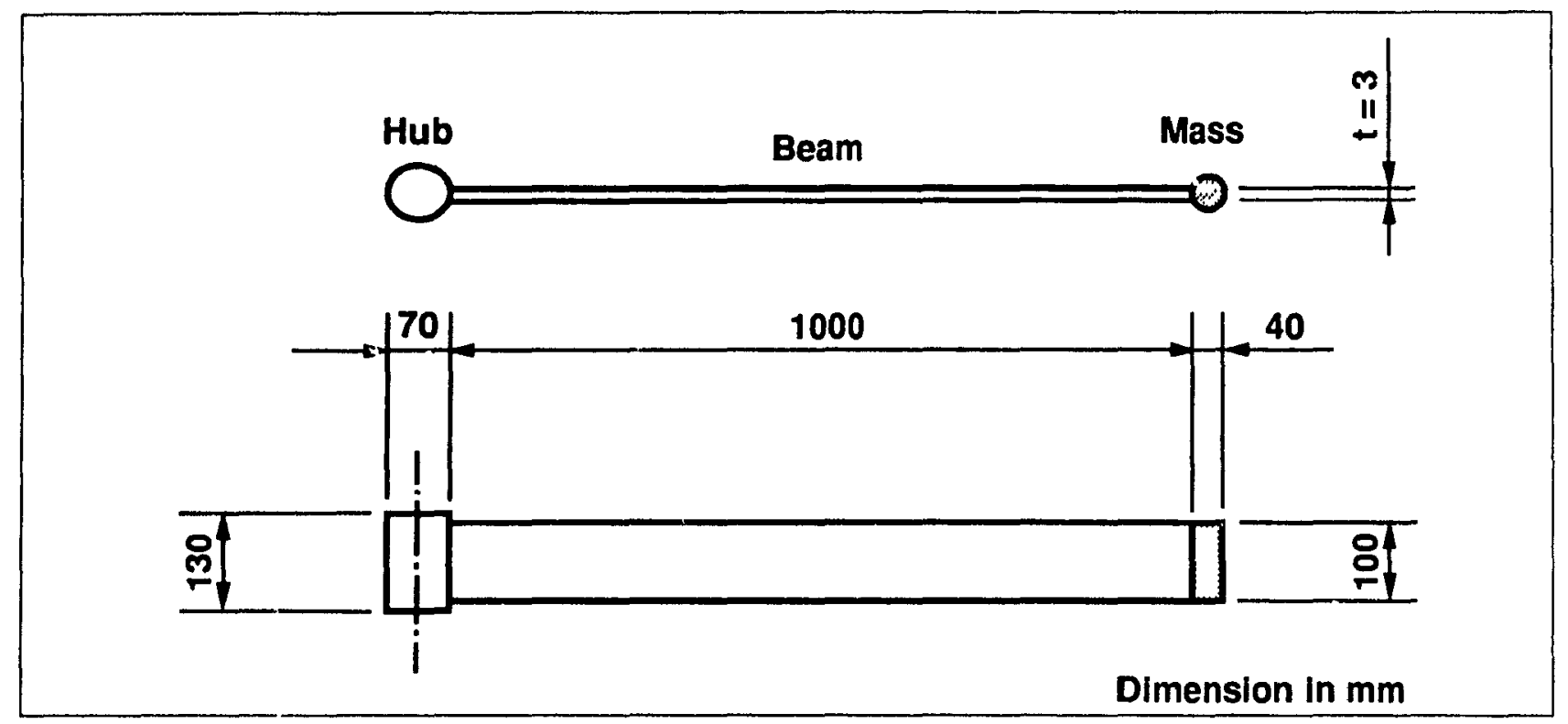

Figure 4.7: Beam used in simulation

stcady-state, discrete-time, Kalman filter gain matrix $\mathbf{L}_{\infty}$ and controller gain vector $\mathbf{k}_{\infty}$

$$
\mathbf{L}_{\infty}=\left[\begin{array}{rrr}
0.0095 & 0.0006 & -0.0037 \\
0.0338 & 0.0010 & -0.0135 \\
-0.0069 & 0.0015 & -0.0137 \\
0.0033 & 0.0007 & -0.0087 \\
-0.0084 & 0.0003 & -0.0022 \\
-0.0017 & 0.0009 & 09045 \\
-0.0037 & -0.0002 & 0.0716 \\
-35.6900 & 0.3392 & 1.0485 \\
21.3990 & -0.4260 & -0.4360 \\
-7.7234 & 0.2005 & -0.3134 \\
0.4238 & -0.0199 & -0.4091 \\
3.6538 & -0.0043 & -0.2632 \\
-0.3160 & -0.0000 & -0.0083 \\
1.6028 & 0.0011 & 0.0800
\end{array}\right]
$$




$$
k^{\prime}=\left[\begin{array}{r}
17.1077 \\
-1.20758 \\
1.3 .5336 .3 \\
-1.96859 \\
1.533: 37 \\
0.8517 \\
0.0176 \\
-0.00633 \\
0.0025 \\
0.0017 \\
-0.0053 \\
-0.0001 \\
-0.0018 \\
0.0306
\end{array}\right]
$$

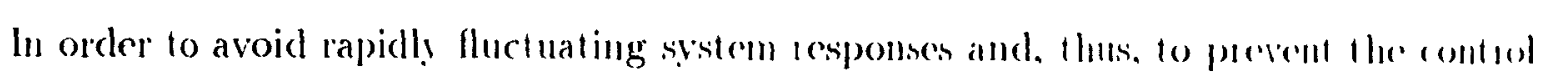
signal from exceeding its physical limits, a smoothed step impul using a cycloidal motion (Fig. 4.8) was employed to generate reference inputs for the hub rotational angle. 0 , . and its angular velocity, $\dot{\theta}_{r}$, namoly.

$$
\begin{aligned}
& \theta_{1}=\theta_{0}\left(\tau-\frac{1}{2 \pi} \sin (2 \pi \tau)\right), \\
& \dot{0}_{1}=\theta_{0}(1-\cos (2 \pi \tau)), 0 \leq \tau \leq 1
\end{aligned}
$$

where $\theta_{0}$ is the amplitude of the hub rotational angle. (onsidenation of the tume tat:" wh change for the given input offered the advantage of eliminating the smatl strodle-state flut tuations of the response, at the expense of a slightly longer setfling time.

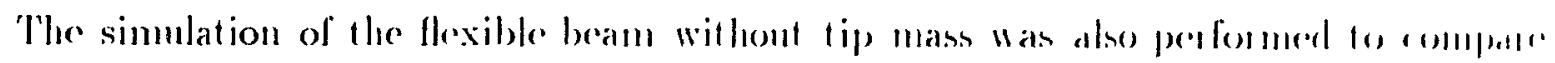
the results with those of the heam with tip mass (Fig. 1.9) and (Fig. 1.10) luth will

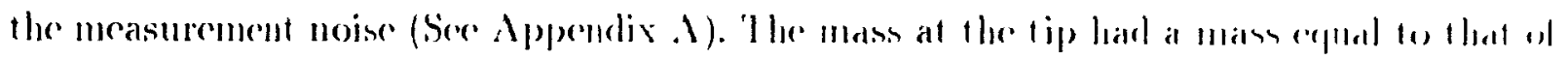

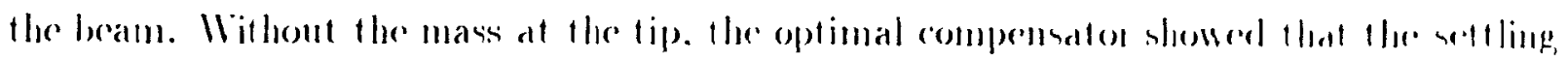

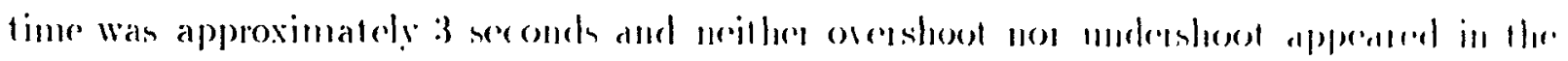




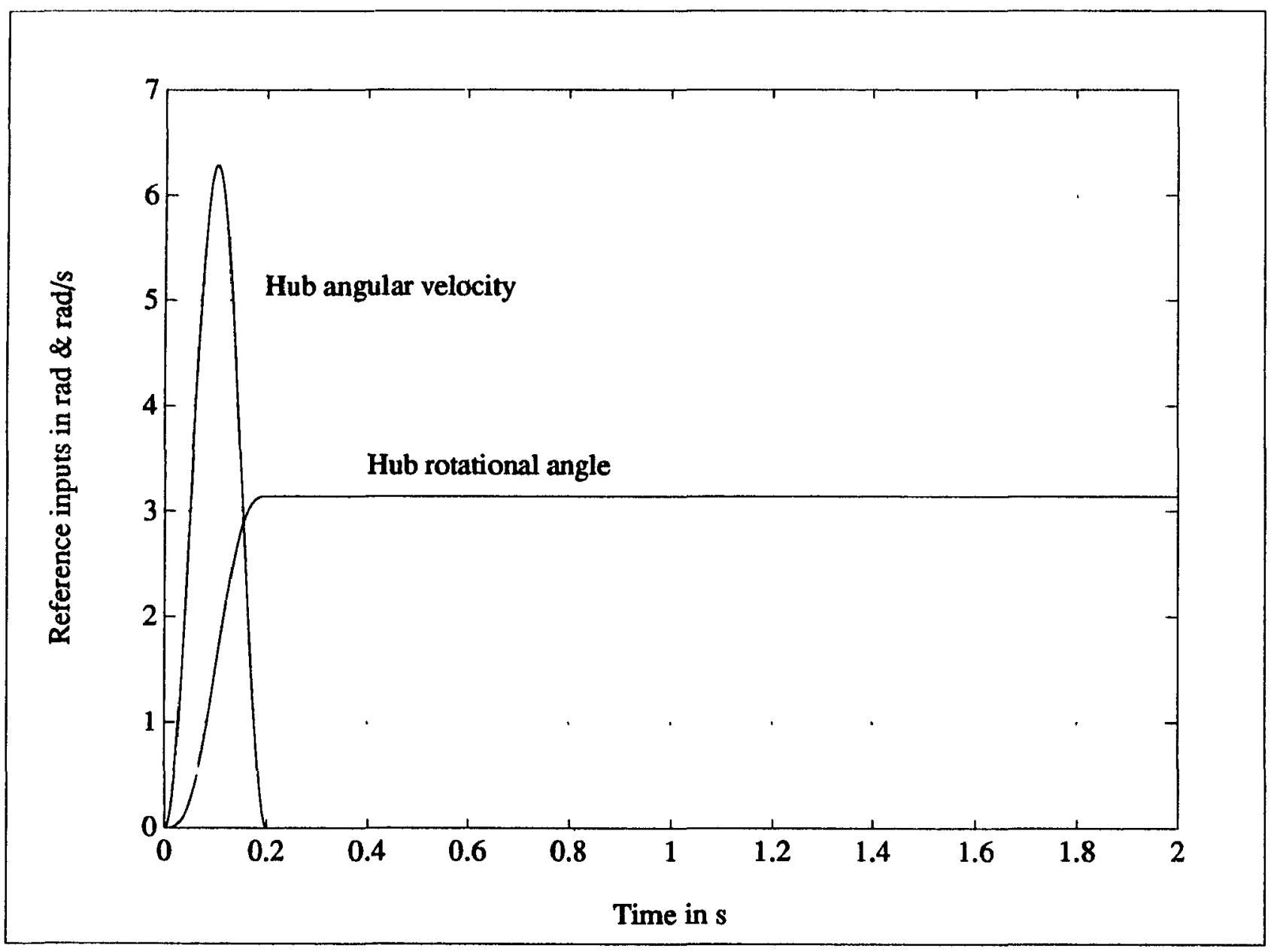

Figure I.S: Smoothed step input using cycloidal motion 


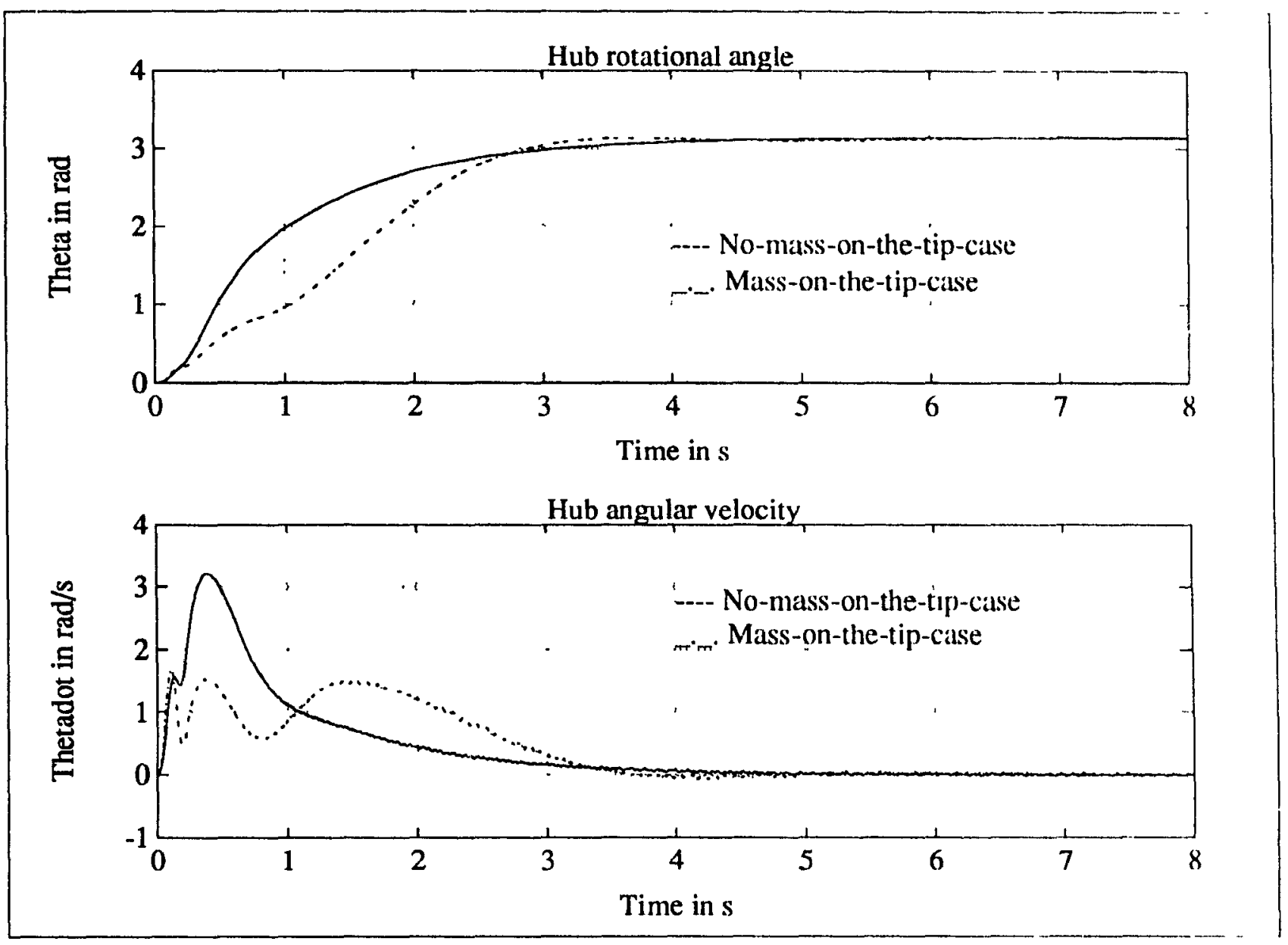

Figure 4.9: Hub rotational angle and its first time rate of optimally conliolled rotating flexible beam

response of both the hub rotational angle and the hub angular velocity (Fig. 4.9). With 1.he mass at the tip, comparatively small overshoot and undershoot with steady-state fluctuations occurred for the displacements at each nodal point (Figs. 4.9) and 4.10). However, it toos longer for the response to settle due to the incrtia of the tip mass, this bang approximatcely 5 seconds. The comparison of control torque inputs for both cases is also shown in ligg. 411 . 


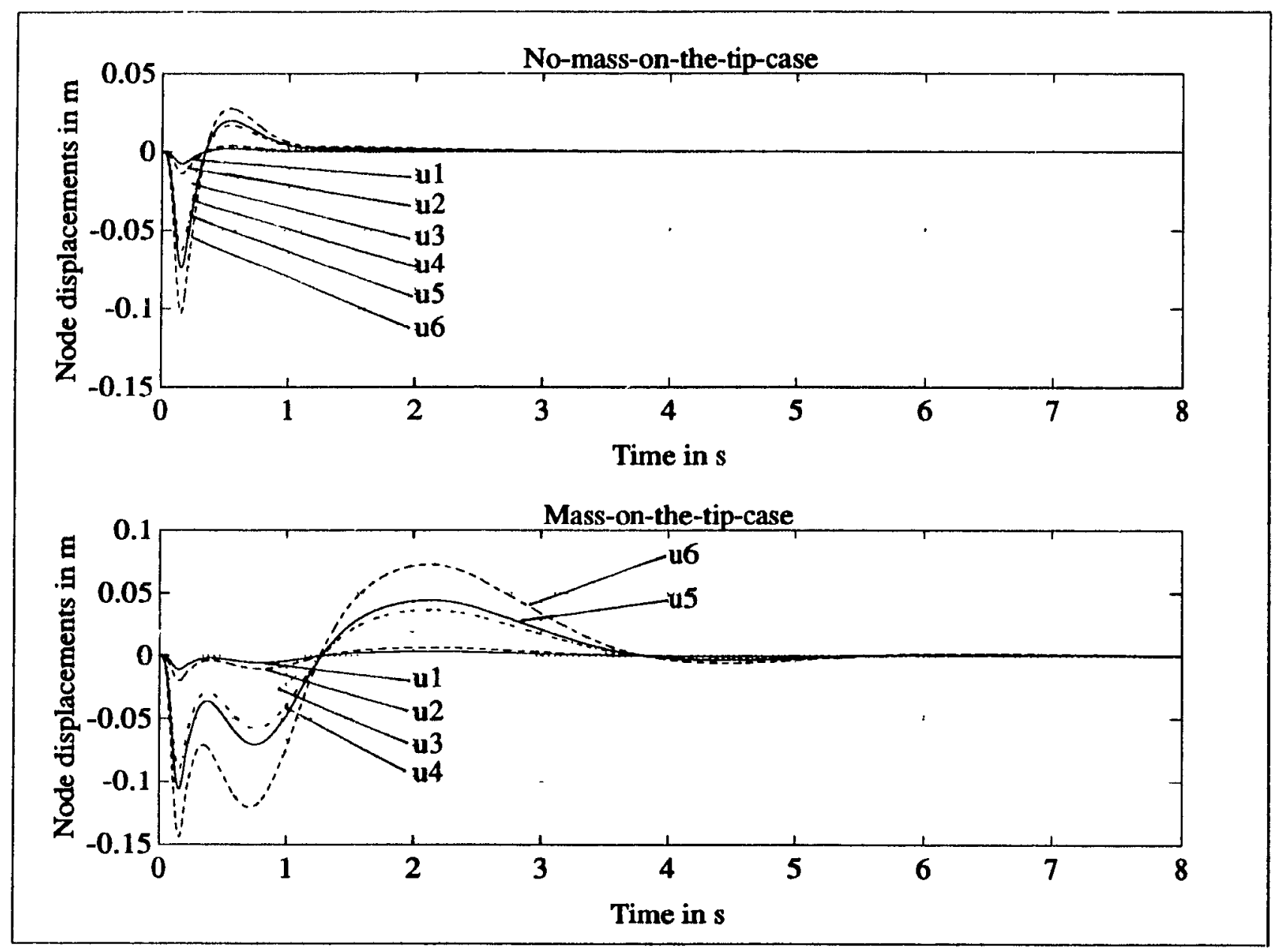

Figure 1.10: Node displacemonts of optimally controlled rotating flexible beam 


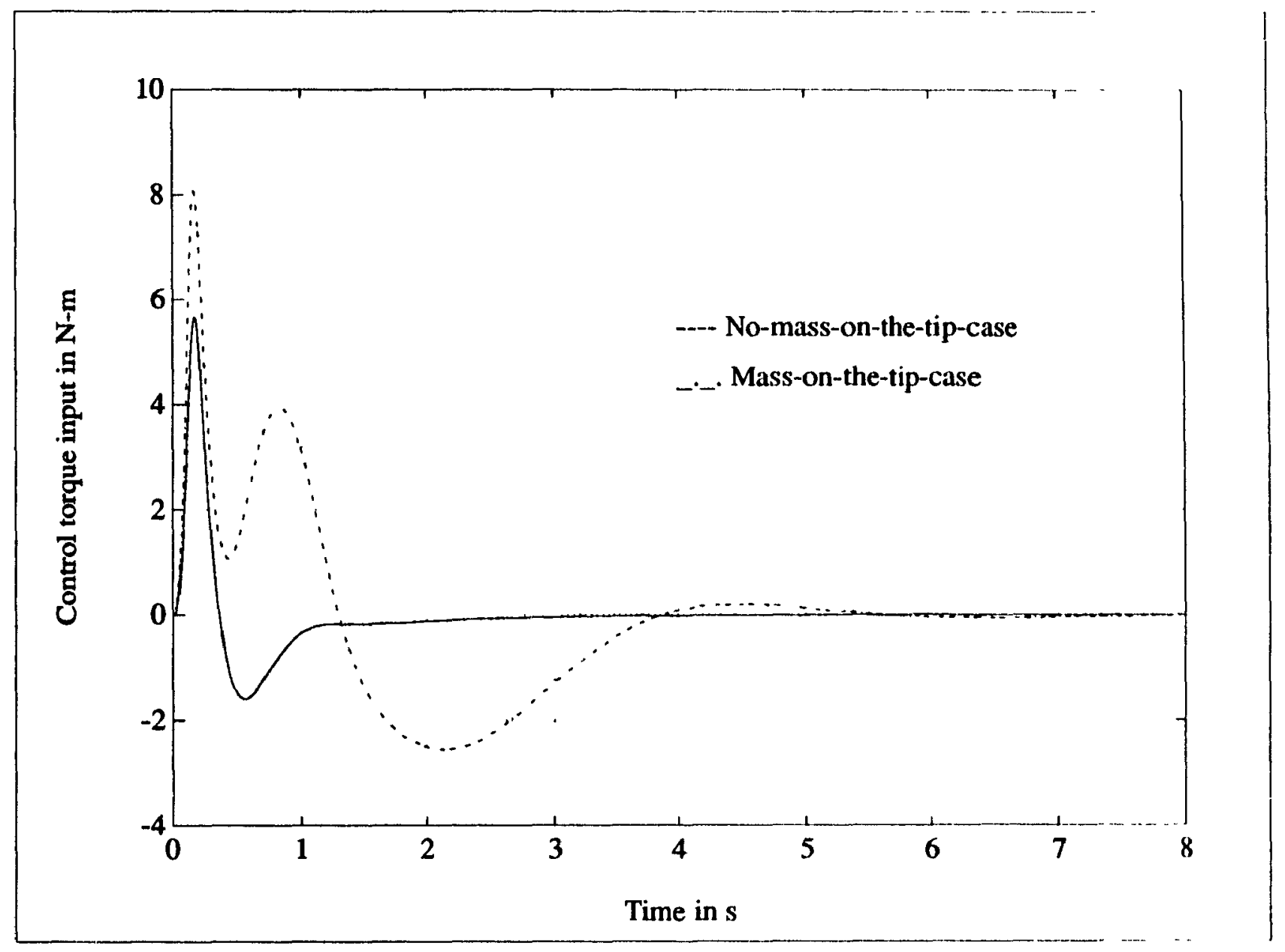

Figure 1.11: ('omparison of optimal comteol impuls 


\section{Chapter 5}

\section{Conclusions and Suggestions for Further Work}

A spatial discretzation method using the cubie-spline technique has been propesed for the dynamic modelling of a cont inuous beam with a tip mass under large rigid-body motions. 'T he major alsantages of this approach lie in the capability of considening a variety of houndary comlitions, an well as permutling the use of position sensors. ather than using vision sytems. Morcores, llus fechungue makes it possible to develop the dynamic modellng of nonunitom and nomsymmetu beans. which would be extremely difficult to model using an assumedmode methorl.

Ising the optimal controlles with the Kalman filter, extensive simnlations have been implemented to asses the feasibility of acal-time control using the proposed moelelling ap-

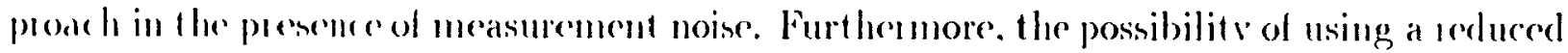

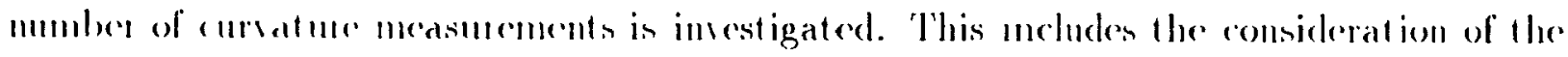

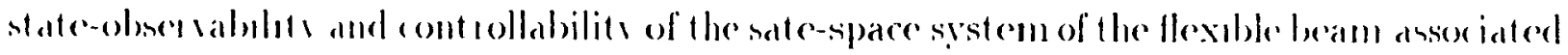

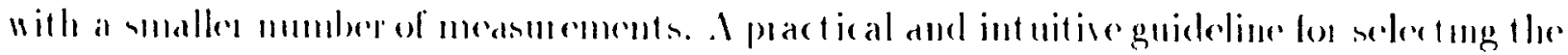

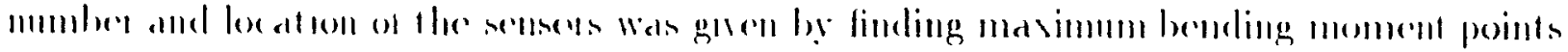

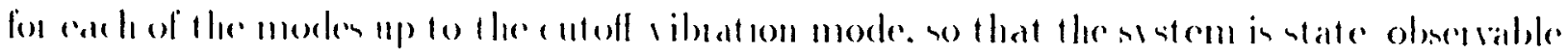

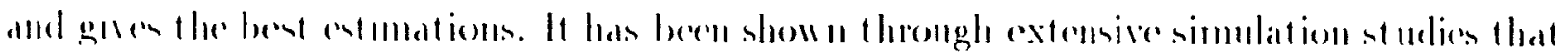




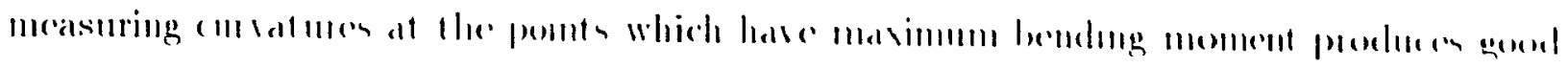

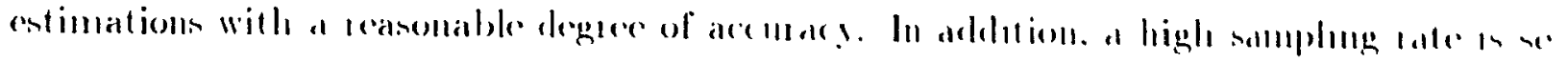

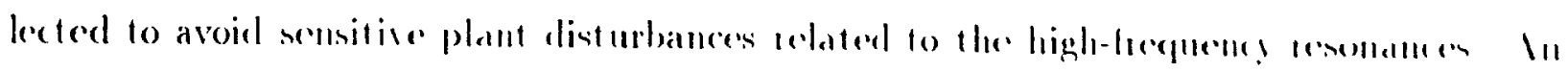

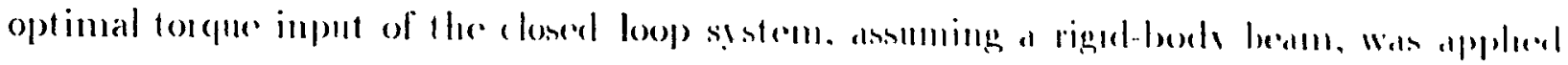

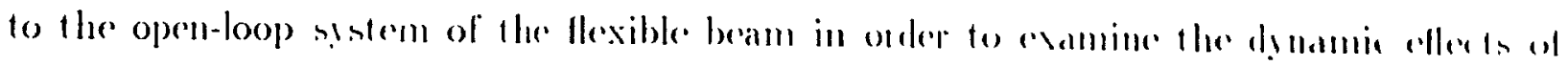

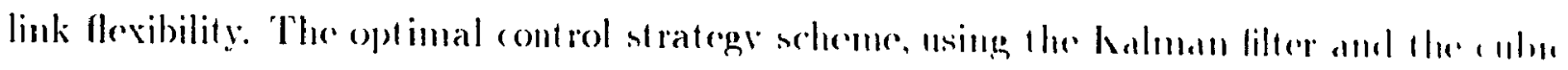

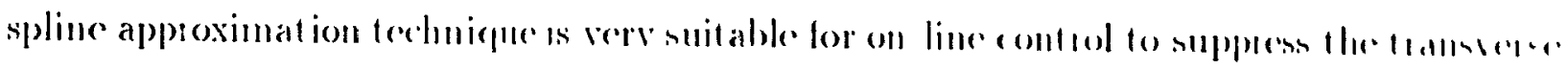

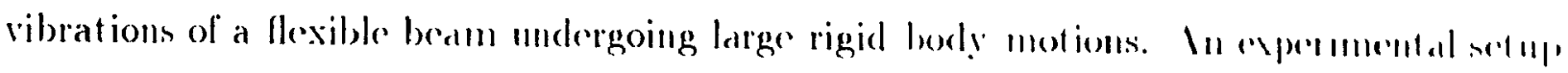
is currently being built to lent the theoretical work repotled in this thesis.

A few extensions of this work to the lollowing:

- Experimental renfication of the proposed method.

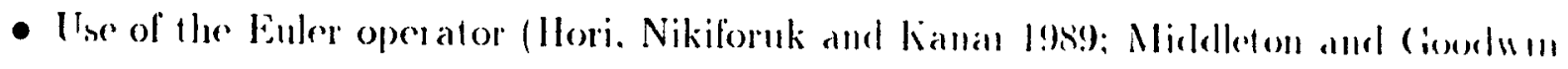
$1990)$.

- Extend the formulation to include two-dimensional bending affects and tonsion alled th accompanying multi-borl! molion.

- Develop an aclaptive control algot ithm to cope with changes ol mass. 


\section{References}

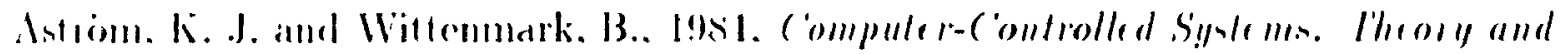

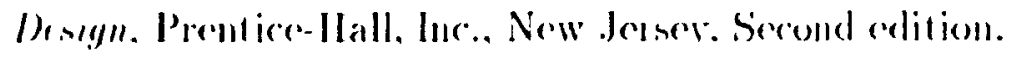

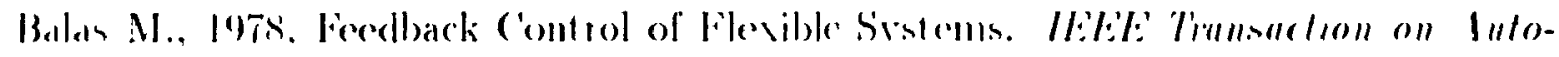

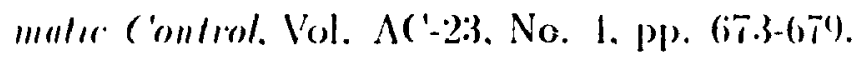

Balas M.. 19k2. Thends in Lange Space Stuncture ('ontrol Theory: Fondest Hopes.

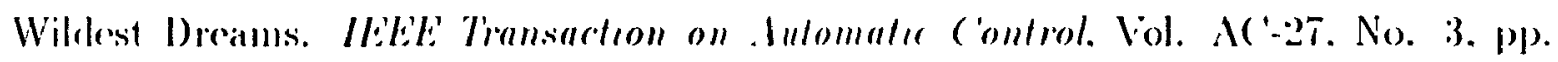
$52.2-535$.

Balas M., 1978, Modal ('ontrol of ('ertain Flexible Dynamic Systems. Sl.1.K Journal of ('ontiol and Optimization. Vol. 16. No. 3. pp. 150-162.

Barme h II. and ('hoe K.. 1990. Sensor Placrmont in Sitructural ('ont rol. Journal of Ciundrunce. Vól. 1:3. No. 3, pp. 5):21-533:3.

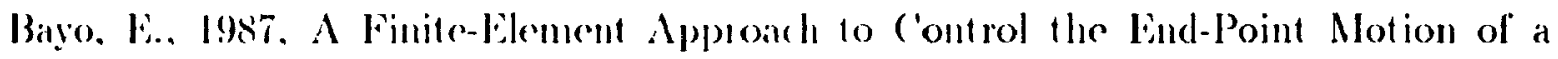
Single-link Flexible Robot. Jomrmal of Robolice System, Vol. 4. No. 1, ppe 6i3-75.

Brenati. M. and Mono, A. M988, Dy namien of ('hain of Flexible Links. Journal of

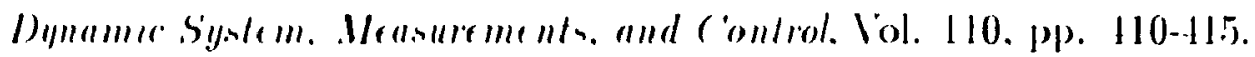

Bishop R. E. D. and Johnson D). ('.. 1960. The Mrehantes of Vibration. ('ambridge lavireste Prons. New York.

Book 11. J and Majetto M.. 19\$:3 ('ontollo Design for Flexible. Distributed Param-

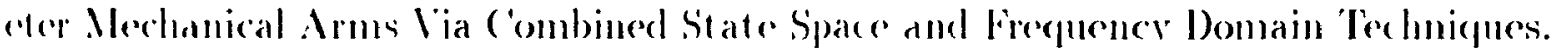

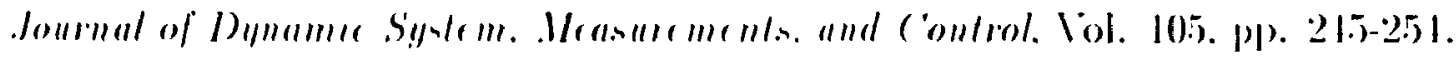

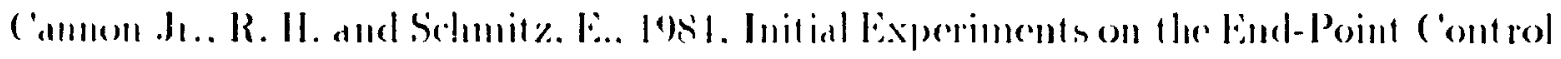

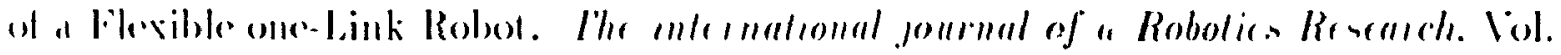
3. . Vo. 3. Pp. (i2-7.). 


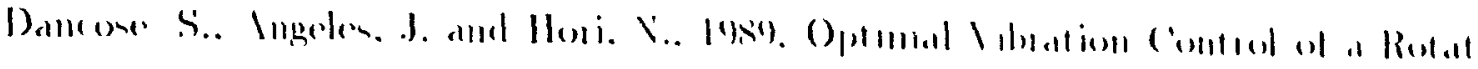

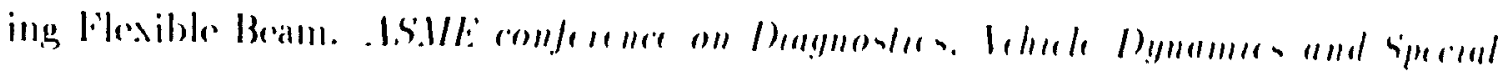
Topres. Montrial. pp. 2.01)-261.

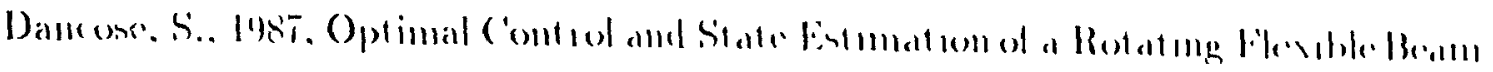

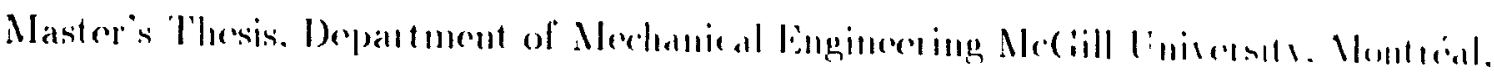
P.Q.

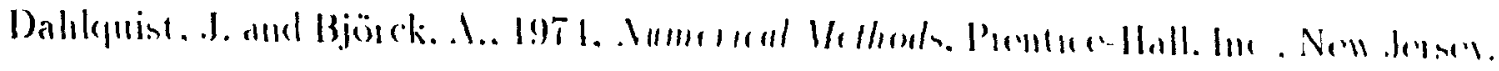

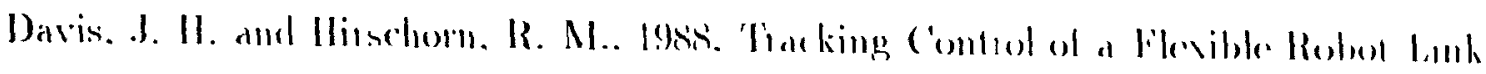

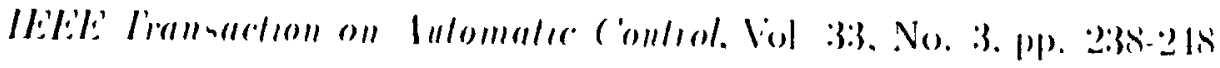

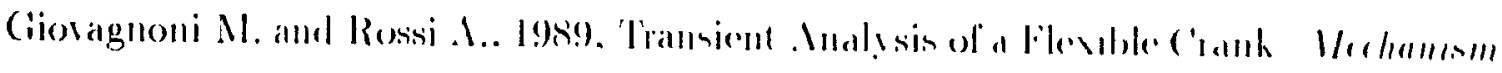
Macherr Theory. Vol. 21. No. 1. pl. 231-213.

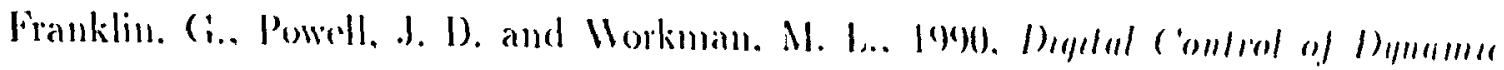

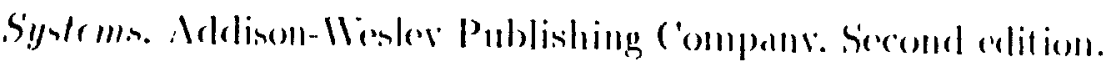

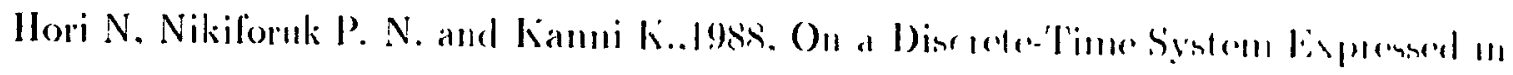

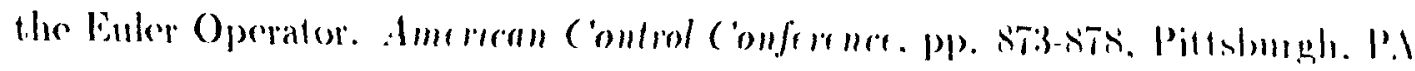

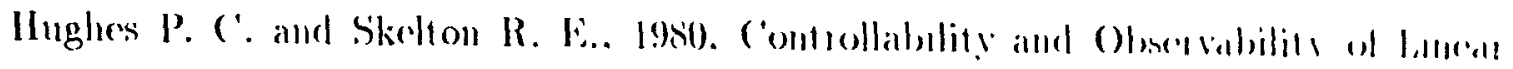

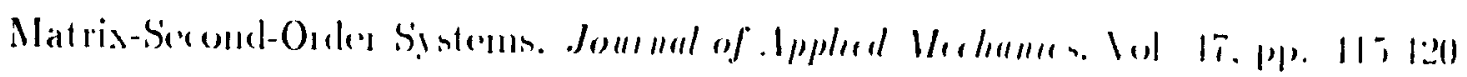

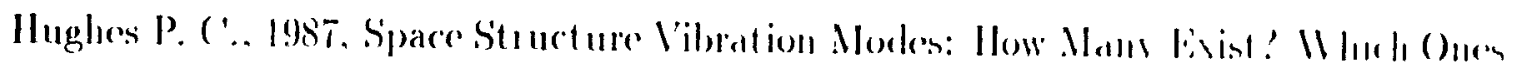

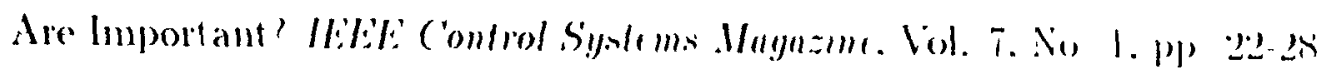

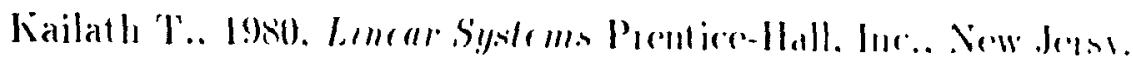

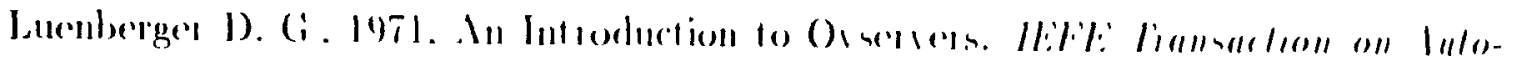

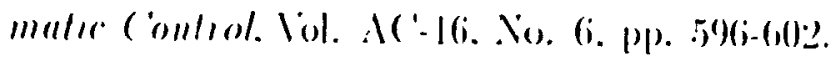

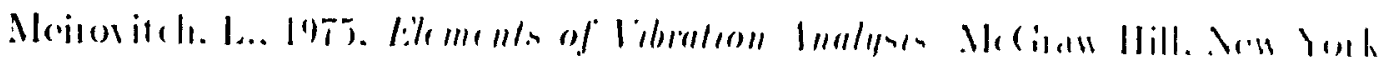

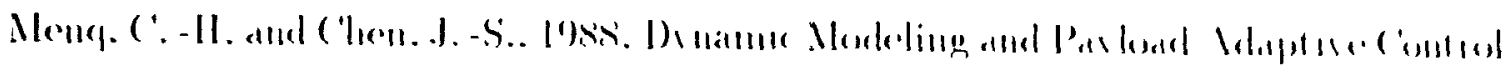

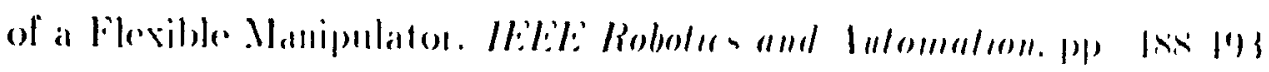




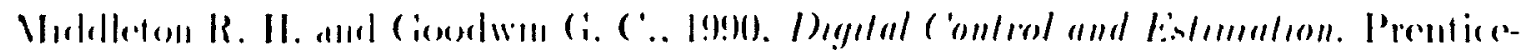
II:Ill. Inr.. Now derser.

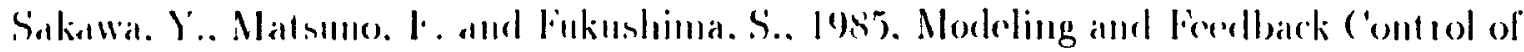

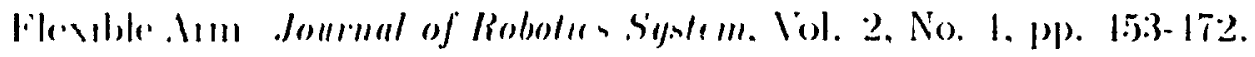

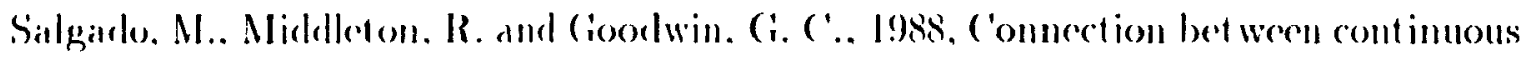
and descrete Ricati cepuations with application to Kalman filtering. H:L: Procerdengs. Vol. 1:35. P1. I), No. 1, p1.26-31.

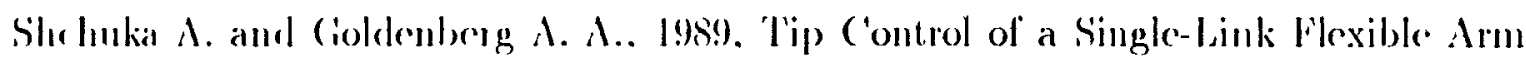

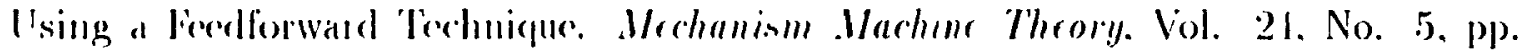
$1.39-15.5$.

Späth, H.. 197s, Splenes Algorithmen zul Konstruktion glaller Kurren und Flachen, R. Oldenloourg Verlag. Serond edition.

'Timoshenko, S . 1955.5. Vibralion Problems in Engmerring, Van Nostrand, Princelon, Now lerse!

Torfis 1)., Swevers J. and Schutle De J., 1991, Quasi-Perfect Thacking ('ontrol of NonMimmorl Phase Systems. Internal Report 91P55) of Katholieke Iniversiteit Leuven. Belgitim. 


\section{Appendix A}

\section{Derivation of Noise Covariance}

\section{Matrices}

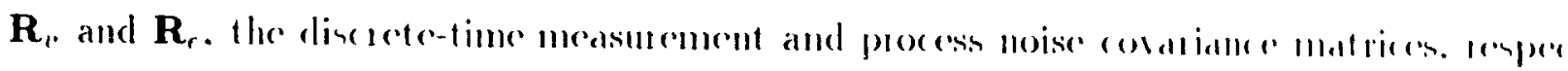
tively, are defined ats

$$
\begin{aligned}
\mathbf{R}_{r} & =E\left\{\mathbf{v}\left(k^{\prime}\right) \mathbf{v}\left(k^{\prime}\right)^{l}\right\} \\
\mathbf{R}_{r} & =E\left\{\mathbf{e}\left(k^{\prime}\right) \mathbf{e}\left(k^{\prime}\right)^{T}\right\}
\end{aligned}
$$

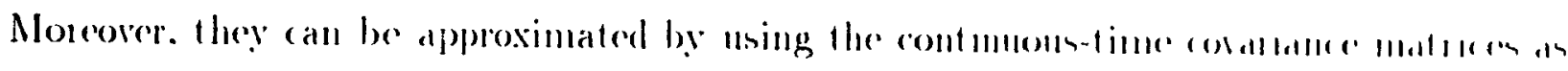
follows (Salgarlo. Midklletion and (Goodwin l!ss):

$$
\begin{aligned}
& \left.\mathbf{R}_{i} \simeq \Delta \mathscr{V} \mathbf{v}(l) \mathbf{v}(I)^{I}\right\} \equiv \Delta \mathbf{R}_{t} \\
& \mathbf{R}_{t} \simeq \frac{1}{J} \in\left\{\mathbf{e}(l) \mathbf{e}(l)^{\prime}\right\} \equiv \frac{1}{د} \mathbf{R}_{1}
\end{aligned}
$$

where $\lrcorner$ is the sampling interal.

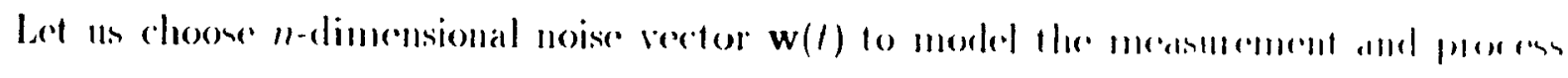
noise ats

$$
\mathbf{w}(f)=\left[\begin{array}{l}
n_{1} \cdot n_{1} \\
n_{2} \cdot r_{2} \\
\vdots \\
n_{n} \cdot l_{n}
\end{array}\right]
$$




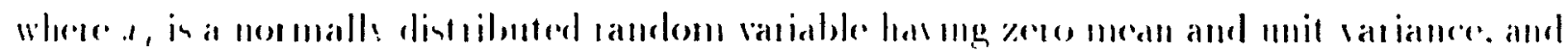
h, is a constant which in used to define the ampliturle ol the noise. The correspending noise coialiance mallix $l:\left\{w w^{l}\right\}$ is clearly given as

$$
E\left\{w w^{r}\right\}=\left[\begin{array}{cccc}
\kappa_{1}^{2} & 0 & \cdots & 0 \\
0 & \kappa_{2}^{2} & \cdots & 0 \\
\vdots & & \ddots & \vdots \\
0 & 0 & \cdots & \kappa_{1}^{2}
\end{array}\right]
$$

'Therefore, matrices $\mathbf{R}_{\text {t" and }} \mathbf{R}_{1}$ can be evaluated fiom lle above covariane matix. 